Aus der Abteilung Klinische Chemie

(Prof. Dr. med. Dr. h.c. M. Oellerich)

im Zentrum Innere Medizin

der Medizinischen Fakultät der Universität Göttingen

\title{
Der Einfluss von Mycophenolat-Mofetil (MMF) auf die renale Fibrogenese: Bedeutung für neue therapeutische Ansätze
}

\author{
INAUGURAL-DISSERTATION \\ zur Erlangung des Doktorgrades \\ der Medizinischen Fakultät \\ der Georg-August-Universität zu Göttingen
}

vorgelegt von

Franziska Brehmer

aus

Magdeburg

Göttingen 2010 
Dekan: Prof. Dr. med. Frömmel

I. Berichterstatter: Prof. Dr. med. Dr. h.c. Oellerich

II. Berichterstatter: Priv.-Doz. Dr. med. Koziolek

III. Berichterstatter: Prof. Dr. med. Oppermann

Tag der mündlichen Prüfung: 15.02.2011 


\section{Inhaltsverzeichnis}

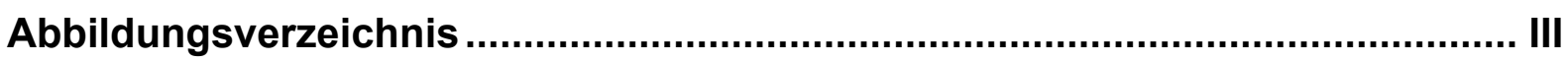

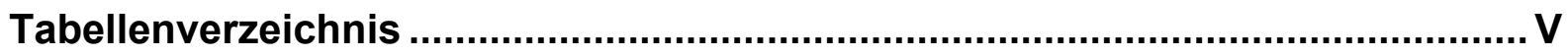

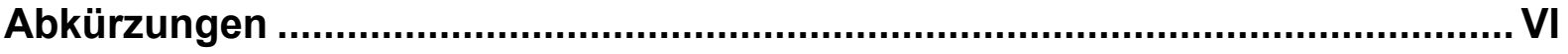

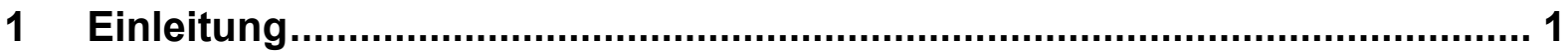

1.1 Historische Entwicklung der Verwendung von MMF ……........................ 2

1.2 Pharmakokinetik von MMF.......................................................... 4

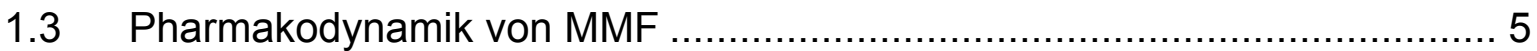

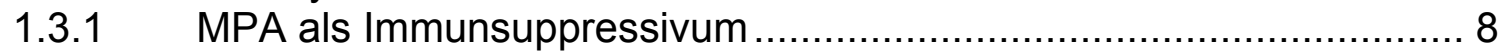

1.3.2 Neue Einsatzmöglichkeiten für MPA ………............................ 10

1.4 Grundzüge der Fibrogenese ……............................................... 13

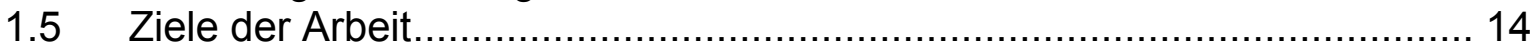

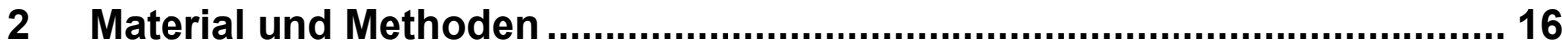

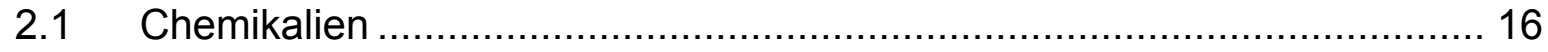

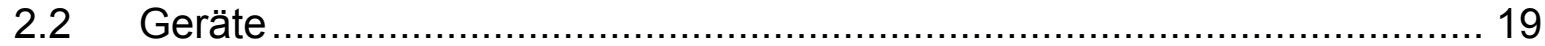

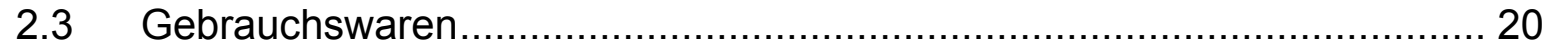

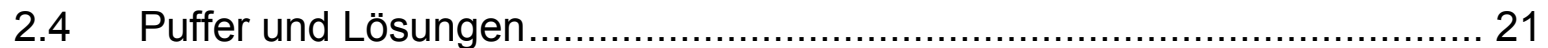

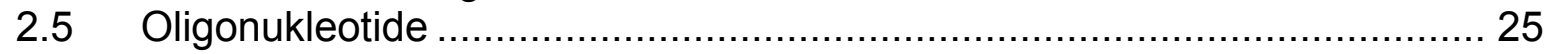

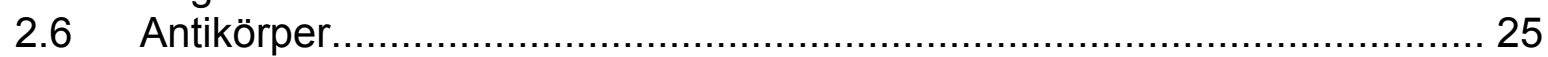

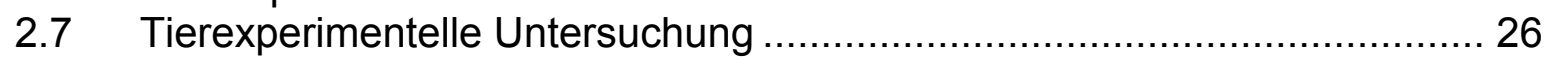

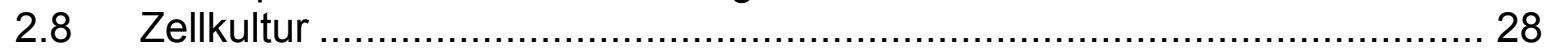

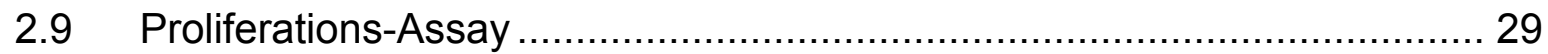

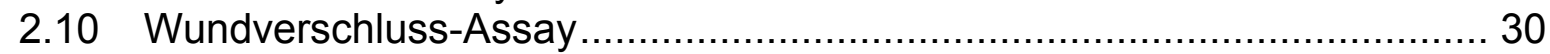

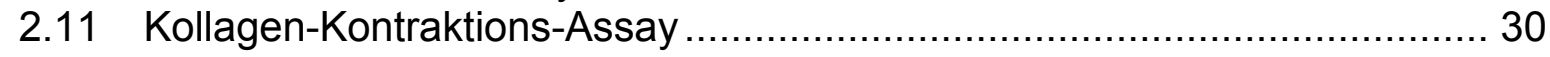

2.12 Nukleinsäuretechnische Methoden ..................................................... 31

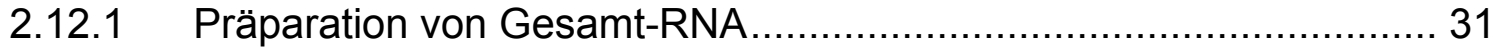

2.12.1.1 Präparation von Gesamt-RNA aus COS-7-Zellen ......................... 31

2.12.1.2 Präparation von Gesamt-RNA aus Nierengewebe ........................ 31

2.12.2 Konzentrationsbestimmung von RNA ……................................. 32

2.12.3 Agarosegelelektrophorese ................................................... 32

2.12.4 Reverse-Transkriptase-Polymerasekettenreaktion (RT-PCR)........... 33

2.12.4.1 Reverse Transkription ............................................................ 33

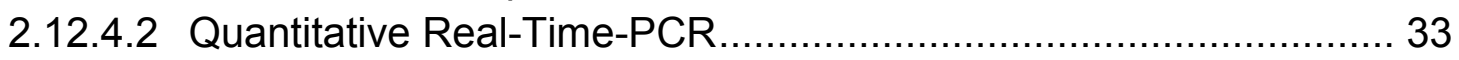

2.13 Proteinchemische Methoden....................................................... 35

2.13.1 Präparation von Proteinen aus COS-7-Zellen und Nierengewebe .... 35

2.13.2 Konzentrationsbestimmungen von Proteinen .................................. 36

2.13.3 SDS-Polyacrylamidgelelektrophorese ……................................ 36

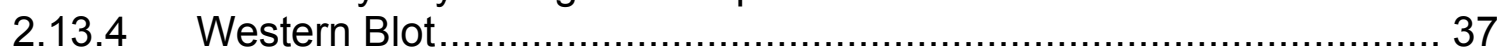

2.13.5 Anfärbung von Proteinen auf Membranen...................................... 38

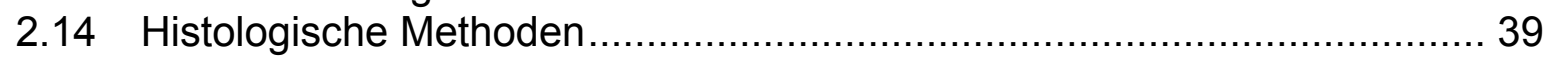

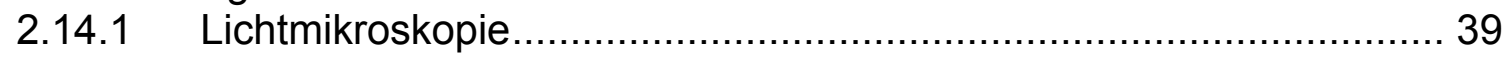

2.14.1.1 Präparation und Fixierung.................................................... 39

2.14.1.2 Hämatoxylin-Eosin-Färbung und Trichrom-Färbung nach MassonGoldner 
2.14.2 Auswertung der Gewebeschnitte.............................................. 41

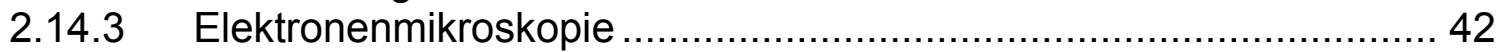

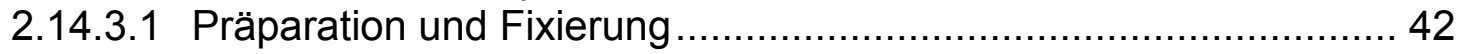

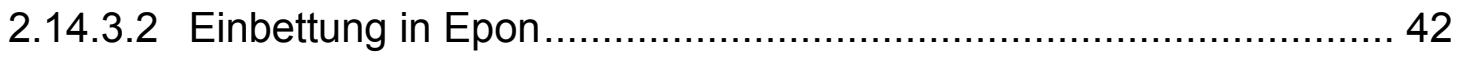

2.14.3.3 Anfertigung der Gewebsschnitte ........................................... 43

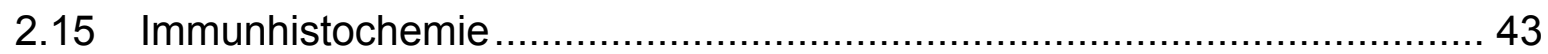

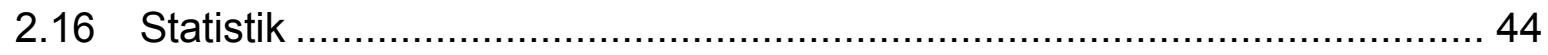

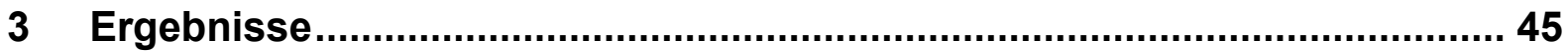

3.1 Ergebnisse der in-vitro-Experimente .............................................. 45

3.1.1 Untersuchungen zur Fibroblastenproliferation.............................. 45

3.1.2 Untersuchungen zur Fibroblastenfunktion.................................... 46

3.1.3 Ergebnisse der Kollagen-Kontraktion ....................................... 49

3.1.4 Ergebnisse der Genexpression von IL-6, TGFß1, COL1A1, CTGF und

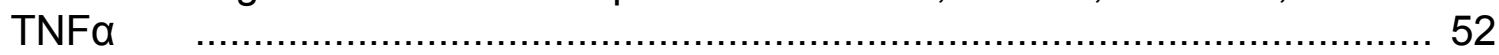

3.1.5 Ergebnisse der Expression von TGFß1 und Annexin im Western Blot

3.1.5.1 Expression von TGFß1 im Western Blot .......................... 56

3.1.5.2 Expression von Annexin A5 im Western Blot................................ 57

3.2 Ergebnisse der in-vivo-Experimente ................................................... 59

3.2.1 Überlebenszeit der COL4A3-defizienten Mäuse .............................. 59

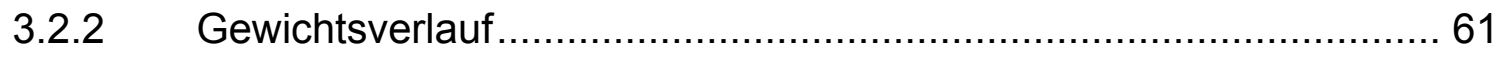

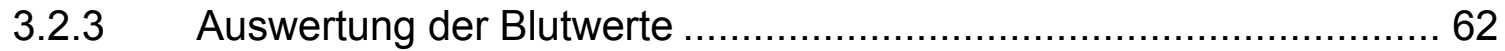

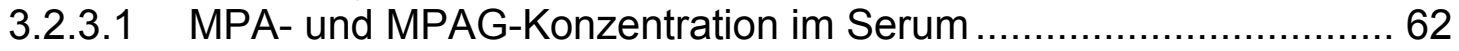

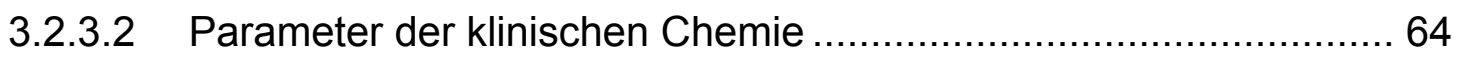

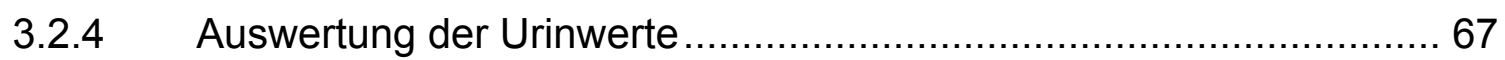

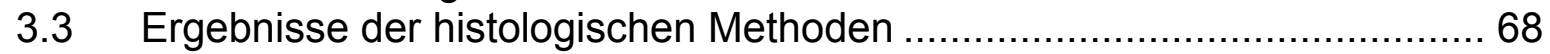

3.3.1 Ergebnisse der Lichtmikroskopie..................................................... 68

3.3.2 Ergebnisse der Elektronenmikroskopie ……............................. 75

3.3.3 Ergebnisse der immunhistochemischen Untersuchung.................... 80

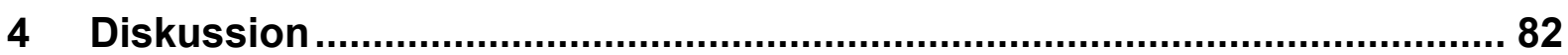

4.1 Die antifibrotische Wirkung von MMF auf COS-7-Zellen......................... 82

4.2 Die antifibrotische Wirkung von MMF auf COL4A3-defiziente Mäuse........ 85

4.2.1 Der Einfluss von MMF auf die Überlebenszeit................................ 86

4.2.2 Der Einfluss von MMF auf die Nierenhistologie.............................. 87

4.2.3 Der Einfluss von MMF auf die Nierenfunktion .............................. 87

4.2.4 Der Einfluss von MMF auf die Proteinexpression von TGFß1 .......... 90

4.3 MMF und seine mögliche Bedeutung in der antifibrotischen Therapie....... 90

4.3.1 Strategien in der antifibrotischen Therapie .................................... 91

4.3.2 Therapeutische Optionen bei renaler Fibrose ............................... 91

4.3.3 Stellenwert des TGFß in der antifibrotischen Therapie .................... 93

4.3.4 Mycophenolat-Mofetil und die Prävention der renalen Fibrose ......... 94

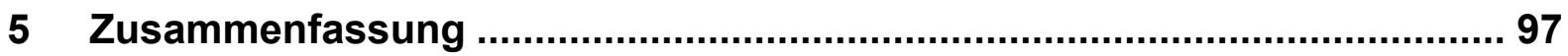

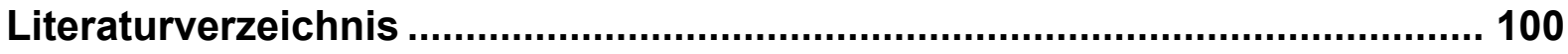




\section{Abbildungsverzeichnis}

Abb. 1 Strukturformeln von Mycophenolat-Mofetil (MMF) und Mycophenolsäure

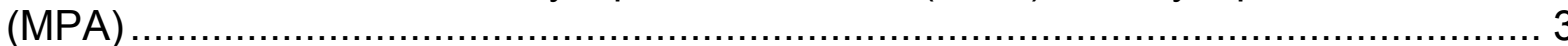

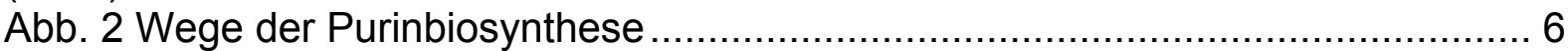

Abb. 3 Behandlungsschema für COL4A3-defiziente Mäuse ............................... 27 Abb. 4 Konzentrationsabhängige Inhibition der Proliferation von COS-7-Zellen durch MPA oder AcMPAG in An- oder Abwesenheit von Guanosin/8-Aminoguanosin (G/8-

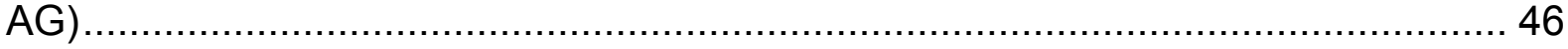

Abb. 5 Einfluss von MPA in unterschiedlichen Konzentrationen auf den

Wundverschluss

Abb. 6 Konzentrations- und zeitabhängige Inhibition des Wundverschlusses durch MPA im COS-7-Zellrasen in An- und Abwesenheit von Guanosin/8-Aminoguanosin (G/8-AG).

Abb. 7 Einfluss von 100 umol/l MPA auf die Kollagen-Matrix-Kontraktion in An- und Abwesenheit von Guanosin/8-Aminoguanosin (G/8-AG)

Abb. 8 Zeitabhängige Inhibition der Kontraktion von Kollagen-Matrix durch $100 \mu \mathrm{mol} / \mathrm{l}$ MPA in An- und Abwesenheit von Guanosin/8-Aminoguanosin (G/8-AG) .............. 51 Abb. 9 Einfluss von 100 umol/l MPA in An- und Abwesenheit von Guanosin/8-

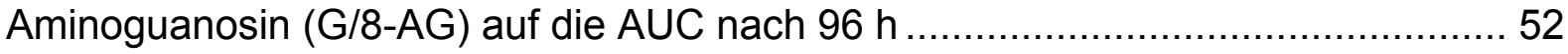
Abb. 10 Einfluss von $100 \mu \mathrm{mol} / \mathrm{l} \mathrm{MPA}$ in An- und Abwesenheit von Guanosin/8Aminoguanosin (G/8-AG) auf die Genexpression von IL-6, TGFß1, COL1A1, CTGF

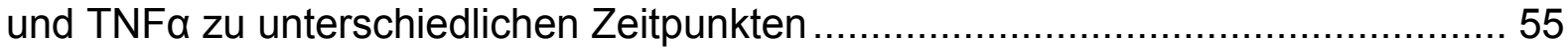
Abb. 11 Expression von TGFß1 in den Nieren der Mäuse im Western Blot stratifiziert nach Versuchsgruppen ......................................................................... 56 Abb. 12 Expression des Proteins TGFß1 in den Nieren der Mäuse normalisiert zur Ponceaufärbung... 57 Abb. 13 Expression des Proteins ANXA 5 in den Nieren der Mäuse im Western Blot stratifiziert nach Versuchsgruppen ............................................................... 57 Abb. 14 Expression des Proteins ANXA 5 in COS-7-Zellen im Western Blot.......... 58 Abb. 15 Expression des Proteins ANXA 5 in den Nieren der Mäuse normalisiert zur Ponceaufärbung stratifiziert nach Versuchsgruppen ..................................... 58 Abb. 16 Expression des Proteins ANXA 5 in COS-7-Zellen normalisiert zum

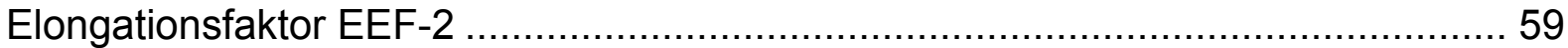
Abb. 17 Überlebenszeit stratifiziert nach Versuchsgruppen ................................ 60 Abb. 18 Gewichtsverläufe der Versuchstiere stratifiziert nach Versuchsgruppen .... 62 Abb. 19 Überlebenszeit der Versuchstiere in Abhängigkeit von MPA-Talspiegeln $(\mathrm{n}=24)$.

Abb. 20 MPA- und MPAG-Konzentrationen stratifiziert nach Versuchsgruppen $(\mathrm{n}=24)$

Abb. 21 Gesamtprotein, Kreatinin und Harnstoff-N im Serum als

Einzelpunktmesswerte stratifiziert nach Versuchsgruppen

Abb. 22 Kreatinin-Werte im Serum der Versuchstiere in Abhängigkeit von der MPA-

Konzentration $(n=23)$

Abb. 23 Im Urin gemessenes Gesamtprotein und Albumin als Einzelpunktmesswerte stratifiziert nach Versuchsgruppen

Abb. 24 Gegenüberstellung der lichtmikroskopischen Übersichtsaufnahmen HE- und Trichrom-gefärbter Nieren..... 70 Abb. 25 Exemplarische Gegenüberstellung einzelner Ausschnitte HE- und Trichromgefärbter Nieren 
Abb. 26 Glomerulumsklerose-Score der jeweiligen Behandlungsgruppen $(n=5) \ldots . .73$ Abb. 27 Tubulointerstitieller Fibrose-Score der jeweiligen Behandlungsgruppen $(\mathrm{n}=5)$

Abb. 28 Exemplarische Darstellung elektronenmikroskopischer Aufnahmen von renalem Gewebe......................................................................................... 78 Abb. 29 Exemplarische Darstellung elektronenmikroskopischer Aufnahmen. Ausmaß der Synthese kollagener Fasern im Interstitium der Nieren der Versuchstiere. 80 Abb. 30 Immunhistochemie. Exemplarische Gegenüberstellung repräsentativer Aufnahmen einer unbehandelten und einer behandelten Maus. 


\section{Tabellenverzeichnis}

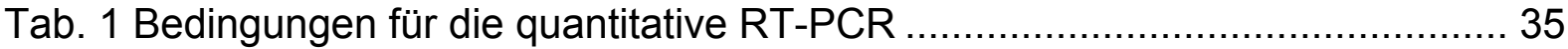

Tab. 2 Protokoll für Trenn- und Sammelgele.................................................... 37

Tab. 3 Semiquantitative Auswertung der Glomerulumsklerose ............................... 73

Tab. 4 Semiquantitative Auswertung der tubulointerstitiellen Fibrose ..................... 74 


\section{Abkürzungen}

\begin{tabular}{|c|c|}
\hline A & Ampere \\
\hline Abb. & Abbildung \\
\hline AP & Alkalische Phosphatase \\
\hline APS & Ammoniumpersulfat \\
\hline${ }^{\circ} \mathrm{C}$ & Grad Celsius \\
\hline cDNA & komplementäre DNA \\
\hline CHAPS & 3-[(3-Cholamidopropyl)dimethylammonio]-1-propansulfonat \\
\hline $\mathrm{cm}$ & Zentimeter \\
\hline d & Tag \\
\hline $\mathrm{dd} \mathrm{H}_{2} \mathrm{O}$ & doppelt destilliertes Wasser \\
\hline $\mathrm{dH}_{2} \mathrm{O}$ & destilliertes Wasser \\
\hline DMEM & Dulbeccos Modified Eagle Medium \\
\hline DMSO & Dimethylsulfoxid \\
\hline DNA & Desoxyribonukleinsäure \\
\hline \multirow[t]{2}{*}{ DSMZ } & Deutsche Sammlung von Mikroorganismen und Zellkulturen \\
\hline & $\mathrm{GmbH}$ \\
\hline DTT & Dithiothreitol \\
\hline EDTA & Ethylendiamintetraessigsäure \\
\hline et al. & et alii \\
\hline $\mathrm{EtOH}$ & Ethanol \\
\hline FCS & Fetales Kälberserum \\
\hline g & Gramm; Erdbeschleunigung \\
\hline $\mathrm{h}$ & Stunde(n) \\
\hline $\mathrm{HCl}$ & Chlorwasserstoff (Salzsäure) \\
\hline $\lg G$ & Immunglobulin G \\
\hline $\mathrm{kDa}$ & Kilodalton \\
\hline $\mathrm{kg}$ & Kilogramm \\
\hline I & Liter \\
\hline $\mathrm{m}$ & Meter; Milli $\left(10^{-3}\right)$ \\
\hline$\mu$ & Mikro $\left(10^{-6}\right)$ \\
\hline $\mathrm{MeOH}$ & Methanol \\
\hline $\mathrm{MgCl}_{2}$ & Magnesiumchlorid \\
\hline
\end{tabular}




$\begin{array}{ll}\text { min } & \text { Minute(n) } \\ \text { mRNA } & \text { messanger-RNA } \\ \mathrm{n} & \text { Nano }\left(10^{-9}\right) \\ \mathrm{NaCl} & \text { Natriumchlorid } \\ \text { PBS } & \text { phosphatgepufferte Kochsalzlösung } \\ \text { PCR } & \text { Polymerase-Kettenreaktion } \\ \text { pH } & \text { pondus Hydrogenii } \\ \text { PMA } & \text { Phorbol-12-myristat -13-acetat } \\ \text { PMSF } & \text { Phenylmethylsulfonylfluorid } \\ \text { RNA } & \text { Ribonukleinsäure } \\ \text { RNase } & \text { Ribonuklease } \\ \text { RT } & \text { Raumtemperatur } \\ \text { SDS } & \text { Natriumdodecylsulfat } \\ \text { SPSS } & \text { Statistical Product and Service Solutions } \\ \text { Tab. } & \text { Tabelle } \\ \text { TBE } & \text { Tris-Borat-EDTA } \\ \text { TEMED } & \text { Tetramethylethylendiamin } \\ \text { Tris } & \text { Trishydroxymethylaminomethan } \\ \text { U } & \text { Einheit der Enyzmaktivität (Unit) } \\ \text { V } & \text { Volt } \\ \text { VCAM-1 } & \text { Vascular cell adhesion molecule-1 } \\ \text { v/v } & \text { Gewicht pro Volumen } \\ \text { w/v } & \end{array}$




\section{Einleitung}

Gegenwärtig steigt die Zahl der Patienten mit progredient chronischen Nierenerkrankungen kontinuierlich (Frei und Schober-Halstenberg 2005/2006). Die Prävalenz der terminalen Niereninsuffizienz, in der angloamerikanischen Literatur als End Stage Renal Disease (ESRD) bezeichnet und nach der National Kidney Foundation definiert durch eine glomeruläre Filtrationsrate unter $15 \mathrm{ml} / \mathrm{min} / 1,73 \mathrm{~m}^{2}$, beträgt in Deutschland derzeit etwa 1000 pro 1 Mio. Einwohner, wobei die Tendenz zunehmend steigend verläuft (Levey et al. 2003). Die am häufigsten zur terminalen Niereninsuffizienz führenden Erkrankungen sind die diabetische Nephropathie (ca. $35 \%$ ), hypertensive Nephropathien (ca. $25 \%$ ), chronische Glomerulonephritiden (ca. $10 \%)$ sowie chronisch-tubulointerstitielle Erkrankungen einschließlich System- und hereditärer Erkrankungen. Gemeinsame Endstrecke fast aller Formen chronischer Nierenerkrankungen unterschiedlicher Pathogenese ist dabei die renale Fibrose, welche durch eine Glomerulumsklerose, tubulointerstitielle Fibrose und Veränderungen in der Gefäßarchitektur charakterisiert ist und progredient zur Niereninsuffizienz führt (Boor et al. 2007). Dabei stellt die tubulointerstitielle Fibrose den bedeutendsten Faktor zum irreversiblen Verlust der renalen Funktion dar (Nangaku 2004).

In chronisch erkrankten Nieren dient die reaktive intraglomeruläre Drucksteigerung mit Hyperfiltration in den verbliebenen gesunden Glomerula zur Aufrechterhaltung der Nierenfunktion (Brenner 1985). Besteht gleichzeitig ein arterieller Hypertonus, wird die Hyperfiltration noch verstärkt. In diesem Prozess wesentlich beteiligt ist das Peptidhormon Angiotensin II, welches maßgeblich im Renin-Angiotensin-AldosteronSystem wirkt. Über eine gesteigerte Produktion von diversen Zytokinen und Wachstumsfaktoren führt Angiotensin II zur glomerulären Hypertrophie und Hyperplasie. Da es ebenso die Permeabilität der glomerulären Basalmembran erhöht, kommt es konsekutiv zur Proteinurie, welche durch ihre Nephrotoxizität zur progressiven Glomerulumsklerose und letztendlich zur Entwicklung von Schrumpfnieren führt (Mezzano et al. 2001). Die Folgen der chronischen Niereninsuffizienz sind neben dem Versagen der exkretorischen Nierenfunktion Störungen im Wasser-, Elektrolyt- und Säure-Basen-Haushalt sowie toxische 
Organschäden bedingt durch die retinierten harnpflichtigen Substanzen. Weiterhin resultiert eine verminderte Synthese bzw. Sekretion von Erythropoetin, Renin, 1,25$\mathrm{OH}(2)$-Vitamin D und Prostaglandinen.

Die Behandlungsmöglichkeiten der chronischen Niereninsuffizienz sind begrenzt. Meist richten sie sich nach der vorliegenden Grunderkrankung und sind lediglich darauf ausgerichtet, ein Fortschreiten der Fibrose zu verhindern. Als kurativer Ansatz steht letztendlich bisher nur die Nierentransplantation zur Verfügung. Da bereits stattgefundene fibrotische Umbauprozesse zumeist irreversibel sind, wird entsprechend der Prävention der renalen Fibrose eine große Bedeutung beigemessen. Einen aktuellen Ansatz im Rahmen der antifibrotischen Therapie stellt das als Immunsuppressivum etablierte Mycophenolat-Mofetil (MMF) dar.

\subsection{Historische Entwicklung der Verwendung von MMF}

Bereits 1896 gelang bei Untersuchungen an verdorbenem Mais die Isolation des Mykotoxins Mycophenolsäure (MPA) aus Kulturen von Penicillium species (Gosio 1896). Aufgereinigt und benannt wurde die Säure dagegen erst im Jahre 1913 nachdem es möglich war, die Säure als ein metabolisches Produkt aus dem Pilz Penicillium brevicompactum zu isolieren (Clutterbuck et al. 1932). Über die vollständige chemische Struktur von MPA wurde erst Anfang der 50er Jahre berichtet (Birkinshaw et al. 1952). Antibakterielle, antifungizide sowie antivirale Effekte des MPA sind nachgewiesen worden (Florey et al. 1946, Ando et al. 1968). Des Weiteren gelang weiterhin der Nachweis antineoplastischer Wirkungen, indem das Wachstum transplantierbarer solider Tumoren in Mäusen effektiv durch MPA inhibiert werden konnte (Williams et al. 1968). Dieses antineoplastische Potential von MPA ließ sich in mehreren darauf folgenden tierexperimentellen Studien bestätigen (Carter et al. 1969, Suzuki et al. 1969, Sweeney et al. 1972a). Die bedeutendste Wirkung von MPA, sein immunsuppressives Potential, war bereits frühzeitig in 2 japanischen Studien erwähnt worden (Mitsui und Suzuki 1969, Ohsugi et al. 1976), allerdings konzentrierten sich die ersten experimentellen Studien mit MPA vor allem auf dessen antiproliferative bzw. zytostatische Wirkungen. Weitere wichtige und damit richtungsgebende Entdeckungen waren der Nachweis, dass MPA selektiv auf Lymphozyten antiproliferativ wirkt sowie die Existenz zweier Isoformen der 
Inosinmonophosphat-Dehydrogenase (IMPDH) und die strenge Assoziation der Isoform Typ II mit der Proliferation von aktivierten Lymphozyten (Nagai et al. 1992). Somit stand MPA als neues potentielles Immunsuppressivum, welches spezifischer als bisherige Medikamente in den Stoffwechsel von Lymphozyten eingriff, im Fokus der Aufmerksamkeit (Allison und Eugui 1993). Schließlich wurde MycophenolatMofetil, der biologisch inaktive Morpholinoethylester, entwickelt, um die systemische Bioverfügbarkeit seines aktiven Metaboliten Mycophenolsäure zu erhöhen (Lee et al. 1990).

Nach der International Union de Pure and Applied Chemistry (IUPAC) lautet der chemische Name für Mycophenolat-Mofetil (E)-6-(-4-Hydroxy-6-methoxy-7-methyl-3oxo-1,3-dihydroisobenzofuran-5-yl)-4-methylhex-4-ensäure-2-morpholinoethylester.

Die Strukturformeln von Mycophenolat-Mofetil und Mycophenolsäure sind in Abb. 1 dargestellt.

MMF<smiles>COc1c(C)c2c(c(O)c1C/C=C(\C)CCC(=O)OCCN1CCOCC1)C(=O)OC2</smiles>

MPA<smiles>COc1c(C)c2c(c(O)c1C/C=C(\C)CCC(=O)O)C(=O)OC2</smiles>

Abb. 1 Strukturformeln von Mycophenolat-Mofetil (MMF) und Mycophenolsäure (MPA) MMF ist biologisch inaktiv und wird durch Abspaltung einer Estergruppe in den aktiven Metaboliten MPA hydrolysiert. 


\subsection{Pharmakokinetik von MMF}

Mycophenolat-Mofetil $\left(\mathrm{C}_{23} \mathrm{H}_{31} \mathrm{NO}_{7}\right.$, Molekulargewicht $\left.433,50 \mathrm{~g} / \mathrm{mol}\right)$ ist der 2Morpholinoethylester des aktiven Metaboliten Mycophenolsäure. Nach oraler Applikation wird das Prodrug schnell und vollständig absorbiert. Durch die rasche Abspaltung einer Estergruppe in der Darmschleimhaut entsteht die pharmakologisch wirksame Mycophenolsäure. Die orale Bioverfügbarkeit des MMF liegt unabhängig von der Darreichungsform bei nahezu 100 \% (Bullingham et al. 1996). Messbare periphere Plasmakonzentrationen von MMF per se dagegen gibt es in der Regel nicht (Shaw und Nowak 1995). Durch hepatische Glukuronidierung mittels Glucuronyltransferase wird MPA zum stabilen, aber pharmakologisch inaktiven phenolischen Hauptmetaboliten 7-O-MPA-Glucuronid (MPAG) umgewandelt (Nowak und Shaw 1997). MPAG wird hauptsächlich über die Nieren, zu einem geringen Teil auch über die Galle ausgeschieden. Durch intestinale, bakterielle Deglukuronidierung des MPAG entsteht wiederum MPA, welches in den Blutkreislauf reabsorbiert wird. Dieser enterohepatische Kreislauf trägt im Mittel mit bis zu $40 \%$ zur Konzentrationszeitkurve (AUC) von MPA bei und ist daher für die Pharmakokinetik bedeutsam.

Shipkova et al. identifizierten 1999 zwei weitere MPA-Metabolite im Plasma organtransplantierter und mit MMF behandelter Patienten, das 7-OH-Glukosid und das Mycophenolsäure-Acylglucuronid, AcMPAG (Shipkova et al. 1999). AcMPAG wirkt ebenso wie MPA über Inhibition der IMPDH II in vitro, besitzt jedoch kein pharmakologisches Potential in vivo (Gensburger et al. 2009).

MPA und sein Metabolit MPAG sind im Serum im Wesentlichen an Albumin gebunden (MPA zu $97 \%$, MPAG zu $82 \%$ ). Eine hohe Serumkonzentration des MPAG bewirkt eine Verdrängung des MPA aus der Plasmaalbuminbindung und folglich eine Erhöhung der freien Fraktion, d.h. des nicht an Serumalbumin gebundenen Anteils, des MPA. Dies ist insofern klinisch relevant, da nur das ungebundene MPA pharmakologisch aktiv ist (Nowak und Shaw 1995).

In therapeutischen Dosen wird die systemische Gabe von MMF gut toleriert. Die am häufigsten beobachteten unerwünschten Arzneimittelwirkungen betreffen gastrointestinale Beschwerden wie Diarrhoe, Übelkeit und Erbrechen. Des Weiteren können selten Leukopenien bedingt durch Knochenmarkssuppression und opportunistische Infektionen vor allem mit dem Cytomegalievirus auftreten. Ferner 
besteht bei Hochdosisimmunsuppression das Risiko zur Induktion von Lymphomen bzw. lymphoproliferativen Erkrankungen (Sollinger et al. 1992, Sollinger 1995).

Eine sichere Alternative zu MMF stellt das Mycophenolat-Natrium (EC-MPS, entericcoated mycophenolate sodium) dar, welches zur Verringerung der MMF-bedingten Nebenwirkungen vor allem im oberen Gastrointestinaltrakt entwickelt wurde (Filler und Buffo 2007). Hierbei handelt es sich um eine magensaftresistente Formulierung von Mycophenolat-Natrium, wobei durch die verzögerte Freisetzung von MPA im Dünndarm die Verträglichkeit verbessert werden soll. In äquipotenten Dosen sind die pharmakologischen Eigenschaften und therapeutische Wirkung sowie das Risikoprofil von EC-MPS und MMF nahezu identisch (Sollinger 2004, Budde et al. 2004).

\subsection{Pharmakodynamik von MMF}

Das Prodrug MMF bewirkt über seinen aktiven Metaboliten MPA eine potente, durch Guanin reversible und nicht-kompetitive Inhibition der Inosin-MonophosphatDehydrogenase, dem Schlüsselenzym in der de-novo-Synthese von Purinbasen, welches die NAD-abhängige Oxidation von IMP zu XMP katalysiert (Franklin und Cook 1969, Sweeney et al. 1972b). Wie in Abb. 2 dargestellt, nimmt IMP eine zentrale Stellung innerhalb der Purinbiosynthese ein. Die Hemmung der IMPDH führt folglich zu einer Verringerung der Guanosinnukleotide GMP, GTP und dGTP, welche für die RNA- bzw. DNA-Synthese essentiell sind (Lowe et al. 1977). 


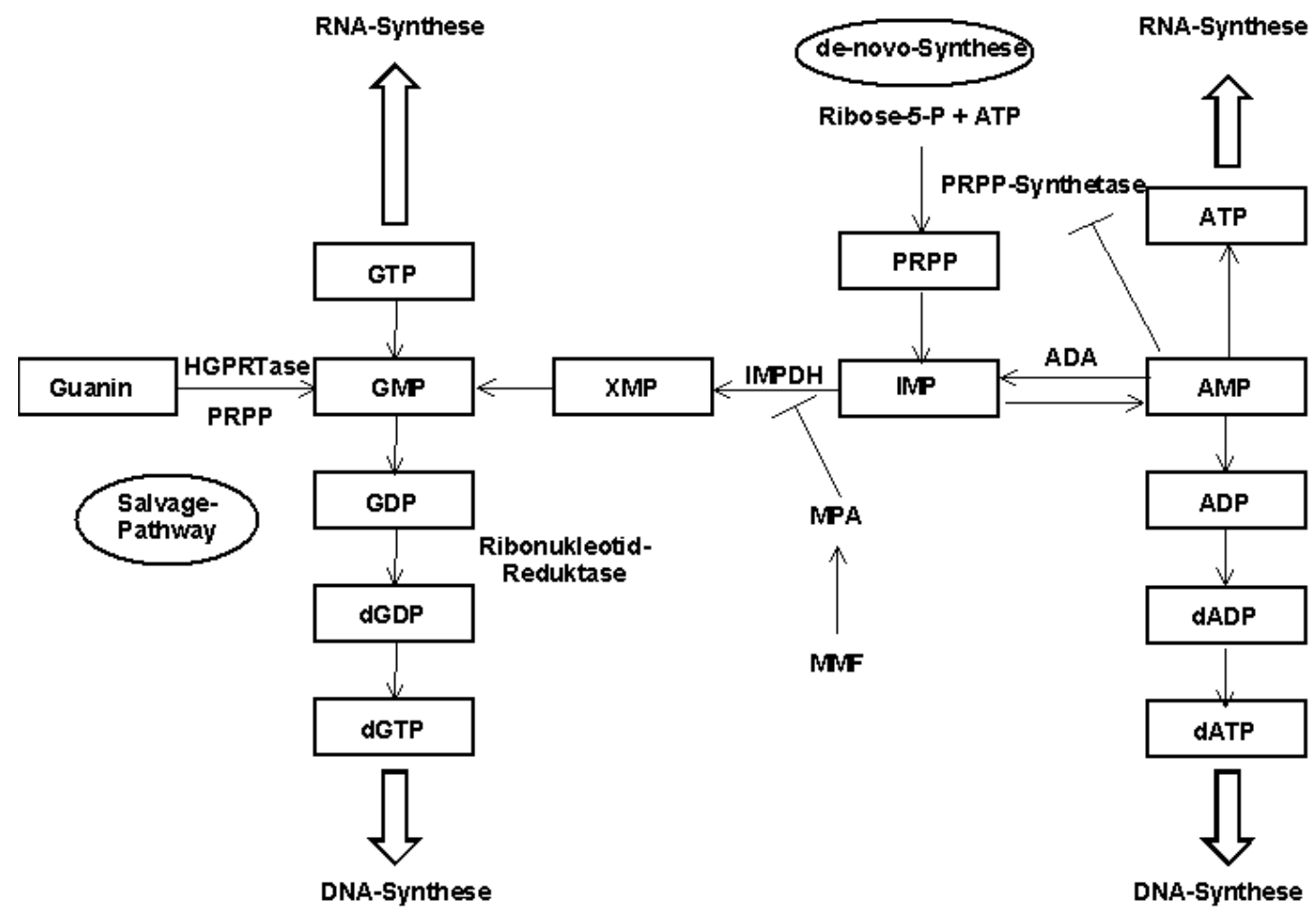

\section{Abb. 2 Wege der Purinbiosynthese}

IMP nimmt eine zentrale Position in der Purinbiosynthese ein. Die IMPDH, welche die Umwandlung von IMP zu XMP katalysiert, wird durch MPA, den aktiven Metaboliten des Prodrugs MMF, inhibiert. Folglich sinkt die Bildung der Guanosinnukleotide, wobei GTP und dGTP für die RNA- bzw. DNASynthese benötigt werden. Die Hemmung des Schlüsselenzyms in der de-novo-Synthese führt weiterhin zu einem Überschuss an AMP und damit zu einer Blockade der PRPP-Synthetase und durch dATP zu einer Hemmung der Ribonukleotid-Reduktase, welche GDP zu dGDP reduziert. Da vor allem T- und B-Lymphozyten auf den Neusyntheseweg der Nukleotide angewiesen sind, bei dem PRPP zu IMP umgewandelt wird, führt die Inhibition der IMPDH durch MPA zu einer selektiven Proliferationshemmung der Lymphozyten. Die meisten anderen Zelltypen sind dagegen in der Lage, den durch HGPRTase katalysierten Salvage-Pathway für die Nukleotidbildung zu nutzen.

ADA=Adenosindeaminase,$\quad$ ADP=Adenosindiphosphat $\quad A M P=$ Adenosinmonophosphat,$\quad A T P=$ Adenosintriphosphat, $\quad \mathrm{dATP}=$ Desoxyadenosintriphosphat, $\quad \mathrm{GDP}=$ Guanosindiphosphat, GMP=Guanosinmonophosphat, GTP=Guanosintriphosphat, dGDP=Desoxyguanosindiphosphat, dGTP=Desoxyguanosintriphosphat, DNA=Desoxyribonukleinsäure, HGPRTase=Hypoxanthin-GuaninPhosphoribosyltransferase, IMP=Inosinmonophosphat, IMPDH=IMP-Dehydrogenase, $\quad$ PRPP=5Phosphoribosyl-1-pyrophosphat, RNA=Ribonukleinsäure, $\mathrm{XMP}=$ Xanthosinmonophosphat (in Anlehnung an Allison und Eugui 2000, S. 87 sowie Mele und Halloran 2000, S. 217) 
Grundsätzlich gibt es 2 Wege der Nukleotidbiosynthese, zum einen über die denovo-Synthese, bei dem die Nukleotide für die DNA- und RNA-Produktion aus den verschiedenen metabolischen Vorstufen neu gebildet werden, zum anderen über den sog. Salvage-Pathway, bei dem die Purinbasen, die beim DNA-/RNA-Abbau anfallen, erneut metabolisiert werden können. Da die T- und B-Lymphozyten im Gegensatz zu den meisten anderen Zellen fast ausschließlich auf den Neusyntheseweg von GMP aus IMP angewiesen sind, führt die Hemmung des geschwindigkeitslimitierenden Enzyms IMPDH durch MPA im de-novo-Syntheseweg zu einer selektiven Proliferationshemmung, wogegen andere Zellen durch Nutzung des Salvage-Pathways, bei dem die Bildung von GMP aus Guanin durch die HGPRTase katalysiert wird, kaum von MPA beeinflusst werden (Allison et al. 1975).

Ein wichtiges Schrittmacherenzym im Neusyntheseweg von humanen Lymphozyten ist die PRPP-Synthetase. Ein Überschuss an AMP hemmt, GMP fördert ihre Aktivität, wogegen in Bakterien beide Nukleotide über einen negativen feedbackMechanismus das Enzym inhibieren (Garcia et al. 1977). Ein Mangel an Guanosinnukleotiden und ein Überschuss von Adenosinnukleotiden führen daher zusätzlich zu einer Inhibition der de-novo-Purinbasensynthese der T- und BLymphozyten (Allison und Eugui 2000).

Ferner hemmt MPA die in aktivierten Lymphozyten vorkommende IMPDH Isoform Typ II etwa 5x stärker als die Isoform Typ I (Carr et al. 1993). Während die Isoform Typ II in aktivierten Lymphozyten und neoplastischen Zellen dominiert, wird die Isoform Typ I überwiegend in ruhenden Lymphozyten und den meisten anderen Zelltypen exprimiert (Konno et al. 1991, Nagai et al. 1992). Die beiden Isoformen der humanen IMPDH stimmen zu $84 \%$ in ihrer Aminosäuresequenz überein (Natsumeda et al. 1990).

Die MPA-bedingte Reduktion von Guanosinnukleotiden hemmt die Glykosylierung von Adhäsionsmolekülen, die für die Interaktion von Zellen untereinander bzw. für die Interaktion von Zellen mit der extrazellulären Matrix unabdingbar sind (Allison et al. 1993). Folglich wird das Recruitment von Lymphozyten und Monozyten stark verringert, was wiederum in einer abgeschwächten Entzündungs- bzw. Abstoßungsreaktion resultiert. Neben der herabgesetzten Funktion der Adhäsionsmoleküle hemmt MPA auch deren Expression auf Endothelzellen. 
Nachgewiesen wurde dies u.a. für VCAM-1, eines der wichtigsten Moleküle für die Adhäsion von Immunzellen und deren Migration ins Gewebe und einiger anderer Selektine (Blaheta et al. 1999). Da die Adhäsionsmoleküle auch für Zellinteraktionen, z. B. zwischen Lymphozyten und Antigen-präsentierenden Zellen bedeutungsvoll sind, trägt MMF weiter zur Immunsuppression bei. Neben den antiproliferativen Wirkungen sind auch spezifische immunsuppressive Effekte des MMF auf die Zytokinproduktion beschrieben worden. So supprimiert MMF dosis- und zeitabhängig die Synthese proinflammatorischer Zytokine wie beispielsweise Interferon $\gamma$ (IFN $\gamma$ ) und Tumornekrosefaktor $\alpha(\mathrm{TNF} \alpha)$, welche von T-Lymphozyten und Makrophagen gebildet werden (Hildner et al. 1998).

\subsubsection{MPA als Immunsuppressivum}

Das immunsuppressive Potential von MPA auf die Antikörperbildung im Tierexperiment wurde erstmals Ende der 60er Jahre beschrieben. Hierbei konnte nachgewiesen werden, dass im Gegensatz zu unbehandelten Tieren bei Mäusen, die nach intravenöser Antigenstimulation (Erythrozyten vom Schaf) intraperitoneal mit unterschiedlichen Dosen von MPA behandelt wurden, die Zahl der Antikörperbildenden Zellen und die Antikörperkonzentrationen abnahmen (Mitsui und Suzuki 1969). Trotz frühzeitiger Entdeckung des Einflusses von MPA auf das Immunsystem war der Möglichkeit seines Einsatzes als potentielles Immunsuppressivum erst einmal nicht nachgegangen worden.

1991 gelang schließlich der Nachweis, dass MPA sowohl in vitro als auch in vivo ohne wesentliche Nebenwirkungen selektiv auf Lymphozyten antiproliferativ und immunsuppressiv wirkt, indem es die Immunglobulinproduktion in Lymphozyten sowie die Bildung zytotoxischer T-Lymphozyten hemmt (Eugui et al. 1991 a,b). Die nächsten erfolgreichen Experimente, die die immunsuppressiven Effekte von MMF in vivo bestätigten, wurden an Ratten durchgeführt, denen ein heterotopes Herz transplantiert wurde. Unter Monotherapie mit MMF konnte eine Organabstoßung effektiv verhindert werden (Morris et al. 1990). Ebenso wurde in einem an Hunden durchgeführten allogenen Nierentransplantationsmodell die lebensverlängernde Wirkung durch potente Immunsuppression von MMF nachgewiesen (Platz et al. 
1990). Diese und andere tierexperimentellen Studien lieferten die Basis für sich anschließende Experimente an organtransplantierten Menschen.

Die Pilotstudie zur Überprüfung der Sicherheit und Verträglichkeit des MMF am nierentransplantierten Patienten wurde 1992 erfolgreich durchgeführt. Beobachtete Nebenwirkungen, die unter der Therapie mit MMF bis zur Höchstdosis von $3500 \mathrm{mg} / \mathrm{d}$ auftraten, umfassten gastrointestinale Störungen wie Übelkeit, Erbrechen und Diarrhoe; Knochenmarkssuppression sowie nephro- oder hepatotoxische Nebenwirkungen traten dagegen nicht auf (Sollinger et al. 1992). Seit der Erstzulassung 1995 durch die US Food and Drug Administration dient MMF in Kombination mit Cyclosporin A und Corticosteroiden zur Verhinderung einer akuten Abstoßungsreaktion bei Patienten mit allogener Nierentransplantation. In 3 randomisierten, doppelblinden Studien konnte die Effektivität von MMF als Immunsuppressivum in der Kombination mit Cyclosporin und Glucocorticosteroiden bei der Prävention einer akuten Abstoßungsreaktion nach postmortaler Nierentransplantation an insgesamt 1493 Patienten eindeutig belegt werden (European Mycophenolate Mofetil Cooperative Study Group 1995, Sollinger 1995, Tricontinental Mycophenolate Mofetil Renal Transplantation Study Group 1996). Eine Analyse dieser 3 großen Studien ein Jahr post transplantationem ergab eine signifikante Reduzierung der Zahl der bioptisch gesicherten Abstoßungsreaktionen sowie eine bessere Nierenfunktion unter MMF-Therapie (Halloran et al. 1997). 1998 bzw. 2001 folgen die Zulassungen des MMF für die Verhinderung einer akuten Organabstoßungsreaktion nach Herz- bzw. Lebertransplantation und 2001 für die pädiatrische Nierentransplantation. Im Jahre 2004 erhielten bereits $81 \%$ der nierentransplantierten Patienten MMF, womit es das am häufigsten eingesetzte antiproliferative und immunsuppressive Medikament in der Therapie der akuten Abstoßungsreaktion nach Nierentransplantation darstellt (Meier-Kriesche et al. 2006).

Die antiinflammatorische und immunmodulierende bzw. immunsuppressive Effizienz des MMF resultiert zusammengefasst aus der selektiven Hemmung der T- und BLymphozytenproliferation und der daraus abgeschwächten primären, zellulären und humoralen Immunantwort, weiterhin aus der toleranz-induzierenden Fähigkeit zur Induktion von Apoptose aktivierter T-Lymphozyten sowie aus der verringerten Expression von Adhäsionsmolekülen und dem damit verminderten Recruitment von 
Lymphozyten und Monozyten bzw. der reduzierten Interaktion von Immun- und Endothelzellen (Cohn et al. 1999, Allison und Eugui 2000).

\subsubsection{Neue Einsatzmöglichkeiten für MPA}

Durch die zunehmend verbesserte Immunsuppression und das damit verringerte Auftreten akuter Abstoßungsreaktionen ist heute die Entwicklung einer chronischen Allograft-Nephropathie (CAN) zum wichtigsten prognostischen Faktor für das Langzeitorganüberleben nach Nierentransplantation geworden. Die CAN ist charakterisiert durch eine zunehmende renale Dysfunktion, die mit Gefäßendothelschäden, Tubulusatrophie, Glomerulumsklerose und interstitieller Fibrose einhergeht und letztendlich zum terminalen Organversagen führt. Das Risiko der Entwicklung einer CAN 10 Jahre post transplantationem beträgt fast $60 \%$ (Nankivell et al. 2003). Dabei scheinen sowohl immunologische als auch nichtimmunologische Faktoren einen wichtige Rolle zu spielen (Nankivell und Chapman 2006).

Bereits 2000 erkannte man, dass MMF unabhängig vom Auftreten einer akuten Abstoßungsreaktion das Risiko der Entwicklung eines chronischen Nierenversagens nach Organtransplantation verringerte (Ojo et al. 2000). Weiterhin zeigte sich ein verbessertes Langzeitüberleben Nierentransplantierter, die mit MMF behandelt worden (Meier-Kriesche et al. 2000) sowie ein verringertes Risiko eine CAN zu entwickeln (Merville et al. 2004, Morales 2005). Bei bereits eingetretener CAN konnte durch MMF die Nierenfunktion aufrecht erhalten und ein Fortschreiten der renalen Insuffizienz verzögert werden (Gonzalez et al. 2004). Damit nimmt MMF auch in der Behandlung der CAN einen hohen Stellenwert ein.

Zusätzlich zu seiner antiproliferativen Wirkung auf Lymphozyten wurden für MPA vergleichbare antiproliferative Wirkungen auch auf nicht-immunologische Zellen, wie beispielsweise glatte Gefäßmuskelzellen (Gregory et al. 1993), proximale und distale Tubuluszellen (Baer et al. 2000), vor allem aber auf Fibroblasten beschrieben (Johnsson et al. 2004), welche maßgeblich an der Entwicklung einer Organfibrose beteiligt sind. Direkte antifibrotische Effekte von MPA konnten nachgewiesen werden, indem MPA neben der inhibierten Proliferation von humanen 
Mesangiumzellen auch die Produktion der extrazellulären Matrixkomponenten Fibronektin und Kollagen Typ I hemmte (Dubus et al. 2002).

Zahlreiche in-vivo-Experimente konnten die antifibrotischen Effekte von MPA bestätigen. Im Remnant Kidney Model, ursprünglich bereits in den 70er Jahren beschrieben (Shimamura und Morrison 1975), führt eine subtotale Nephrektomie bei gesunden Ratten zur progressiven Glomerulumsklerose und letztendlich zum chronischen Nierenversagen und stellt somit eine weit verbreitete Methode zur Erforschung der nicht-immunologisch vermittelten Mechanismen der Organfibrose dar. Die zunehmende Fibrosierung ist dabei als Folge der durch den Nephronverlust bedingten reaktiven renalen Hypertonie, der glomerulären Hypertrophie sowie der gesteigerten glomerulären Filtrationsrate im bestehenden Restgewebe anzusehen (Hostetter et al. 1981, Zatz 1996). So konnte beispielsweise die Progredienz der Nierenschädigung durch MMF verlangsamt werden, indem MMF eine deutlich geringere Zunahme der Kreatinin-Konzentration und Proteinurie bewirkte sowie die segmentale und interstitielle Fibrose im Gegensatz zu unbehandelten 5/6nephrektomierten Versuchstieren reduzierte (Romero et al. 1999). In einem weiteren Experiment konnte durch die Behandlung mit MMF neben verbesserten renalen Funktionsparametern eine Reduktion der Myofibroblasteninfiltration in das Interstitium sowie damit verbunden eine verringerte interstitielle Ablagerung von Kollagen Typ III nachgewiesen werden (Badid et al. 2000). Myofibroblasten spielen durch ihre Fähigkeit zur Synthese extrazellulärer Matrix eine wichtige Rolle im Wundheilungs- und Fibrosierungsprozess und gelten als Surrogatparameter für eine progrediente renale Schädigung (Badid et al. 2001). Durch Reduktion der Myofibroblasteninfiltration konnte der Fibrosierungsprozess deutlich verlangsamt werden. Diese Ergebnisse am Remnant Kidney Model führten erstmals zu der Hypothese, dass MMF der Fibrogenese entgegen wirken könnte.

Aber nicht nur im Tiermodell zeigten sich antifibrotische Effekte von MMF. Auch beim Menschen führte die Behandlung mit MMF zur abgeschwächten Expression profibrotischer Gene, z. B. für Metalloproteinasen, TGFß (transforming growth factor beta) und Kollagen III (Waller et al. 2005). Nankivell et al. untersuchten histologisch renale Biopsien nierentransplantierter Patienten, die mit einer Triple-Therapie bestehend aus Cyclosporin, Prednisolon und MMF bzw. Azathioprin behandelt wurden. Hierbei zeigten sich unter dem Einsatz von MMF eine geringgradigere Glomerulumsklerose und Tubulusatrophie, eine reduzierte Akkumulation 
mesangialer Matrix sowie insgesamt eine abgeschwächte chronisch interstitielle Fibrose und niedrigere Glomerulopathie-Scores (Nankivell et al. 2007). Ein weiterer entscheidender Schritt in der Pathogenese der interstitiellen Fibrose ist die phänotypische Differenzierung renaler Tubulusepithelzellen in Myofibroblasten, genannt epitheliale mesenchymale Umwandlung (epithelial-mesenchymal transition, EMT), wobei TGFß1 diese Umwandlung dosisabhängig reguliert ( $\mathrm{Ng}$ et al. 1998, Fan et al. 1999). Die renale Fibrose ist charakterisiert durch eine massive Aktivierung interstitieller Myofibroblasten, welche durch die gesteigerte Ablagerung extrazellulärer Matrix eine zentrale Rolle in der Pathogenese der interstitiellen Nierenfibrose spielt. Der Arbeitsgruppe um Copeland gelang kürzlich der Nachweis, dass MMF den TGFß-induzierten Übergang humaner renaler Tubulusepithelzellen in Myofibroblasten verhindert und Myofibroblasten in Tubulusepithelzellen zurückverwandelt (Copeland et al. 2007). Dadurch und bedingt durch die Tatsache, dass MMF sowohl antiproliferativ als auch funktionsinhibierend auf extrazelluläre Matrix bildende Epithelzellen und Myofibroblasten wirkt, trägt MMF zur Prävention der fibroseassoziierten chronischen Allograft-Nephropathie bei.

Auch zahlreiche andere Erkrankungen gehen bei fortschreitendem Krankheitsgeschehen mit einer progredienten renalen Fibrose einher. Beispiele aus dem klinischen Altag sind arterieller Hypertonus, Diabetes mellitus, aber auch seltenere Erkrankungen wie Glomerulonephritiden oder das Alport-Syndrom. Die Organfibrose ist dabei gemeinsame Endstrecke fast aller chronischen Erkrankungen, dementsprechend wird deren Prävention eine hohe klinische Bedeutung beigemessen. Da die Einschränkung der Nierenfunktion mit dem Ausmaß der Organfibrose korreliert (Bohle 1982), ist eine frühzeitige antifibrotische Therapie erstrebenswert. Abgesehen von der Therapie der Grunderkrankung sind die derzeitigen therapeutischen Möglichkeiten allerdings begrenzt. Daher stellt sich die Frage, inwieweit MMF im Rahmen fibroseassoziierter Erkrankungen neben der Behandlung der chronischen Allograft-Nephropahtie als antifibrotisches Medikament zukünftig therapeutisch eingesetzt werden kann. 


\subsection{Grundzüge der Fibrogenese}

Fibrose bezeichnet eine überschießende Produktion des Bindegewebes vor allem der kollagenen Bindegewebsfasern in Gewebe und Organen (Wynn 2008). Eine zunehmende Organsklerosierung bedingt eine progressive Einschränkung der Funktion, die letztendlich zum terminalen Organversagen führt.

Eddy teilt den Pathomechanismus der renalen Fibrose willkürlich in 4 Phasen ein: a.) die zelluläre Aktivierungs- und Schädigungsphase, in der die Besiedlung des Interstitiums mit Makrophagen und aktivierten Fibroblasten erfolgt, b.) die fibrogenetische Signalphase, in der fibrosefördernde Faktoren ausgeschüttet werden, c.) gefolgt von der fibrogenetischen Phase, die durch eine Akkumulierung von Matrixproteinen im Interstitium gekennzeichnet ist und schließlich d.) die Phase der renalen Destruktion als Folge der exzessiven Matrixakkumulation (Eddy 2000). Der Schweregrad der Erkrankung und die Langzeitprognose werden vor allem durch das Ausmaß der tubulointerstitiellen Schädigung bestimmt (Eddy 1996).

TGFß1, einer der 3 Isoformen der TGFß-Zytokinfamilie, reguliert die Zellproliferation und -differenzierung sowie die Produktion extrazellulärer Matrix und ist gleichermaßen für Reparaturprozesse als auch für Gewebszerstörung durch Fibrosierung verantwortlich (Barnard et al. 1990, Border und Ruoslahti 1992). Die Aktivierung von TGFß1 führt über Membranrezeptoren mit Serin/Threonin-KinaseAktivität (Ebner et al. 1993) neben der Angiogenese-Induktion zur Chemotaxis von Monozyten, Leukozyten und Fibroblasten sowie zur Differenzierung der Fibroblasten zu matrixsynthetisierender Myofibroblasten (Roberts et al. 1986, Eddy 1996). TGFß1 stimuliert die Synthese von Fibronektin, Kollagenen und Proteoglykanen und inhibiert gleichzeitig die Produktion von Proteasen, welche diese Matrixbestandteile wiederum abbauen (Ignotz und Massagué 1986). Des Weiteren wird die Bildung von ProteaseInhibitoren gesteigert (Edwards et al. 1987). Dadurch verschiebt sich das sonst bestehende Fließgleichgewicht zwischen Matrixsynthese und -degradierung zu Gunsten der Synthese und damit zur Fibrose. Weiterhin bewirkt TGFß1 die verstärkte Bildung von Integrinen, was in einer erleichterten Adhäsion der Zellen mit der Matrix resultiert (Ignotz und Massagué 1987). TGFß1 ist überdies zur Autoinduktion fähig und wird in geschädigtem renalen Gewebe vermehrt gebildet (Kim et al. 1989, Border und Noble 1994). Ferner konnte gezeigt werden, dass unter 
pathologischen Bedingungen die TGFß-Rezeptoren in den Tubulusepithelzellen verstärkt exprimiert werden (Sutaria et al. 1998).

Ein weiterer Faktor, der an der Pathogenese und Progredienz der renalen Fibrose beteiligt ist, ist das von TGFß1-stimulierten Fibroblasten sezernierte Protein CTGF (connective tissue growth factor), ein nachgeschalteter Mediator des TGFß1. CTGF wirkt ebenso wie TGFß1 profibrotisch, indem es die Fibroblastenproliferation und die Synthese der extrazellulären Matrix durch Fibroblasten und Mesangiumzellen fördert. In zahlreichen mit Fibrose assoziierten Nierenerkrankungen werden TGFß1 und CTGF sowohl in Glomerula als auch im Tubulointerstitium überexprimiert (Gupta et al. 2000). Wiederum werden Effekte des TGFß1 auf Fibroblasten teilweise durch CTGF vermittelt, in dem CTGF an TGFß1 bindet und so zu dessen Wirkungsverstärkung beiträgt (Abreu et al. 2002). Weitere wichtige profibrotische Faktoren sind beispielsweise Angiotensin II, Endothelin-I sowie die Zytokine TNF $\alpha$ und IL-1 (Interleukin 1), wobei TGFß1 den bedeutendsten zur Fibrose beitragende Faktor darstellt.

Zusammenfassend ist die TGFß1-vermittelte Akkumulation der extrazellulären Matrix das Hauptcharakteristikum der Fibrose, wobei die Differenzierung der Fibroblasten in matrixsynthetisierende Myofibroblasten ein relativ früher Schritt in der Pathogenese der Fibrose darstellt. Da die renale interstitielle Fibrosierung zur fortschreitenden Nierenschädigung führt, stellen Fibroblasten einen pivotalen Angriffspunkt zur Prävention eines progressiven Organversagens dar.

\subsection{Ziele der Arbeit}

Im Rahmen dieses Projektes sollte die antifibrotische Wirkung von MycophenolatMofetil sowohl in vitro als auch in vivo untersucht werden.

Für die in-vitro-Experimente wurde eine Zellkultur aus fibroblasten-ähnlichen COS-7Zellen verwendet. Hierbei wurde die Wirkung des MPA und seines aktiven Metaboliten AcMPAG sowohl auf zellulärer als auch auf molekularer Ebene bezüglich der Proliferation und Funktion der Zellen untersucht.

Im Tierexperiment mit COL4A3-defizienten Mäusen sollten untersucht werden:

- die Überlebenszeit der behandelten im Gegensatz zu den unbehandelten Versuchstieren 
- die Auswirkung der MMF-Dosis auf die Retentionsparameter

- die Auswirkung der MMF-Dosis auf eine veränderte Expression profibrotischer Gene und Proteine

- die Histologie der Nieren der Versuchstiere zur Quantifizierung der Fibrose in Abhängigkeit von der Dosis.

Durch die Untersuchung der antifibrotischen Wirkung von MMF sollten entsprechende biochemisch-pharmakologische Zusammenhänge aufgeklärt werden, um neue therapeutische Ansätze zur Therapie und Prävention der renalen Fibrose zu erschließen. 


\section{Material und Methoden}

\subsection{Chemikalien}

AcMPAG

Acrylamid/Bisacrylamid

Agarose

Alkalische-Phosphatase-Konjugat-

Substrat-Kit

8-Aminoguanosin

Ampholyte

Roche, Palo Alto, CA, USA

AppliChem $\mathrm{GmbH}$, Darmstadt

Life Technologies, Paisley, Schottland

Bio-Rad Laboratories $\mathrm{GmbH}$, München

Ampuwa

APS

Azophloxin

Azur

Sigma-Aldrich Chemie $\mathrm{GmbH}$, Steinheim

Bio-Rad Laboratories $\mathrm{GmbH}$, München

Fresenius Kabi Deutschland $\mathrm{GmbH}$, Bad Homburg

Bio-Rad Laboratories $\mathrm{GmbH}$, München

Waldeck Division Chroma $\mathrm{GmbH}$ \& Co., Münster

Benzylalkohol

MERCK KGaA, Darmstadt

Sigma-Aldrich Chemie $\mathrm{GmbH}$, Steinheim

Bleinitrat

Sigma-Aldrich Chemie $\mathrm{GmbH}$, Steinheim

Borsäure

MERCK KGaA, Darmstadt

Bromphenolblau

Carl Roth $\mathrm{GmbH}$ \& Co., Karlsruhe

BSA Fraktion $V$

Paesel + Lorei, Hanau

BSA purified

New England Biolabs Inc., Ipswich, USA

Butanol

MERCK KGaA, Darmstadt

Carboxymethylcellulose

CHAPS

Chloroform

DDSA

Dinatriumtetraborat

Sigma-Aldrich Chemie $\mathrm{GmbH}$, Steinheim

AppliChem $\mathrm{GmbH}$, Darmstadt

MERCK KGaA, Darmstadt

SERVA Electrophoresis $\mathrm{GmbH}$, Heidelberg

MERCK KGaA, Darmstadt

DMP-30

SERVA Electrophoresis $\mathrm{GmbH}$, Heidelberg

DMSO

Sigma-Aldrich Chemie $\mathrm{GmbH}$, Steinheim

dNTP

Roche Diagnostics $\mathrm{GmbH}$, Mannheim

DTT

Sigma-Aldrich Chemie $\mathrm{GmbH}$, Steinheim 
EDTA Dinatriumsalz Dihydrat

Eisen(III)-chlorid-Hexahydrat

Eosin

Epon

Essigsäure $100 \%$

Ethanol

Ethidiumbromid

Fetales Kälberserum

5x First Strand Puffer

Formaldehyd Load Dye

Formalin

Glutaraldehyd

Glycerin

Glycin

Guanidinhydrochlorid

Guanosin

$\mathrm{HCl}$

Ionomycin

Isopropanol

Kollagen Typ 1

Lichtgrün SF gelblich

Magnesiumchlorid

Mayers Hämalaunlösung

2-Mercaptoethanol

Methanol

Methylenblau

Milchpulver

Mycophenolat-Mofetil

MNA
Carl Roth $\mathrm{GmbH} \&$ Co., Karlsruhe

Carl Roth $\mathrm{GmbH} \&$ Co., Karlsruhe

AppliChem $\mathrm{GmbH}$, Darmstadt

SERVA Electrophoresis $\mathrm{GmbH}$, Heidelberg

MERCK KGaA, Darmstadt

MERCK KGaA, Darmstadt

MERCK KGaA, Darmstadt

PAA Laboratories $\mathrm{GmbH}$ Pasching, Österreich

Invitrogen Life Technologies $\mathrm{GmbH}$, Karlsruhe

Applied Biosystems/Ambion, Austin, TX, USA

Carl Roth $\mathrm{GmbH}$ \& Co., Karlsruhe

SERVA Electrophoresis $\mathrm{GmbH}$, Heidelberg

Carl Roth $\mathrm{GmbH} \&$ Co., Karlsruhe

AppliChem $\mathrm{GmbH}$, Darmstadt

Fluka-Sigma-Aldrich Chemie $\mathrm{GmbH}$,

Steinheim

Sigma-Aldrich Chemie $\mathrm{GmbH}$, Steinheim

MERCK KGaA, Darmstadt

MERCK KGaA, Darmstadt

MERCK KGaA, Darmstadt

BD Biosciences, Bedford, USA

Fluka-Sigma-Aldrich Chemie $\mathrm{GmbH}$,

Steinheim

MERCK KGaA, Darmstadt

MERCK KGaA, Darmstadt

MERCK KGaA, Darmstadt

J.T. Baker, Deventer, Niederlande

MERCK KGaA, Darmstadt

Carl Roth $\mathrm{GmbH}$ \& Co., Karlsruhe

Roche, Palo Alto, CA, USA

SERVA Electrophoresis $\mathrm{GmbH}$, Heidelberg 
Natriumchlorid

Natriumhydroxid

Oligo-dT-Primer

Orange G

Osmiumtetroxid

Paraffin

Paraformaldehyd

Paraplast

Penicillin/Streptomycin

PMA

PMSF

Ponceau S

Propylenoxid

Protein Längenstandard Precision

Plus Protein ${ }^{\mathrm{TM}}$ Standards

Reverse Transkriptase

RNase Inhibitor

Roti® Blue

Roti® Histokitt

SDS

SYBR-Green I

TagPolymerase

TEMED

Tri-Natrium-Citrat-Dihydrat

Tris

TRIzoI@ Reagenz

Trypanblau

Trypsin-EDTA
MERCK KGaA, Darmstadt

MERCK KGaA, Darmstadt

Roche Diagnostics $\mathrm{GmbH}$, Mannheim

Carl Roth $\mathrm{GmbH}$ \& Co., Karlsruhe

Sigma-Aldrich Chemie $\mathrm{GmbH}$, Steinheim

Shandon Southern Products LTD, Runcorn, UK

Carl Roth $\mathrm{GmbH}$ \& Co., Karlsruhe

Carl Roth $\mathrm{GmbH} \&$ Co., Karlsruhe

PAA Laboratories $\mathrm{GmbH}$ Pasching, Österreich

AppliChem GmbH, Darmstadt

Sigma-Aldrich Chemie $\mathrm{GmbH}$, Deisenhofen

SERVA Electrophoresis $\mathrm{GmbH}$, Heidelberg

SERVA Electrophoresis $\mathrm{GmbH}$, Heidelberg

Bio-Rad Laboratories $\mathrm{GmbH}$, München

Invitrogen Life Technologies $\mathrm{GmbH}$,

Karlsruhe

Promega $\mathrm{GmbH}$, Mannheim

Carl Roth $\mathrm{GmbH}$ \& Co., Karlsruhe

Carl Roth $\mathrm{GmbH} \&$ Co., Karlsruhe

SERVA, Boehringer Ingelheim Bioproducts

Partnerchip, Heidelberg

Roche Diagnostics $\mathrm{GmbH}$, Mannheim

Pan-Biotech $\mathrm{GmbH}$, Aidenbach

Bio-Rad Laboratories $\mathrm{GmbH}$, München

Carl Roth $\mathrm{GmbH} \&$ Co., Karlsruhe

Carl Roth $\mathrm{GmbH} \&$ Co., Karlsruhe

Invitrogen Life Technologies $\mathrm{GmbH}$,

Karlsruhe

MERCK KGaA, Darmstadt

PAA Laboratories $\mathrm{GmbH}$ Pasching, Österreich 
Tween 20

Tween 80

Uranylacetat

Wolframatophosphorsäure Hydrat Xylol
Fluka-Sigma-Aldrich $\mathrm{GmbH}$, Steinheim

Sigma-Aldrich Chemie $\mathrm{GmbH}$, Steinheim

MERCK KGaA, Darmstadt

MERCK KGaA, Darmstadt

Carl Roth $\mathrm{GmbH} \&$ Co., Karlsruhe

\subsection{Geräte}

Autoklav

Brutschrank Cytoperm 2

Digitales Stereomikroskop Leica EZ4

Dispergiergerät Polytron PT 3100

Einbettautomat Duplex Processor

Eismaschine

Elektronenmikroskop Leo 906E

Färbeautomat Stainix

Folienschweißgerät Vacupack 2 Plus

Gelelektrophoresekammer

Gene Quant 2

Hamiltonpipette

Kühlzentrifuge Rotina 35R

LightCycler

Magenknopfkanüle

Magnetrührer

Mikroskop Diavert

Mikroskop Olympus CX40

Mikrotom Jung Biocut 2035

Minifuge 2

Netzteil Power Pac 1000

Paraffinheiz- und -abfüllgerät

Personal Cycler
Integra Biosciences $\mathrm{GmbH}$, Fernwald Heraeus Instruments $\mathrm{GmbH}$, Hanau Leica Microsystems $\mathrm{GmbH}$, Wetzlar Kinematica AG, Littau-Luzern, Schweiz Shandon Southern Products LTD, Runcorn, UK

Ziegra Eismaschinen $\mathrm{GmbH}$, Isernhagen

Carl Zeiss AG, Oberkochen

DiaPath s.r.l., Martinengo, Italien

Krups $\mathrm{GmbH}$, Offenbach am Main

Bio-Rad Laboratories $\mathrm{GmbH}$, München

Pharmacia Biotech, Freiburg

Hamilton Bonaduz AG, Bonaduz, Schweiz

Hettich, Tuttlingen

Roche Diagnostics $\mathrm{GmbH}$, Mannheim

Sarstedt AG \& Co., Nümbrecht

IKA Werke GmbH \& Co., Staufen

Leitz $\mathrm{GmbH}$, Wetzlar

Olympus Deutschland $\mathrm{GmbH}$, Hamburg

Leica Microsystems Nussloch $\mathrm{GmbH}$, Nussloch

Heraeus Instruments $\mathrm{GmbH}$, Hanau

Bio-Rad Laboratories $\mathrm{GmbH}$, München

Schütt, Göttingen

Biometra, Göttingen 
PH-Meter

Power Supply

Schnellkühlplatte Para Cooler

Schüttelmaschine

Spektrophotometer DU-7500

Spiegelreflexkamera NIKON D 90

Thermomixer compact

Ultramikrotom Reichert Jung

Ultracut E

Ultraschall-Desintegrator Sonifier

UV-Transilluminator mit Kamera

Vakuumzentrifuge Univapo $150 \mathrm{H}$

Vortex Genie 2

Waagen

Wärmeplatte Hot Plate 062

Wasserbad GFL Typ 1003

96-Well-Photometer Milenia

Zentrifuge $5415 \mathrm{C}$
Wissenschaftlich-technische Werkstätten $\mathrm{GmbH}$, Weilheim

Bio-Rad Laboratories $\mathrm{GmbH}$, München

RWW Medizintechnik, Forchheim

Schütt, Göttingen \& Bühler, Tübingen

Beckman Coulter, Inc., Fullerton, CA, USA

Nikon $\mathrm{GmbH}$, Düsseldorf

Eppendorf, Hamburg

Leica Microsystems Nussloch $\mathrm{GmbH}$, Nussloch

Branson Ultraschall GmbH, Dietzenbach

Bachofer $\mathrm{GmbH}$, Reutlingen

UniEquip $\mathrm{GmbH}$, Martinsried/München

Scientific Industries, Inc., Bohemia, NY, USA und Schütt, Göttingen

Sartorius, Göttingen

Labotect $\mathrm{GmbH}$, Göttingen

Krannich $\mathrm{GmbH}$ \& Co., Göttingen

Diagnostic Products Corporation, Los Angeles, CA, USA

Eppendorf, Hamburg

\subsection{Gebrauchswaren}

Beem-Kapsel

Deckgläser

Einstreu

Faltenfilter 595 1/2

Filterpapier

Gelgießplatten
Polysciences, Inc., Warrington, PA, USA

Menzel GmbH \& Co., Braunschweig

J. Rettenmaier \& Söhne, $\mathrm{GmbH}$ \& Co., Rosenberg

Whatman Schleicher \& Schuell $\mathrm{GmbH}$, Dassel

Whatman Schleicher \& Schuell $\mathrm{GmbH}$, Dassel

Bio-Rad Laboratories GmbH, München 
Gewebekulturplatte 6- bzw. 96- Loch

Glasröhrchen 3,5 ml

Halterungsfutter

Kämme

Kryoröhrchen

Küvetten

Nitrozellulosemembran 0,45 $\mu \mathrm{mol} / \mathrm{l}$

Objektträger

Pipettenspitzen

Pipettierhilfe pipetus-akku

Röhrchen $15 \mathrm{ml}, 50 \mathrm{ml}$

Serologische Pipette $10 \mathrm{ml}$

Zellkulturflachen
Greiner Bio-One $\mathrm{GmbH}$, Frickenhausen Sarstedt AG \& Co., Nümbrecht Ssniff Spezialdiäten $\mathrm{GmbH}$, Soest Bio-Rad Laboratories $\mathrm{GmbH}$, München Nunc Intermed, Roskilde, Dänemark Hellma, Müllheim Schleicher \& Schuell, Dassel Carl Roth $\mathrm{GmbH}$ \& Co., Karlsruhe Sarstedt AG \& Co., Nümbrecht Hirschmann Laborgeräte $\mathrm{GmbH}$ \& Co., Eberstadt Greiner Bio-One $\mathrm{GmbH}$, Frickenhausen Sarstedt AG \& Co., Nümbrecht Sarstedt AG \& Co., Nümbrecht

\subsection{Puffer und Lösungen}

Die verwendeten Puffer und Lösungen wurden, sofern nicht anders angegeben, je nach Bedarf mit deionisiertem Wasser $\left(\mathrm{dH}_{2} \mathrm{O}\right)$ oder Ampuwa (steriles pyrogenfreies Wasser) hergestellt.

Agaroselösung

$1,5 \%(w / v)$ Agarose

1x TBE-Puffer

Azophloxin

$0,5 \%$ (w/v) Azophloxin

$0,2 \%$ (v/v) Eisessig

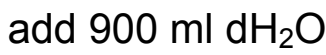

Bleizitrat

1,33 g Bleinitrat

1,76 g Tri-Natrium-Citrat-Dihydrat

$30 \mathrm{ml} \mathrm{dH_{2 }} \mathrm{O}$

nach 30 min Inkubation: $8 \mathrm{ml} 1 \mathrm{~N} \mathrm{NaOH}$

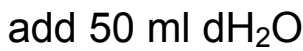


Blockpuffer

Carboxymethylcelluloselösung

Coomassie

Coomassie-Entfärber

dNTP-Lösung

Einfriermedium

Eisenhämatoxylin nach Weigert
$50 \mathrm{mmol} / \mathrm{l}$ Tris/HCl pH 7,5

$200 \mathrm{mmol} / \mathrm{l} \mathrm{NaCl}$

$5 \%$ (w/v) Magermilchpulver

0,861 ml Benzylalkohol

0,376 $\mathrm{ml}$ Tween 80

$0,9 \mathrm{~g} \mathrm{NaCl}$

0,5 g Carboxymethylcellulose

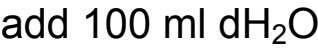

$\mathrm{pH} 3,5$

$40 \%(v / v) \mathrm{dH}_{2} \mathrm{O}$

$40 \%(v / v)$ Methanol

$20 \%$ (v/v) Roti® Blue

$20 \%$ (v/v) Methanol

$5 \%$ (v/v) Essigsäure $100 \%$

$10 \mathrm{mmol} / \mathrm{l} \mathrm{dATP}$

$10 \mathrm{mmol} / \mathrm{l} \mathrm{dCTP}$

$10 \mathrm{mmol} / \mathrm{l} \mathrm{dGTP}$

$10 \mathrm{mmol} / \mathrm{l} \mathrm{dTTP}$

$80 \%(v / v)$ DMEM

$10 \%(v / v)$ FCS gold

$10 \%(v / v)$ DMSO

Lösung A: 1 \% (w/v) Hämatoxylin add $500 \mathrm{ml} 96 \% \mathrm{EtOH}$

Lösung B: 2 \% (w/v) Eisen(III)-chloridHexahydrat $1 \%(v / v) 25 \% \mathrm{HCl}$ add $490 \mathrm{ml} \mathrm{dH}_{2} \mathrm{O}$ 
Mischung der Lösungen $A$ und $B$ unmittelbar vor Gebrauch im Verhältnis 1:1

Elektrophoreselaufpuffer

Eosin

Lichtgrün

Osmiumpuffer

10x PCR-Puffer

Phosphorwolframsäure und Orange G
$25 \mathrm{mmol} / \mathrm{l}$ Tris $\mathrm{pH} \mathrm{8,3}$

0,192 mol// Glycin

$0,1 \%(w / v)$ SDS

$0,1 \%(w / v)$ Eosin

$0,15 \%(w / v)$ Lichtgrün

$0,2 \%(v / v)$ Eisessig

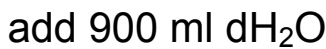

$50 \%$ (v/v) $2 \%$ wässriges Osmiumtetroxid 50 \% (v/v) 0,3 M Sörensen-Puffer

$200 \mathrm{mmol} / / \mathrm{Tris} / \mathrm{HCl} \mathrm{pH} \mathrm{8,4}$ $500 \mathrm{mmol} / \mathrm{KCl}$

Ponceau-Rot

0,5 \% (w/v) Ponceau S

$40 \%$ (v/v) Methanol

$15 \%$ (v/v) Essigsäure 100\%

Richardson-Blau

Lösung A: 1 \% (w/v) Azur

Lösung B: 2 \% (w/v) Methylenblau

Lösung C: $2 \%(w / v)$ Dinatriumtetraborat

Lösung $\mathrm{A}: \mathrm{B}: \mathrm{C}=2: 1: 1$

2x SDS-Probenpuffer

0,125 mol// Tris/HCl pH 6,8

$20 \%$ (v/v) Glycerin 
$4 \%$ (w/v) SDS

$2 \%$ (v/v) 2-Mercaptoethanol

0,03 mmol// Bromphenolblau

Sörensen-Puffer

$18,2 \%(v / v)$ Lösung $A$

$81,8 \%(v / v)$ Lösung $B$

Lösung A: 41,37 $\mathrm{g} \mathrm{KH}_{2} \mathrm{PO}_{4}$

add $1 \mathrm{I} \mathrm{dH}_{2} \mathrm{O}$

Lagerung bei $4^{\circ} \mathrm{C}$

Lösung B: $42,58 \mathrm{~g} \mathrm{Na}_{2} \mathrm{HPO}_{4}$

add $1 \mathrm{I} \mathrm{dH}_{2} \mathrm{O}$

Lagerung bei RT

Mischung der Lösungen $A$ und $B$ unmittelbar vor Gebrauch

10x TBE-Puffer

$890 \mathrm{mmol} / \mathrm{l}$ Tris

$890 \mathrm{mmol} / \mathrm{l}$ Borsäure

$10 \mathrm{mmol} / \mathrm{l} \mathrm{Na}_{2}$ EDTA $\mathrm{pH} 8,0$

TBS-Puffer

$50 \mathrm{mmol} / \mathrm{l} \mathrm{Tris} / \mathrm{HCl} \mathrm{pH} \mathrm{7,5}$

$200 \mathrm{mmol} / \mathrm{l} \mathrm{NaCl}$

Transblottpuffer

$25 \mathrm{mmol} / / \mathrm{Tris}$

$160 \mathrm{mmol} / /$ Glycin

$20 \%$ (v/v) Methanol

Waschpuffer

$50 \mathrm{mmol} / \mathrm{l}$ Tris/HCl pH 7,5

$200 \mathrm{mmol} / \mathrm{l} \mathrm{NaCl}$

$0,05 \%$ (v/v) Tween 20

Zelllysepuffer

$7 \mathrm{~mol} / /$ Urea

$2 \mathrm{~mol} / \mathrm{l}$ Thiourea

$4 \%(w / v)$ CHAPS 


\author{
$2 \%$ (v/v) Ampholyte \\ $1 \%(w / v)$ DTT \\ $10 \mathrm{mmol} / / \mathrm{PMSF}$
}

\title{
2.5 Oligonukleotide
}

Alle für die quantitative Real-Time-PCR verwendeten Primer wurden durch die Firma Operon Biotechnologies $\mathrm{GmbH}$ (Köln) synthetisiert, in sterilem Wasser gelöst, so dass die Konzentration $100 \mu \mathrm{mol} / \mathrm{l}$ betrug und bei $-20^{\circ} \mathrm{C}$ gelagert.
COL1A1-F
5' - ggtttcagtggtttggatgg - 3'
COL1A1-R
5'- gcaccagtagcaccatcattt - 3'
CTGF-F
5' - ggaattttagcgtgctcactg - 3'
CTGF-R
5' - ttcacttgccacaagctgtc - 3'
EF-2-F
5' - agacgccttgttgcagatg - 3'
EF-2-R
5' - aaggcgtagaaccgaccttt - 3'
IL-6-F
5' - agttcctgcagaaaaaggca - 3'
IL-6-R
5' - aagaaggaatgcccattaac - 3'
TGFß1-F
5' - actgcaagtggacatcaacg- 3'
TGFß1-R
5' - tcttctccgtggagctgaag - 3'
TNFa-F
5' - cagagggcctgtacctcatc - 3'
TNFa-R
5' - gagtcgatcaccettctcca - 3'

\subsection{Antikörper}

monoclonal anti-rabbit-IgG-Alkaline-Phosphatase-Conjugate Clone RG-96 (SigmaAldrich, Steinheim) monoclonal mouse-anti-TGFß1-IgG (R\&D Systems, Wiesbaden) 
polyclonal goat-anti-mouse-IgG-Alkaline-Phosphatase-Conjugate (Sigma-Aldrich, Steinheim)

polyclonal goat-anti-rabbit-lgG-Alkaline-Phosphatase-Conjugate (Bio-Rad, München) polyclonal rabbit-anti-ANXA 5-IgG (Abcam, Hiddenhausen)

polyclonal rabbit anti-EEF2-IgG (Abcam, Cambridge, UK)

\subsection{Tierexperimentelle Untersuchung}

Der tierexperimentellen Untersuchung dienten COL4A3-defiziente Mäuse (Jackson Laboratory, Bar Harbor, ME, USA) als Modell für eine progrediente renale Fibrose in Analogie eines humanen Alport-Syndroms (Cosgrove et al. 1996). Das Tierversuchsvorhaben wurde durch das Niedersächsische Landesamt für Verbraucherschutz und Lebensmittelsicherheit (LAVES) genehmigt (Aktenzeichen des Tierversuchantrags: G76.07). Die Unterbringung und Behandlung der Tiere erfolgte in der Zentralen Tierexperimentellen Einrichtung (ZTE) der Universitätsmedizin Göttingen. Dabei wurden maximal 3 Tiere in einem mit keimarmen Einstreu gefüllten Standardkäfig der Größe III (40 x $25 \times 15 \mathrm{~cm})$ unter Kunstlicht mit einer zwölfstündigen Dunkelphase von 18:00 bis $6: 00$ Uhr bei $21^{\circ} \mathrm{C}$ Raumtemperatur und $50 \%$ relativer Luftfeuchtigkeit offen gehalten. Pelletiertes Halterungsfutter sowie Leitungswasser in Tränkeflaschen standen ständig zur Verfügung.

Noch vor Ausbruch der Erkrankung erfolgte bei den Versuchstieren in der 5. Woche postnatal die Genotypisierung durch Schwanzbiopsie, welche in der Inneren Medizin, Abteilung Nephrologie und Rheumatologie der Universitätsmedizin Göttingen durchgeführt wurde. Es wurden 5 Gruppen mit je $n=7$ Mäusen ab der 6 . Woche postnatal mit unterschiedlichen Dosen oral verabreichtem MMF behandelt (Placebo, 10, 50, 100 oder 150 mg/kg/d, Behandlungsschema Abb. 3). Die Versuchstiere wurden den Dosisgruppen durch Randomisierung zugeordnet. 

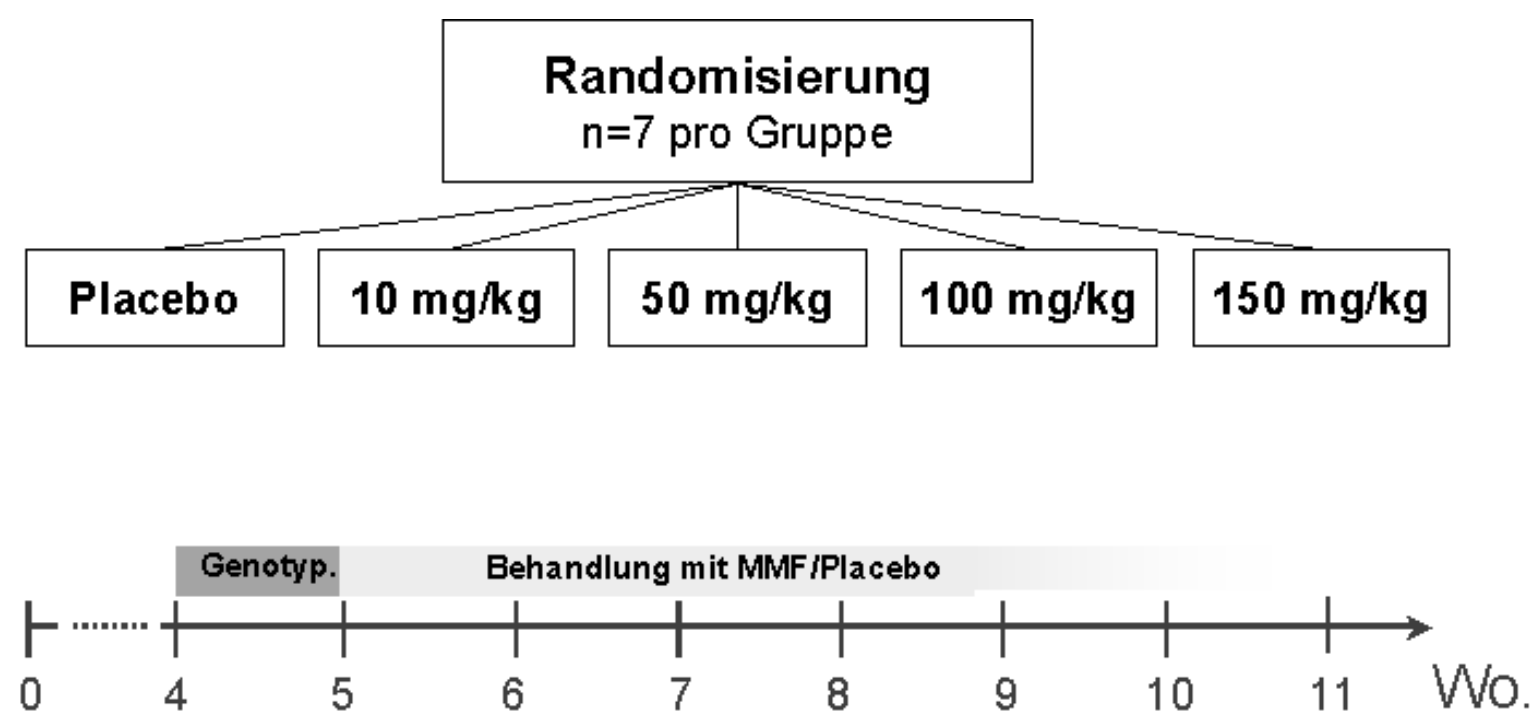

Abb. 3 Behandlungsschema für COL4A3-defiziente Mäuse

Die Verabreichung des Medikamentes bzw. des Placebos erfolgte per os über eine gerade Magenknopfkanüle (Form B, Durchmesser: 0,6 mm, Länge: $30 \mathrm{~mm}$ ). Als Trägersubstanz bzw. Placebo diente eine Carboxymethylcelluloselösung. $100 \mathrm{ml}$ der Lösung wurden hergestellt (2.4), über Nacht auf dem Magnetrührer belassen und am Folgetag autoklaviert. Zur Herstellung der unterschiedlichen Konzentrationen an MMF wurde die entsprechende Menge dem Transfermedium hinzugefügt, die Suspension mit Ultraschall behandelt und bei $4^{\circ} \mathrm{C}$ für maximal 23 Tage gelagert. Um eine gewichtsadaptierte Gabe zu ermöglichen, wurden die Tiere täglich gewogen. Gemäß der Vereinbarung mit der Tierschutzkommission erfolgte bei der täglichen Applikation des MMF neben der Kontrolle des Gewichtes auch die Kontrolle des Allgemeinzustandes der behandelten Mäuse. Bei Einsetzen der terminalen Niereninsuffizienz, erkennbar durch die zunehmende Somnolenz, wurden die Tiere durch Inhalation von Kohlendioxid getötet. Anschließend wurde durch kardiale Punktion ca. 100-200 $\mu \mathrm{l}$ Vollblut gewonnen. Das Serum wurde nach Zentrifugation mit $0,9 \% \mathrm{NaCl}$-Lösung verdünnt $(1: 10)$ und bei $-20^{\circ} \mathrm{C}$ bis zur Messung von MPA, MPAG sowie den Parametern der Klinischen Chemie aufbewahrt. Die Quantifizierung von MPA und MPAG erfolgte mittels einer validierten, massenspektroskopischen Methode (Brandhorst et al. 2006, Streit et al. 2004). Die Bestimmungen von Kreatinin, Harnstoff und Gesamtprotein erfolgten an Modularsystemen (P-Modul) gemäß den Herstellerangaben. Bei der Präparation der Mäuse wurden beide Nieren entnommen. Eine halbe Niere diente der histologischen 
Untersuchung; dazu wurde diese zunächst in Formalin und $8 \mathrm{~h}$ später in $70 \%$ Ethanol bei $4^{\circ} \mathrm{C}$ gelagert. Die restlichen Nieren lagerten bis zum weiteren Gebrauch bei $-80^{\circ} \mathrm{C}$.

\subsection{Zellkultur}

Für die Experimente in Zellkultur wurden COS-7-Zellen (Deutsche Sammlung von Mikroorganismen und Zellkulturen $\mathrm{GmbH}$, Braunschweig) verwendet, welche bereits 1981 erfolgreich etabliert wurden (Gluzman 1981). Hierbei handelt es sich um Fibroblasten-ähnliche Zellen, welche aus dem Nierengewebe der Grünen Meerkatze (Chlorocebus) stammen. Die Inkubation der adhärent wachsenden Zellen erfolgte in $75-\mathrm{cm}^{2}$-Kulturflaschen gemäß den Vorgaben der DSMZ in $90 \%$ DMEM High Glucose $(4,5 \mathrm{~g} / \mathrm{l}), 10 \%$ FCS Gold sowie $100 \mathrm{U} / \mathrm{ml}$ Penicillin und $100 \mu \mathrm{g} / \mathrm{ml}$ Streptomycin sowie Zugabe von $125 \mu \mathrm{g} / \mathrm{l}$ lonomycin und $3 \mu \mathrm{g} / \mathrm{l}$ PMA zur Zellstimulation bei $37^{\circ} \mathrm{C}, 20 \% \mathrm{O}_{2}$ sowie $5 \% \mathrm{CO}_{2}$ im Brutschrank.

Sämtliche Maßnahmen der Zellkultur fanden unter sterilen Bedingungen statt. Alle verwendeten Lösungen wurden vor dem Arbeiten in einem Wärmebad auf $37^{\circ} \mathrm{C}$ vorgewärmt.

Alle 2 bis 3 Tage wurde das Kultivierungsmedium erneuert. Zum Passagieren bei erreichter Konfluenz der Zellen wurde das Medium abgesaugt, die Kultur mit $10 \mathrm{ml}$ PBS gewaschen und mit $1 \mathrm{ml}$ Trypsin/EDTA für 2-3 min im Brutschrank inkubiert, wodurch sich die Zellen vom Flaschenboden lösten. Durch Zugabe von $10 \mathrm{ml}$ DMEM wurde das Trypsin inhibiert. Die nun vereinzelten Zellen wurden je nach Bedarf in einem Verhältnis von 1:3 bis 1:10 ausgesät.

Um bei Bedarf auf Zellpopulationen der gleichen Passage zurückgreifen zu können, wurden die Zellen eingefroren. Dafür wurden die Zellen zunächst trypsinisiert, die Zellsuspension 5 min bei $250 \mathrm{~g}$ zentrifugiert, zum Pellet $1 \mathrm{ml}$ DMEM hinzugefügt und anschließend die Zellzahl unter dem Mikroskop mit Hilfe der Neubauer-Zählkammer bestimmt. Jeweils $1 \times 10^{6}$ COS-7-Zellen wurden mit $1 \mathrm{ml}$ eiskaltem Einfriermedium (2.4) versehen und in Kryoröhrchen über Nacht bei $-20^{\circ} \mathrm{C}$ gelagert, bevor sie am nächsten Tag in flüssigem Stickstoff tiefgefroren wurden.

Beim Wiederauftauen der Zellen wurde das Kryoröhrchen bei RT angetaut und der noch halb gefrorene Inhalt zügig in eine $25-\mathrm{cm}^{2}$-Kulturflasche mit frischem DMEM + 
$20 \%$ FCS Gold $+100 \mathrm{U} / \mathrm{ml}$ Penicillin und $100 \mu \mathrm{g} / \mathrm{ml}$ Streptomycin überführt. Am nächsten Tag erfolgte ein Mediumwechsel unter Beibehaltung der Konzentrationen. Am zweiten Tag wurde dann die FCS-Konzentration auf $15 \%$ und am dritten Tag auf die üblichen $10 \%$ reduziert.

\subsection{Proliferations-Assay}

Für die Quantifizierung der COS-7-Proliferation wurde ein kommerzieller Proliferations-Assay verwendet und laut Herstellerangaben verfahren (BrdU, Roche Diagnostics). Das Testprinzip besteht aus einer Markierung der DNA aller neu gebildeten Zellen in einem definierten Zeitraum. Hierbei wird 5-Brom-2'-desoxyUridin (BrdU), ein synthetisches Thymidinanalogon, anstelle des DNA-Bausteines während der S-Phase des Zellzykluses in die neu synthetisierte DNA eingebaut. Ein gegen das BrdU gerichteter, mit Peroxidase-gekoppelter Antikörper (anti-BrdU-POD) bindet an das in die DNA eingebaute BrdU, welches anschließend durch eine nachgeschaltete Peroxidase-Farbreaktion kolorimetrisch quantifiziert wird und somit als Surrogatparameter ein direktes Maß für die Zellproliferation darstellt.

In einer 96-Loch-Gewebekulturplatte wurden $5 \times 10^{3}$ COS-7-Zellen pro Well in $200 \mu \mathrm{l}$ Medium mit unterschiedlichen Konzentrationen MPA bzw. dessen Metaboliten MPAAcylglukuronid (AcMPAG, jeweils $0 ; 0,1 ; 1 ; 10 ; 100 \mu \mathrm{mol} / \mathrm{l}$ ) sowie mit oder ohne Guanosin/8-Aminoguanosin (50 $\mu \mathrm{mol} / / \mathrm{l}$ Guanosin, $100 \mu \mathrm{mol} / / \mathrm{l}$ 8-Aminoguanosin) behandelt und über $72 \mathrm{~h}$ inkubiert, wobei das Medium alle $24 \mathrm{~h}$ gewechselt wurde. Nach $72 \mathrm{~h}$ wurde BrdU (1:100 mit DMEM verdünnt) hinzugeben und für weitere $24 \mathrm{~h}$ inkubiert. Das Medium wurde mit einer Pumpe abgesaugt und die Zellen auf dem Wellboden mit FixDenat Lösung für 30 min bei RT fixiert, bevor anschließend der Peroxidase-gekoppelte Antikörper (1:100) hinzugegeben wurde. Nach 90 minütiger Inkubation bei RT wurde die Lösung wiederum abgesaugt und die Wells $3 x$ mit Waschpuffer gespült, bevor die Farbreaktion mit einer Substratlösung initiiert wurde. Die Zunahme der Absorption wurde kolorimetrisch im 96-Well-Photometer bei $450 \mathrm{~nm}$ gemessen. 


\subsection{Wundverschluss-Assay}

Für die Durchführung des Wundverschluss-Assays wurden $5 \times 10^{5}$ Zellen in $3 \mathrm{ml}$ Medium in 35-mm-Schalen für $24 \mathrm{~h}$ inkubiert, um einen konfluenten Zellrasen zu erhalten (Javelaud et al. 2003). Die Zellen wurden anschließend mit 0, 1, 10 oder $100 \mu \mathrm{mol} / \mathrm{l}$ MPA sowie mit oder ohne Guanosin/8-Aminoguanosin (50 $\mu \mathrm{mol} / /$ Guanosin, $100 \mu \mathrm{mol} / /$ 8-Aminoguanosin) behandelt. Nach Mediumwechsel wurde mittels einer Pipettenspitze im Sinne einer artifiziellen Wunde ein Defekt gleicher Breite in den Zellrasen gekratzt. Das Wachstum der Zellen sowie die Breite des Defektes wurden im Verlauf nach 12, 24 und $48 \mathrm{~h}$ mikroskopisch beurteilt und photographisch dokumentiert.

\subsection{Kollagen-Kontraktions-Assay}

Der Kollagen-Kontraktions-Assay wurde mit $3 \times 10^{6}$ Zellen in 35-mm-Schalen durchgeführt. Ein Ansatz enthielt jeweils $1,5 \mathrm{mg} / \mathrm{ml}$ Kollagen Typ I in $3 \mathrm{ml}$ Medium sowie 0 oder $100 \mu \mathrm{mol} / / \mathrm{MPA}$ mit oder ohne Guanosin/8-Aminoguanosin $(50 \mu \mathrm{mol} / \mathrm{l}$ Guanosin, $100 \mu \mathrm{mol} / \mathrm{l}$ 8-Aminoguanosin). Nach $60 \mathrm{~min}$ bei $37^{\circ} \mathrm{C}$ waren Zellen, Medium und Kollagen in einer Matrix polymerisiert, so dass die Kontraktion der Matrix durch leichtes Beklopfen der Schale initiiert werden konnte. Alle $24 \mathrm{~h}$ wurde das Medium gewechselt. Der Prozess der Kontraktion wurde durch photographische Dokumentation der Fläche nach 0, 12, 24, 36, 48, 60, 72, 84 und $96 \mathrm{~h}$ ausgewertet. Die Berechnung der Fläche unter der Kontraktions-/Zeit-Kurve (area under the curve, AUC) erfolgte nach der Trapez-Methode mit folgender Formel:

$$
\begin{aligned}
& {[A \cup C]_{t=0}^{t=96}=[A \cup C]_{t=0}^{t=12}+[A \cup C]_{t=12}^{t=24}+[A U C]_{t=24}^{t=36}+[A U C]_{t=36}^{t=48}+[A \cup C]_{t=48}^{t=60}+} \\
& {[A \cup C]_{t=60}^{t=72}+[A \cup C]_{t=72}^{t=84}+[A U C]_{t=84}^{t=96}}
\end{aligned}
$$

wobei

$[A \cup C]_{t=a}^{t=b}=\left(x_{a}+x_{b}\right) / 2 *\left(t_{b}-t_{a}\right)$

AUC area under the curve in \%h 
$x_{n} \quad$ Fläche der Kollagen-Matrix zum Zeitpunkt $n$ prozentual zur Ausgangsfläche

$t_{n} \quad$ Zeitpunkt $\mathrm{n}$ in $\mathrm{h}$

\subsection{Nukleinsäuretechnische Methoden}

\subsubsection{Präparation von Gesamt-RNA}

Die Isolierung von Gesamt-RNA aus den Zellen wurde modifiziert nach Chomczynski und Sacchi (1987) mit Hilfe von TRIzol ${ }^{\circledR}-$ Reagenz durchgeführt. Hierbei handelt es sich um eine monophasische Lösung, bestehend aus Phenol und Guanidinisothiocyanat.

\subsubsection{Präparation von Gesamt-RNA aus COS-7-Zellen}

$1,5 \times 10^{6}$ bzw. $3 \times 10^{6}$ COS-7-Zellen werden in $75-\mathrm{cm}^{2}$-Kulturflaschen mit 0 oder $100 \mu \mathrm{mol} / / \mathrm{MPA}$ bzw. $100 \mu \mathrm{mol} / \mathrm{l}$ MPA mit Guanosin/8-Aminoguanosin für 6, 12, 24 oder $48 \mathrm{~h}$ inkubiert. Zum Ernten der Zellen wurden diese einmalig mit PBS gewaschen, trypsinisiert und anschließend zentrifugiert (250 g, $5 \mathrm{~min})$. Der Überstand wurde verworfen. Die Zellen wurden zunächst für $5 \mathrm{~min}$ in $1 \mathrm{ml}$ TRIzol ${ }^{\circ}$ Reagenz, anschließend in $200 \mu$ Chloroform inkubiert und dann zentrifugiert $\left(12000 \mathrm{~g}, 4^{\circ} \mathrm{C}, 15 \mathrm{~min}\right)$. Es ergaben sich eine obere wässrige Phase, welche die RNA enthielt, eine DNA enthaltene trübe Interphase sowie eine untere rote organische Phase, aus der die Proteine isoliert wurden (2.13.1). Die RNA der oberen Phase wurde mit $500 \mu \mathrm{l}$ Isopropanol für 10 min präzipitiert. Nach Zentrifugation (12000 g, 4 $\mathrm{C}, 10 \mathrm{~min}$ ) wurde das Pellet einmalig mit $1 \mathrm{ml} 70$ \% Ethanol gewaschen, zentrifugiert $\left(7500 \mathrm{~g}, 5 \mathrm{~min}, 4^{\circ} \mathrm{C}\right)$, luftgetrocknet, in $\mathrm{dH}_{2} \mathrm{O}$ aufgelöst und bei $-80^{\circ} \mathrm{C}$ gelagert.

\subsubsection{Präparation von Gesamt-RNA aus Nierengewebe}

Für die Isolierung von Gesamt-RNA aus den Nieren der Mäuse wurden 50-100 mg Organgewebe in $1 \mathrm{ml}$ TRIzol ${ }^{\circ}-$ Reagenz mit einem Dispergiergerät homogenisiert, in 
$200 \mu \mathrm{l}$ Chloroform auf Eis inkubiert und anschließend zentrifugiert $\left(12000 \mathrm{~g}, 4^{\circ} \mathrm{C}\right.$, $15 \mathrm{~min})$. Die Präzipitationszeit der RNA in Isopropanol betrug hier $30 \mathrm{~min}$. Die weiteren Schritte erfolgten analog zur Präparation von Gesamt-RNA aus COS-7Zellen.

\subsubsection{Konzentrationsbestimmung von RNA}

Die Konzentration der isolierten RNA wurde photometrisch am Gene Quant 2 bei 260/280 nm ermittelt und ergab sich wie folgt:

$$
c(\text { RNA })=E_{260}{ }^{*} \varepsilon * f
$$

C Konzentration in $\mu \mathrm{g} / \mathrm{ml}$

$E_{260}$ Extinktion gemessen bei einer Wellenlänge von $260 \mathrm{~nm}$

$\varepsilon \quad$ Nukleinsäurekoeffizient $(0,04 \mu \mathrm{g} / \mathrm{ml}$ für RNA)

f Verdünnungsfaktor

Die Verdünnung wurde so gewählt, dass die Absorption in einem Bereich zwischen 0,2 und 1 lag. Als Maß für die Reinheit wurde der Quotient $E_{260} / E_{280}$ bestimmt, welcher größer als 1,7 sein sollte.

\subsubsection{Agarosegelelektrophorese}

Nachdem die RNA gewonnen und ihre Konzentration bestimmt wurde, erfolgte anschließend die Überprüfung inrer Qualität in einem 1,5 \% Agarose-TBE-Gel. Dazu wurden $50 \mathrm{ml}$ bzw. $100 \mathrm{ml}$ 1x TBE mit 1,5\% (w/v) Agarose aufgekocht und auf einem kleinen bzw. großen Gelträger gegeben. Das ausgehärtete Gel wurde in eine Gelkammer eingesetzt und diese anschließend mit 1x TBE gefüllt. $3 \mu \mathrm{g}$ RNA wurden mit $10 \mu \mathrm{l}$ Formaldehyd Load Dye und 0,1 $\mu$ Ethidiumbromid versehen und in die Taschen des Gels geladen. Die elektrophoretische Auftrennung der RNA erfolgte bei $100 \mathrm{~V}$ für $60 \mathrm{~min}$. Anschließend wurden die mit Ethidiumbromid angefärbten 28Sund 18S-Banden photographiert und mit der Software Lablmage (Kapelan Bio- 
Imaging $\mathrm{GmbH}$, Halle/Saale) ausgewertet, wobei das Verhältnis der Signalstärke 28S- zur 18S-Bande annähernd 2:1 betragen sollte.

\subsubsection{Reverse-Transkriptase-Polymerasekettenreaktion (RT-PCR)}

\subsubsection{Reverse Transkription}

Ein Teil der mit Hilfe der in 2.12.1 erläuterten Methode gewonnenen RNA wurde in einem ersten Schritt zunächst in komplementäre DNA (cDNA) umgeschrieben; dazu diente das Enzym Reverse Transkriptase, eine RNA-abhängige DNA-Polymerase.

$3 \mu \mathrm{g}$ RNA wurden für $3 \mathrm{~min}$ bei $75^{\circ} \mathrm{C}$ denaturiert. Nachdem die Temperatur auf $37^{\circ} \mathrm{C}$ gefallen war, wurde der Reverse-Transkriptase-Mix, bestehend aus $6 \mu$ l 5x First Strand Buffer, $1 \mu$ l Oligo-dT-Primer, 1,5 $\mu$ l dNTP-Lösung (2.4), 1,2 $\mu$ l RNase Inhibitor und $2 \mu$ l Reverse Transkriptase, hinzugegeben. Die cDNA-Synthese erfolgt für $60 \mathrm{~min}$ bei $37^{\circ} \mathrm{C}$ im Personal Cycler.

Die so gewonnene cDNA konnte bei $-20^{\circ} \mathrm{C}$ gelagert oder direkt als Ausgangsmaterial in einer PCR verwendet werden.

\subsubsection{Quantitative Real-Time-PCR}

Nach der reversen Transkription wurde die quantitative Real-Time-PCR auf einem LightCycler durchgeführt. Die quantitative Real-Time-Polymerase-Kettenreaktion dient der exponentiellen Vervielfältigung einer Primer-spezifischen DNA-Sequenz bei gleichzeitig möglicher Quantifizierung der gewonnenen DNA. Diese Quantifizierung erfolgt mit Hilfe von Fluoreszenzmessungen während der exponentiellen Phase der PCR. Der Farbstoff SYBR-Green I wird zur Detektion von DNA eingesetzt, indem er in die doppelsträngige DNA interkaliert, wodurch seine Fluoreszenz ansteigt. Die Zunahme der Lichtemission ist somit ein direktes Maß für die Zunahme der gebildeten DNA. Die Expression des Zielgens wird auf ein housekeeping gene bezogen, welches nicht reguliert und konstitutiv exprimiert wird.

Durch Erhitzen auf $95^{\circ} \mathrm{C}$ denaturiert die doppelsträngige DNA, so dass an den nun vorliegenden Einzelsträngen sequenzspezifische Primer binden können. Primer sind 
Oligonukleotide, welche als Startpunkt für die DNA-Polymerase, wie die TaqPolymerase des Archaebakteriums Thermus aquaticus, dienen. Erleichtert wird die Primerbindung (Annealing) durch ein Herabsetzen der Temperatur auf $55^{\circ} \mathrm{C}$. Die DNA-Synthese erfolgt bei $72^{\circ} \mathrm{C}$, der optimalen Arbeitstemperatur der hitzestabilen TaqPolymerase, welche die Anlagerung von Desoxynukleotiden an das 3'-Ende des Primers katalysiert (Elongation). So entsteht ein zur DNA-Matrize komplementärer Strang, an welchem in einem weiteren Reaktionszyklus die Primer erneut binden können.

Durchführung:

Pro $1 \mu \mathrm{l} \mathrm{cDNA}$ wurde folgendes Reaktionsgemisch hinzufügt (19 $\mu \mathrm{l})$ :

$\begin{array}{ll}\text { 10x PCR-Puffer } & 2 \mu \mathrm{l} \\ \text { SYBR-Green I } & 2 \mu \mathrm{l} \\ \mathrm{MgCl}_{2}(50 \mathrm{mmol} / \mathrm{l}) & 1,25 \mu \mathrm{l} \\ \mathrm{BSA}(10 \mathrm{mg} / \mathrm{ml}) & 1 \mu \mathrm{l} \\ \text { DMSO } & 1 \mu \mathrm{l} \\ \text { TaqPolymerase }(5 \mathrm{U} / \mu \mathrm{l}) & 0,5 \mu \mathrm{l} \\ \text { dNTP }(10 \mathrm{mmol} / \mathrm{l}) & 0,4 \mu \mathrm{l} \\ \text { forward Primer }(100 \mu \mathrm{mol} / \mathrm{l}) & 0,25 \mu \mathrm{l} \\ \text { reverse Primer }(100 \mu \mathrm{mol} / \mathrm{l}) & 0,25 \mu \mathrm{l} \\ \mathrm{dH}_{2} \mathrm{O} & 10,35 \mu \mathrm{l}\end{array}$

Die Proben wurden gemischt und im LightCycler unter folgenden Bedingungen inkubiert (Tab. 1): 


\begin{tabular}{|c|c|c|c|c|}
\hline \multicolumn{2}{|l|}{ Vorgang } & Temperatur & Zeit & Zyklen \\
\hline \multicolumn{2}{|c|}{ Initiale Denaturierung } & $95^{\circ} \mathrm{C}$ & $30 \mathrm{sec}$ & 1 \\
\hline \multicolumn{2}{|c|}{ Denaturierung } & $95^{\circ} \mathrm{C}$ & $1 \mathrm{sec}$ & 35 \\
\hline \multicolumn{2}{|c|}{ Annealing } & $55^{\circ} \mathrm{C}$ & $5 \mathrm{sec}$ & \\
\hline \multicolumn{2}{|c|}{ Elongation } & $72^{\circ} \mathrm{C}$ & $10 \mathrm{sec}$ & \\
\hline \multirow[t]{5}{*}{ Messung: } & EF-2 & $87^{\circ} \mathrm{C}$ & $1 \mathrm{sec}$ & \\
\hline & COL1A1 & $87^{\circ} \mathrm{C}$ & & \\
\hline & TGFß1 & $86^{\circ} \mathrm{C}$ & & \\
\hline & IL-6 & $85^{\circ} \mathrm{C}$ & & \\
\hline & CTGF & $82^{\circ} \mathrm{C}$ & & \\
\hline
\end{tabular}

Tab. 1 Bedingungen für die quantitative RT-PCR

Mit spezifischen Primern wurde nach diesem Schema die mRNA-Expression von TGFß1, CTGF, COL1A1 und IL-6 bestimmt, wobei der Elongationsfaktor-2 (EF-2) als Referenzgen verwendet wurde. Die Genexpression wurde als Quotient der Kopien cDNA des entsprechenden Gens zu den Kopien der cDNA des Referenzgens EF-2 ausgedrückt (Kopien cDNA Gen/Kopien cDNA EF-2).

\subsection{Proteinchemische Methoden}

\subsubsection{Präparation von Proteinen aus COS-7-Zellen und Nierengewebe}

Um Proteine aus der Phenol-Chloroform-Phase gewinnen zu können, musste zunächst die DNA präzipitiert werden. Dies geschah durch Ethanolfällung und anschließender Zentrifugation $\left(2000 \mathrm{~g}, 5 \mathrm{~min}, 4^{\circ} \mathrm{C}\right)$. Aus dem gewonnenen Überstand wurden die Proteine mit $1,5 \mathrm{ml}$ Isopropanol $10 \mathrm{~min}$ präzipitiert und zentrifugiert $\left(12000 \mathrm{~g}, 10 \mathrm{~min}, 4^{\circ} \mathrm{C}\right.$ ). Danach wurde das Proteinpellet zunächst $3 x$ mit $0,3 \mathrm{~mol} / \mathrm{l}$ Guanidinhydrochlorid in $95 \%$ Ethanol, später in $100 \%$ Ethanol gereinigt, zentrifugiert $\left(7500 \mathrm{~g}, 5 \mathrm{~min}, 4^{\circ} \mathrm{C}\right)$ und $10 \mathrm{~min}$ vakuumgetrocknet. Die Proteine wurden nun mit Hilfe des Lysepuffers solubilisiert, mit Ultraschall behandelt und zentrifugiert $\left(13890 \mathrm{~g}, 5 \mathrm{~min}, 4^{\circ} \mathrm{C}\right)$, damit alle unlöslichen Bestandteile 
sedimentierten. Der Überstand wurde in ein neues Röhrchen überführt und bei $-80^{\circ} \mathrm{C}$ gelagert.

\subsubsection{Konzentrationsbestimmungen von Proteinen}

Die Konzentrationsbestimmung von Proteinen erfolgte nach Bradford (Bradford 1976). Das Absorptionsmaximum von Coomassie brilliant blue G-250 verschiebt sich durch Proteinbindung von $465 \mathrm{~nm}$ zu $595 \mathrm{~nm}$. Die Zunahme der Absorption bei $595 \mathrm{~nm}$ ist ein Maß für die Proteinkonzentration der Lösung. Die Bestimmung des Proteingehaltes wurde mit Hilfe des Bio-Rad Protein Assays gemäß den Herstellerangaben durchgeführt. Ein Vergleich mit Standards bekannter Konzentration von Rinderserumalbumin (BSA) ermöglichte eine quantitative Auswertung, wobei die lineare Eichkurve mit BSA im Bereich von 0 bis $1 \mathrm{mg} / \mathrm{ml}$ aus einer $2 \mathrm{mg} / \mathrm{ml}$ Stammlösung aufgenommen wurde.

\subsubsection{SDS-Polyacrylamidgelelektrophorese}

Zur elektrophoretischen Auftrennung von Proteinen wurde eine SDSPolyacrylamidgelelekrophorese (SDS-Page) nach Laemmli durchgeführt (Laemmli 1970). Durch das SDS werden die Proteine stark negativ geladen, so dass Wechselwirkungen zwischen den Proteinen unterbunden werden. Im Gel erfolgt eine Auftrennung nach ihrem Molekulargewicht, wobei die Polyacrylamidmatrix als eine Art molekulares Sieb fungiert. Je nach den zu untersuchenden Proteinen wurden Trenngele mit einem Acrylamidgehalt von 8-12 \% verwendet, die Sammelgele enthielten $4 \%$ Acrylamid. Die Lösungen für Trenn- und Sammelgele wurden nach folgendem Schema hergestellt (Tab. 2): 


\begin{tabular}{|l|r|r|r|}
\hline & $\mathbf{8} \%$ Trenngel & $\mathbf{1 2} \%$ Trenngel & $\mathbf{4 \%}$ Sammelgel \\
\hline dd $\mathrm{H}_{2} \mathrm{O}$ & $3,608 \mathrm{ml}$ & $2,608 \mathrm{ml}$ & $2,325 \mathrm{ml}$ \\
\hline $30 \%$ Acrylamid & $2 \mathrm{ml}$ & $3 \mathrm{ml}$ & $0,25 \mathrm{ml}$ \\
\hline $1,5 \mathrm{M}$ Tris$/ \mathrm{HCl} \mathrm{pH} 8,8$ & $1,867 \mathrm{ml}$ & $1,867 \mathrm{ml}$ & - \\
\hline $1,5 \mathrm{M}$ Tris$/ \mathrm{HCl} \mathrm{pH} 6,8$ & - & $75 \mu \mathrm{l}$ & $30,390 \mathrm{ml}$ \\
\hline $10 \%$ SDS & $75 \mu \mathrm{l}$ & $37,5 \mu \mathrm{l}$ & $15 \mu \mathrm{l}$ \\
\hline $10 \%$ APS & $37,5 \mu \mathrm{l}$ & $7,5 \mu \mathrm{l}$ & $3 \mu \mathrm{l}$ \\
\hline TEMED & $7,5 \mu \mathrm{l}$ & & - \\
\hline
\end{tabular}

Tab. 2 Protokoll für Trenn- und Sammelgele

Nachdem die Glasplatten und der Kamm mit Ethanol gereinigt und die Gelapparatur vorschriftsmäßig aufgebaut waren, wurde zunächst das Trenngel gegossen und mit $500 \mu$ l Butanol überschichtet, um eine gleichmäßige Trennschicht zu gewährleisten und den Kontakt zu Sauerstoff zu vermeiden. Nach 45 min Aushärtung wurde das Butanol entfernt, 3x mit Wasser gespült, das Sammelgel gegossen und der Kamm eingesetzt. Nach weiteren 45 min Polymerisation konnte die Apparatur feucht eingeschlagen bei $4^{\circ} \mathrm{C}$ über Nacht gelagert werden.

Eine Proteinmenge von $30 \mu \mathrm{g}$, ermittelt aus der Konzentrationsbestimmung nach Bradford (2.13.2), wurde 1:1 mit Probenpuffer (2.4) verdünnt und für 5 min bei $95^{\circ} \mathrm{C}$ denaturiert. Für die Elektrophorese wurde das Gel in einer Elektrophoresekammer fixiert und die Kammer mit Tris-Glycin-Puffer (2.4) gefüllt. Anschließend konnten je $20 \mu \mathrm{l}$ der präparierten Proteinprobe sowie der Molekulargewichtsstandard Precision Plus Protein ${ }^{\mathrm{TM}}$ (Volumen nach Herstellerangabe) mit Hilfe der Hamilton-Pipette in die Geltaschen geladen werden.

Die Elektrophorese erfolgte zunächst für 45 min bei $20 \mathrm{~mA}$ pro Gel und anschließend für 30 bis $45 \mathrm{~min}$ bei $40 \mathrm{~mA}$ pro Gel. Die so aufgetrennten Proteine konnten anschließend auf eine Nitrozellulosemembran transferiert werden (2.13.4).

\subsubsection{Western Blot}

Um Proteine immunologisch detektieren zu können, erfolgte nach Separation der Proteine mittels Elektrophorese der Transfer auf eine Nitrozellulosemembran, auf der 
die Proteine durch hydrophobe Wechselwirkung gebunden werden (Towbin et al. 1979). Dafür wurde ein Sandwich bestehend aus Membran, Gel und je 2 in Blotpuffer getränkte Filterpapiere und Fiberpads luftblasenfrei in die entsprechende Kassette eingebaut und die Blotkammer mit kaltem Transblotpuffer gefüllt. Der Transfer erfolgte $120 \mathrm{~min}$ bei $390 \mathrm{~mA}$ auf Eis, wobei nach $60 \mathrm{~min}$ die innere und äußere Kühlung erneuert wurden. Um die aufgetrennten Proteine im Acrylamidgel anzufärben, wurde die Färbelösung Roti® Blue benutzt. Zur Überprüfung eines erfolgreichen Proteintransfers wurde die Membran mit Ponceau S angefärbt, welches reversibel an die positiv geladenen Aminogruppen der Proteine bindet. Anschließend wurde die Membran mit Wasser wieder entfärbt und mit Blockpuffer $2 \times 30$ min gewaschen, um unspezifische Bindungen der Antikörper zu reduzieren.

\subsubsection{Anfärbung von Proteinen auf Membranen}

Nach dem Blockvorgang wurde der Erstantikörper in jeweils einer Verdünnung von 1:500 mit $1 \%$ BSA (monoclonal anti-TGFß1-lgG bzw. polyclonal anti-ANXA5-lgG) bzw. 1:2000 mit 5 \% BSA (polyclonal anti-EEF2-lgG) auf die Membran gegeben. Die Inkubation erfolgte über Nacht bei $4^{\circ} \mathrm{C}$. Anschließend wurde die Membran $5 \times 10 \mathrm{~min}$ mit Waschpuffer (2.4) gereinigt, um nicht gebundene Antikörper zu entfernen. Es folgte eine einstündige Inkubation mit dem Zweitantikörper polyclonal anti-mouseIgG in einer Verdünnung von 1:5000 mit $1 \%$ BSA oder polyclonal anti-rabbit-IgG bzw. monoclonal anti-rabbit-lgG in einer Verdünnung von 1:2000 mit $1 \%$ bzw. $5 \%$ BSA. Anschließend wurde erneut $5 \times 10$ min gewaschen. Abschließend erfolgte die Färbung der Membran mit dem Alkalische-Phosphatase-Konjugat-Substrat-Kit. Hierzu wurde der AP-Farbentwicklungspuffer 1:25 mit Ampuwa verdünnt, mit je $125 \mu \mathrm{l}$ AP-Farbreagenz A und AP-Farbreagenz B versehen und auf die Membran gegeben. Die Farbentwicklung war nach ca. 5-20 min abgeschlossen. Die gefärbte Membran konnte dann getrocknet und eingeschweißt werden. Die angefärbten Proteinbanden wurden anschließend mit der Lablmage Software (Kapelan BioImaging $\mathrm{GmbH}$, Halle/Saale) ausgewertet. 


\subsection{Histologische Methoden}

Die Licht- und Elektronenmikroskopie wurde durchgeführt, um die Wirkungen des MMF auf die renale Fibrose der Versuchstiere auf feingeweblicher Ebene beurteilen zu können.

Sämtliche Chemikalien und Geräte zur Durchführung der folgenden licht- und elektronenmikroskopischen Methoden stammen aus der Zahn-, Mund- und Kieferheilkunde, Abteilung Prothetik der Universitätsmedizin Göttingen.

\subsubsection{Lichtmikroskopie}

\subsubsection{Präparation und Fixierung}

Bevor die Niereneinbettung in Paraffin erfolgen konnte, mussten die Organe zur Entwässerung eine aufsteigende Ethanolreihe $(70 \%, 80 \%, 90 \%, 96 \%, 100 \%$ EtOH) sowie ein Xylolbad in einem vollautomatischen Einbettautomaten (Histokinette) über Nacht durchlaufen. Dieser Durchlauf endete in $56^{\circ} \mathrm{C}$ warmen Paraplast. Anschließend konnten die Nieren in Paraffin eingebettet werden. Aus den Paraffinblöcken wurden am Mikrotom $5 \mu \mathrm{m}$ dicke Schnitte angefertigt, diese auf Objektträger gebracht und zunächst auf einer Heizplatte für $30 \mathrm{~min}$, dann über Nacht bei $37^{\circ} \mathrm{C}$ im Brutschrank getrocknet. Die Präparate wurden anschließend mit Hämatoxylin-Eosin (HE) sowie zur Beurteilung der Fibrosierung mit der TrichromMethode nach Masson-Goldner gefärbt (2.14.1.2) und lichtmikroskopisch ausgewertet.

\subsubsection{Hämatoxylin-Eosin-Färbung und Trichrom-Färbung nach Masson-Goldner}

Beide Färbemethoden erfolgten am Stainix-Färbeautomaten. Die Präparate mussten zunächst in einem 10 minütigen Xylolbad manuell entparaffiniert werden. 


\section{HE-Färbung}

Meyers Hämalaun wurde gebrauchsfertig geliefert, die Eosinfärbelösung dagegen frisch angesetzt (2.4) und unmittelbar vor der Färbung mit einigen Tropfen Essigsäure $100 \%$ versehen.

Durchführung:

1. Rehydrieren in absteigender Alkoholreihe: $100 \% \mathrm{EtOH} \quad$ (2 min)

$80 \% \mathrm{EtOH} \quad(2 \mathrm{~min})$

2. Spülen mit $\mathrm{dH}_{2} \mathrm{O}$

3. Anfärben mit Meyers Hämalaun

4. Spülen mit $\mathrm{dH}_{2} \mathrm{O}$

5. Bläuen mit fließendem Leitungswasser

6. Anfärben mit Eosin

7. Spülen mit $\mathrm{dH}_{2} \mathrm{O}$

8. Dehydrieren in aufsteigender Alkoholreihe:

$80 \% \mathrm{EtOH}$

$100 \% \mathrm{EtOH}$ $100 \% \mathrm{EtOH}$

9. Xylol

Bläuen, d.h. Farbumschlag der zuvor durch Hämatoxylin rötlich-braun gefärbten Zellkerne in das typische blau-violett durch Erhöhung des pH-Wertes mittels Spülung mit fließendem Leitungswasser.

\section{Trichrom-Färbung nach Masson-Goldner}

Für die Trichrom-Färbung wurden zunächst die Färbelösungen frisch angesetzt (2.4).

Durchführung:

1. Rehydrieren in absteigender Alkoholreihe: $100 \% \mathrm{EtOH} \quad$ (2 min)

$80 \% \mathrm{EtOH} \quad(4 \mathrm{~min})$


2. Spülen mit $\mathrm{dH}_{2} \mathrm{O}$

3. Anfärben mit Eisenhämatoxylin nach Weigert

4. Bläuen mit fließendem Leitungswasser

5. Anfärben mit Azophloxin

6. $1 \%$ Eisessig (konzentrierte Essigsäure)

7. Anfärben mit Phosphorwolframsäure und Orange G

8. $1 \%$ Eisessig

9. Anfärben mit Lichtgrün

10. $1 \%$ Eisessig

11. Dehydrieren mit $100 \% \mathrm{EtOH}$

12. Xylol
(2 $\min )$

(3 $\min )$

(9 min)

(5 min)

$(1 \mathrm{~min})$

$(1 \mathrm{~min})$

$(1 \mathrm{~min})$

(5 $\min )$

(3 $\min )$

$(1 \mathrm{~min})$

(5 $\mathrm{min})$

Pro Niere wurden 10 Schnitte angefertigt, dabei wurden 5 Präparate der HE- und 5 Präparate der Trichrom-Färbung unterzogen. Anschließend wurden die Präparate zur Konservierung mit entsprechenden Deckgläsern und Roti®Histokitt als Klebstoff eingedeckt.

\subsubsection{Auswertung der Gewebeschnitte}

Kriterien der Glomerulumsklerose sind die Zunahme der mesangialen Matrix, die Verdickung der Bowman'schen Kapsel und die Sklerosierung der Kapillarschlingen. In Anlehnung an andere Publikationen wurde ein semiquantitativer Score zur Beurteilung der Glomerulumsklerose benutzt (Raij et al. 1984, Berden et al. 1986). Dafür wurden pro Präparat 50 Glomerula ausgezählt und anhand des Ausmaßes der glomerulären Matrixablagerungen in entsprechende Grade von 0 bis $3+$ eingeteilt. Dabei galt: $0=$ keine Veränderungen, $1+=$ weniger als $25 \%$ des Glomerulums, 2+ = 25-50 \% des Glomerulums, 3+ = mehr als $50 \%$ des Glomerulums sind betroffen. Die Multiplikation des jeweiligen Grades mit dem prozentualen Anteil der Glomerula mit denselbem Schädigungsgrad ergab den Glomerulumsklerose-Score.

Für die Beurteilung der tubulointerstitiellen Fibrose wurde ein semiquantitatives Bewertungssystem verwendet, das in Anlehnung an die Banff-Klassifikaton für die chronische Nierentransplantatpathologie basiert (Racusen et al. 1999). Kriterien für die chronische Allograft-Nephropathie sind die interstitielle Fibrose und 
Tubulusatrophie. Diese histologischen Veränderungen wurden ebenfalls in eine Bewertungsskala von 0 bis $3+$ eingeteilt, wobei $0=$ keine Veränderungen, $1+=$ weniger als $25 \%$ der Fläche, 2+ = zwischen 25 und $50 \%$ der Fläche und 3+ = mehr als $50 \%$ der Fläche sind betroffen, bedeutet.

Die Auswertungen erfolgten dabei jeweils verblindet.

\subsubsection{Elektronenmikroskopie}

\subsubsection{Präparation und Fixierung}

Zur genaueren Untersuchung des Ausmaßes der glomerulären und tubulären Schädigung der Nieren der Versuchstiere wurde die Elektronenmikroskopie durchgeführt. Dafür wurden die in $70 \%$ Ethanol aufbewahrten Nieren in etwa $2 \times 2 \mathrm{~mm}$ große Gewebsstücke geschnitten. Vor der eigentlichen Fixierung mussten diese zunächst rehydriert werden. Dafür inkubierten die Gewebsstücke für jeweils 10 min in 50 \% Ethanol, dann in 30 \% Ethanol und abschließend in Sörensen-Puffer (2.4). Es folgte die Fixierung in 3\% Paraformaldehyd und 3\% Glutaraldehyd in $0,15 \mathrm{~mol} / \mathrm{l}$ Sörensen-Puffer $(\mathrm{pH} 7,5)$ für $1 \mathrm{~h}$ bei $4^{\circ} \mathrm{C}$.

Eine weitere 10 minütige Inkubation in 0,15 $\mu \mathrm{mol} /$ Sörensen-Puffer folgte, bevor die Nierenstücke für $1,5 \mathrm{~h}$ bei $4^{\circ} \mathrm{C}$ in Osmiumpuffer lagerten. Nach der Spülung in 0,15 mol/l Sörensen-Puffer schloss sich eine aufsteigende Ethanolreihe (30 \%, 50 \%, $70 \%, 90 \%, 100 \%$ jeweils $10 \mathrm{~min}$ bei $4^{\circ} \mathrm{C}$ ) zur Entwässerung an. Um aus Viskositätsgründen die Gewebestücke schrittweise an das Epon zu gewöhnen, inkubierten diese zunächst in reinem Propylenoxid für $2 \times 15 \mathrm{~min}$, dann für $1 \mathrm{~h}$ in Propylenoxid und Epon im Verhältnis 1:1 und schließlich über Nacht bei $4^{\circ} \mathrm{C}$ in Epon und Propylenoxid im Verhältnis 3:1.

\subsubsection{Einbettung in Epon}

Die Einbettung in das strukturerhaltende Kunstharz Epon (Epoxidharz) erfolgte mit den Teilkomponenten Epon A und Epon B, wobei sich ersteres aus 38 \% (v/v) Epon und $62 \%(\mathrm{v} / \mathrm{v})$ DDSA (Dodecenylbernsteinsäureanhydrid), letzteres aus $53 \%(\mathrm{v} / \mathrm{v})$ Epon und $47 \%$ (v/v) MNA (Methylnadicanhydrid) zusammensetzt. Beide Lösungen 
wurden 5 min getrennt voneinander gerührt, in einem Verhältnis von 3:2 zusammengeführt und mit dem Polymerisierungsbeschleuniger DMP-30 (2,4,6tris[dimethylaminomethyl]phenol) in $2 \%$ Endkonzentration versetzt. Je ein Gewebestück wurde in eine eigene halbvoll mit Epon gefüllte Beem-Kapsel überführt und mit weiterem Epon übergossen. Bei $60^{\circ} \mathrm{C}$ im Brutschrank über $24 \mathrm{~h}$ härteten die Präparate aus.

\subsubsection{Anfertigung der Gewebsschnitte}

Nach der Aushärtung wurden die eingebetteten Gewebestücke aus der BeemKapsel herausgelöst und mit einem Diamantmesser auf einem Ultramikrotom etwa $1 \mu \mathrm{m}$ dicke Semidünnschnitte angefertigt, welche anschließend mit Richardsonblau (2.4) angefärbt wurden. Die Semidünnschnitte dienten zur Beurteilung des Gewebes im Lichtmikroskop vor der eigentlichen elektronenmikroskopischen Untersuchung. Nach Identifizierung der optimalen Ebene wurden am gleichen Gerät Ultradünnschnitte mit einer Dicke von $95 \mathrm{~nm}$ angefertigt, diese auf Grids überführt und bei RT über Nacht in einer Gridbox getrocknet. Anschließend erfolgte die Kontrastierung der Grids, zunächst 10 min mit $1 \%$ Uranylacetat, dann 10 min mit Bleizitrat (2.4) nach Watson (Watson 1958). Nach der Kontrastierung wurden die Ultradünnschnitte im Elektronenmikroskop mit integrierter CCD-Kamera analysiert und dokumentiert.

\subsection{Immunhistochemie}

Die Methoden der Immunhistochemie wurden freundlicherweise von den Mitarbeitern und Mitarbeiterinnen aus der Inneren Medizin Abteilung Nephrologie und Rheumatologie durchgeführt.

Der Immunhistochemie liegt die Antigen-Antikörper-Reaktion zugrunde. Durch Markierung von Proteinen mittels spezifischer Antikörper, die mit einem Detektionssystem gekoppelt sind, kann deren Expression in bestimmten Geweben untersucht werden. Bei der direkten Methode ist der spezifische Antikörper direkt mit einem Enzym bzw. Fluorophor gekoppelt. Bei der indirekten Methode dagegen erfolgt durch sogenannte Sekundärantikörper, die gegen den ersten Antikörper 
gerichtet und mit einem Enzym gekoppelt sind, eine Enzym-Substrat-Reaktion und damit die Farbentstehung. Bei fluorochrom-markierten Antikörpern erfolgt die Detektion im Fluoreszenzmikroskop.

Für die immunhistochemische Untersuchung wurden von den in Paraffin eingebetteten Nieren $5 \mu \mathrm{m}$ dicke Schnitte angefertigt, welche anschließend $3 x$ mit PBS für 5 min bei RT gewaschen wurden. Nach dem Blockvorgang in $5 \%$ BSA in PBS für 30 min bei RT wurde der Erstantikörper rabbit anti-EHS-laminin in einer Verdünnung von 1:1000 über Nacht bei $4^{\circ} \mathrm{C}$ hinzugegeben. Anschließend erfolgten 3 Waschschritte mit PBS und 1,9\% NaCl. Es folgten eine einstündige Inkubation mit dem fluorochrom-markierten Zweitantikörper goat anti-rabbit lgG und eine erneute Waschung. Schließlich wurden die fluoreszenzmarkierten Präparate im Fluoreszenzmikroskop mit integrierter Kamera analysiert.

\subsection{Statistik}

Mittelwerte und Standardabweichungen wurden mit dem Computerprogramm Microsoft Excel, Version 2000 (Microsoft Corporation, Washington, USA) errechnet. Die Überlebenszeit der Versuchstiere wurde mit dem Log-Rang-Test analysiert, nicht normalverteilte, unverbundene Stichproben wurden mit dem Mann-Whitney-U-Test verglichen. Ein p-Wert < 0,05 wurde als signifikant gewertet. Zur Auswertung wurde die Software SSPS Version 15.0 verwendet (SPSS Inc., Chicago, USA). 


\section{Ergebnisse}

\subsection{Ergebnisse der in-vitro-Experimente}

Für die Experimente in Zellkultur wurden die COS-7-Zellen unter verschiedenen Bedingungen behandelt und die Proliferation und Funktion der Zellen unter der Wirkung von MPA und dessen Reversibilität durch Guanosin/8-Aminoguanosin untersucht.

\subsubsection{Untersuchungen zur Fibroblastenproliferation}

Die Wirkung von MPA und dessen aktivem Metaboliten AcMPAG auf die Fibroblastenproliferation sowie die Umkehrbarkeit dieses Prozesses durch Guanosin/8-Aminoguanosin wurden mit Hilfe eines Proliferations-Assays untersucht (Abb. 4). Es zeigte sich eine Inhibition der Zellproliferation unter steigenden MPAKonzentrationen, wobei die maximale Inhibition bei ca. $50 \%$ lag und ab $10 \mu \mathrm{mol} / \mathrm{I}$ MPA erreicht wurde ( $p<0,05$ für $0 \mu \mathrm{mol} / \mathrm{l}$ MPA versus 1,10 und $100 \mu \mathrm{mol} / \mathrm{l} \mathrm{MPA}$, Mann-Whitney-U-Test). Ebenso konnte unter AcMPAG die Zellproliferation gehemmt werden ( $p<0,05$ für $0 \mu \mathrm{mol} / / \mathrm{AcMPAG}$ versus 1,10 und $100 \mu \mathrm{mol} / \mathrm{l}$ AcMPAG, MannWhitney-U-Test), allerdings waren dabei höhere Konzentrationen nötig, um einen vergleichbaren Effekt zu erzielen. Durch die Zugabe von Guanosin/8-Aminoguanosin konnte die Wirksamkeit sowohl von MPA als auch von AcMPAG vollständig aufgehoben werden ( $p<0,05$ für 1,10 und $100 \mu \mathrm{mol} / \mathrm{l}$ MPA versus 1,10 und $100 \mu \mathrm{mol} / / \mathrm{MPA}+\mathrm{G} / 8-\mathrm{AG}$ bzw. $\mathrm{p}<0,05$ für 1,10 und $100 \mu \mathrm{mol} / \mathrm{l}$ AcMPAG versus 1, 10 und $100 \mu \mathrm{mol} / \mathrm{l} \quad$ AcMPAG+G/8-AG, Mann-Whitney-U-Test). Aufgrund des umfangreichen Versuchaufbaus mit AcMPAG und der Feststellung, dass es keine wesentlichen Unterschiede zwischen MPA und seinen aktiven Metaboliten gibt, wurde entschieden, keine weiteren Experimente mit AcMPAG durchzuführen. 


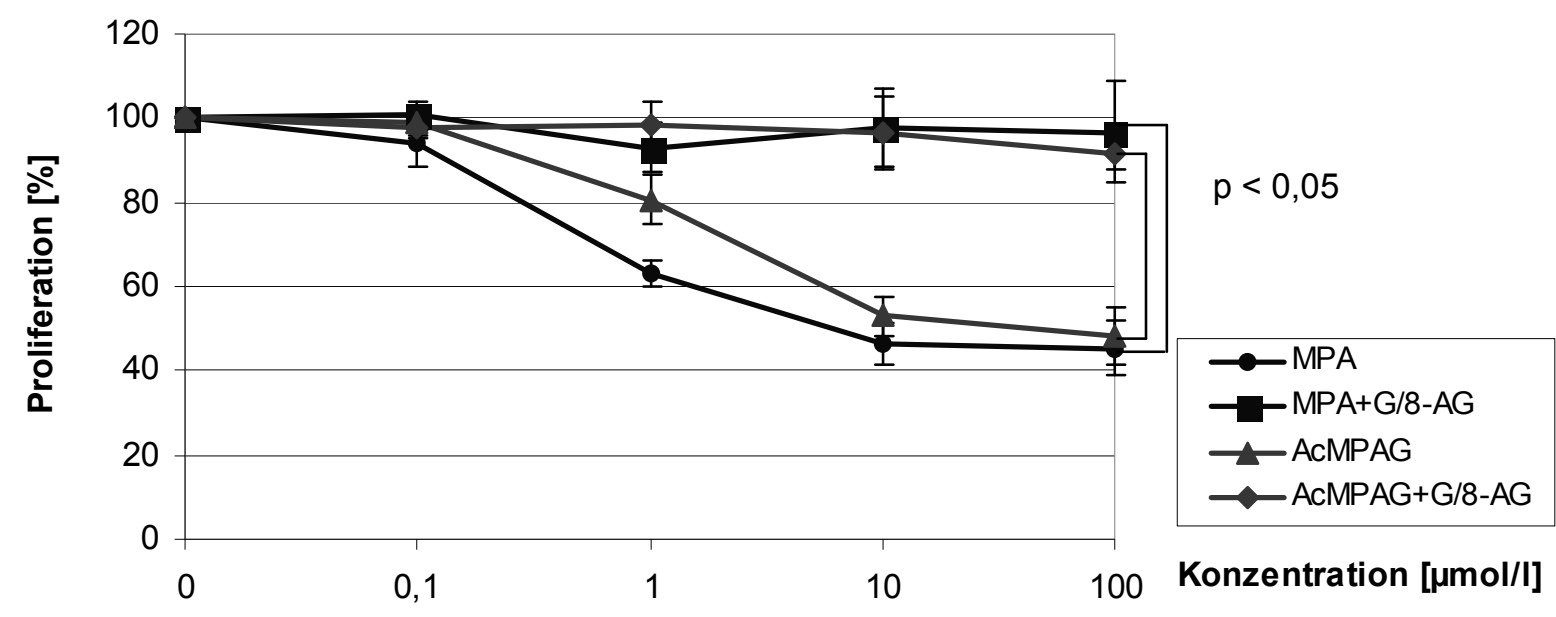

Abb. 4 Konzentrationsabhängige Inhibition der Proliferation von COS-7-Zellen durch MPA oder AcMPAG in An- oder Abwesenheit von Guanosin/8-Aminoguanosin (G/8-AG)

Graphisch dargestellt sind die Ergebnisse als Mittelwerte mit Standardabweichung von 4 Experimenten.

\subsubsection{Untersuchungen zur Fibroblastenfunktion}

Zur Untersuchung des Einflusses von MPA auf die Fibroblastenfunktion sowie die Reversibilität dieses Effektes durch die Zugabe von Guanosin/8-Aminoguanosin in vitro diente der Wundverschluss-Assay. Der Verschluss einer artifiziell zugeführten Wunde im konfluenten Zellrasen wurde prozentual zur Größe der Ausgangswunde ausgewertet. Die mikroskopische Darbietung eines repräsentativen Versuches zeigt Abb. 5, die Ergebnisse dieser Versuchsreihe mit 4 Experimenten sind in Abb. 6 dargestellt. MPA bewirkte eine zeit- und konzentrationsabhängige Verzögerung des Wundverschlusses. Der früheste signifikante Effekt wurde nach $24 \mathrm{~h}$ mit der Höchstdosis von $100 \mu \mathrm{mol} / \mathrm{l}$ MPA erreicht $(\mathrm{p}<0,05$ für $0 \mu \mathrm{mol} / \mathrm{l}$ MPA versus $100 \mu \mathrm{mol} / \mathrm{l}$ MPA, Mann-Whitney-U-Test). Nach $48 \mathrm{~h}$ waren die Wunden ohne MPA vollständig verschlossen, wogegen die Zugabe von MPA die Wundheilung konzentrationsabhängig hemmte. Bei einer MPA-Konzentration von $1 \mu \mathrm{mol} / \mathrm{l}$ sind nach $48 \mathrm{~h} 81,6 \%$, bei $10 \mu \mathrm{mol} / / \mathrm{l} 64,8 \%$ und bei $100 \mu \mathrm{mol} / /$ lediglich $49,1 \%$ der Ausgangswunde verschlossen ( $p<0,05$ für $0 \mu \mathrm{mol} / \mathrm{l}$ MPA versus 1,10 und $100 \mu \mathrm{mol} / \mathrm{l}$ MPA, Mann-Whitney-U-Test). Die Zugabe von Guanosin/8-Aminoguanosin bewirkte bei allen Gruppen einen nahezu vollständigen Wundverschluss nach $48 \mathrm{~h}$, so dass 
die hemmende Wirkung des MPA auf die Fibroblastenmotilität weitestgehend aufgehoben wurde ( $p<0,05$ für 1, 10 und $100 \mu \mathrm{mol} / / \mathrm{MPA}$ versus 1, 10 und $100 \mu \mathrm{mol} / \mathrm{l}$ MPA+G/8-AG, Mann-Whitney-U-Test).

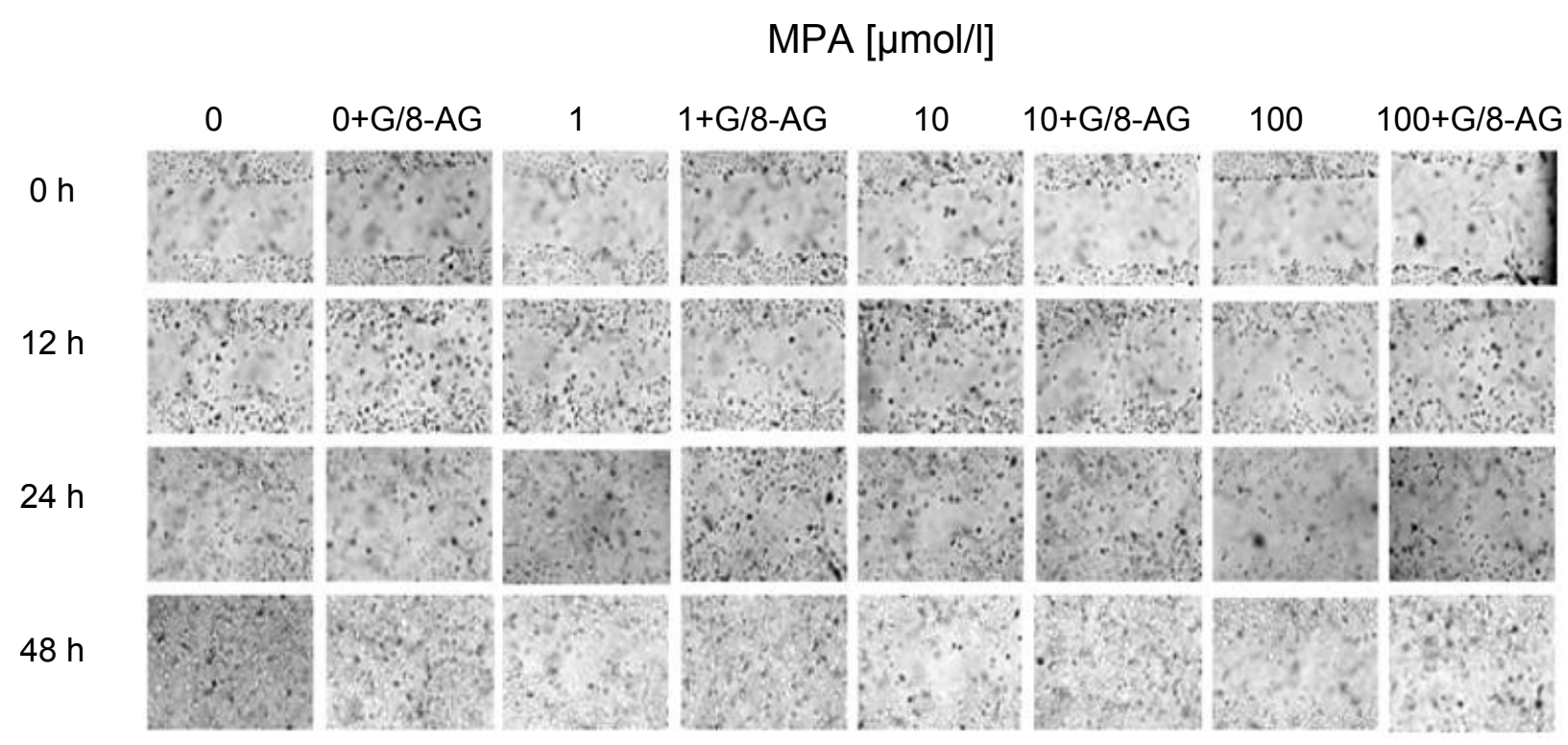

\section{Abb. 5 Einfluss von MPA in unterschiedlichen Konzentrationen auf den Wundverschluss}

Mikroskopische Darstellung eines repräsentativen Experiments mit konfluierend wachsenden COS-7Zellen, denen mit einer Pipettenspitze mechanisch eine artifizielle Wunde zugefügt wurde und in Medien mit aufsteigenden MPA-Konzentrationen (0, 1, 10 oder $100 \mu \mathrm{mol} / \mathrm{l})$ in An- oder Abwesenheit von Guanosin/8-Aminoguanosin (G/8-AG) inkubierten. Der Wundverschluss wurde nach 0, 12, 24 und $48 \mathrm{~h}$ mikroskopisch beurteilt und durch photographische Dokumentation quantifiziert. 
ohne Guanosin/8-Aminoguanosin (G/8-AG)

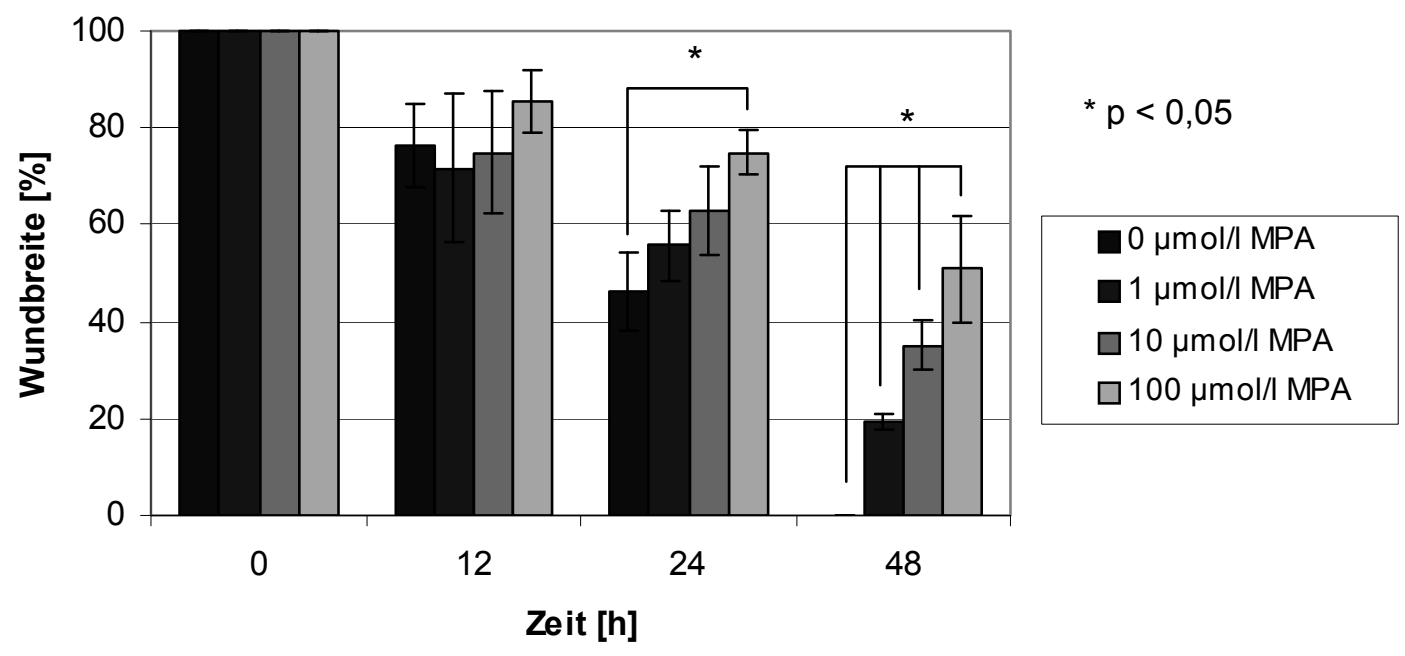

mit Guanosin/8-Aminoguanosin (G/8-AG)

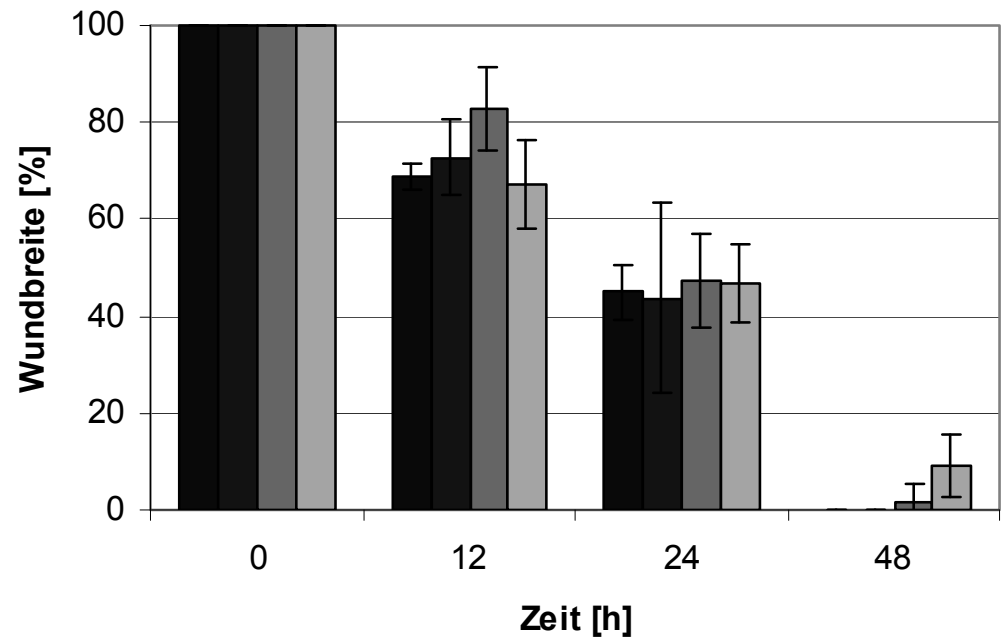

$0 \mu \mathrm{mol} / \mathrm{l} \mathrm{MPA}+\mathrm{G} / 8-\mathrm{AG}$

$1 \mu \mathrm{mol} / \mathrm{MPA}+\mathrm{G} / 8-\mathrm{AG}$

$\square 10 \mu \mathrm{mol} / \mathrm{MPA}+\mathrm{G} / 8-\mathrm{AG}$

$\square 100 \mu \mathrm{mol} / \mathrm{l} \mathrm{MPA}+\mathrm{G} / 8-\mathrm{AG}$

Abb. 6 Konzentrations- und zeitabhängige Inhibition des Wundverschlusses durch MPA im COS-7-Zellrasen in An- und Abwesenheit von Guanosin/8-Aminoguanosin (G/8-AG)

MPA hemmt die Motilität der Fibroblasten. Graphisch dargestellt sind die Ergebnisse als Mittelwerte mit Standardabweichung von 4 Experimenten. Die Wundbreite wurde prozentual zum Ausgangswert beurteilt. 


\subsubsection{Ergebnisse der Kollagen-Kontraktion}

Der Kollagen-Kontraktionstest diente der Untersuchung der Auswirkungen des MPA auf die Fibroblasten bezüglich einer veränderten Kontraktion der Bestandteile der extrazellulären Matrix. Ebenso wurde die Umkehrbarkeit dieses Effektes durch die Zugabe von Guanosin/8-Aminoguanosin überprüft. In Abb. 7 ist ein repräsentatives Experiment dargestellt. Abb. 8 zeigt die Auswertung von 6 Experimenten. Bei allen Proben zeigte sich eine Kontraktion des Kollagen-Gels über dem Beobachtungszeitraum von $96 \mathrm{~h}$. Die durchschnittliche Fläche der Kollagenmatrix ohne MPA betrug nach 96 h 50,4 \% der Ausgangsfläche, wogegen die Kollagenmatrix mit $100 \mu \mathrm{mol} / \mathrm{l} \mathrm{MPA} 65,8 \%$ von der Ausgangsfläche betrug und damit etwa $30 \%$ größer als die Kontrolle war. Die Zugabe von $100 \mu \mathrm{mol} / \mathrm{l}$ MPA bewirkte somit eine signifikante Hemmung der Kontraktion im Vergleich zur Kontrolle ( $\mathrm{p}<0,05$ für $0 \mu \mathrm{mol} / / \mathrm{MPA}$ versus $100 \mu \mathrm{mol} / / \mathrm{MPA}$, Mann-Whitney-U-Test), d.h. MPA verringert die Fähigkeit der Fibroblasten die Kollagengitter adäquat zu kontrahieren. Im Gegensatz zu den vorherigen Experimenten zur Proliferation und Fibroblastenfunktion ließ sich hier hingegen eine Reversibilität des Effektes von MPA durch die Zugabe von Guanosin/8-Aminoguanosin nicht bestätigen ( $p>0,05$ für $100 \mu \mathrm{mol} / \mathrm{l}$ MPA versus $100 \mu \mathrm{mol} / / \mathrm{MPA}+\mathrm{G} / 8-\mathrm{AG}$, Mann-Whitney-U-Test). Die Fläche des Gels nach $96 \mathrm{~h}$ unter $100 \mu \mathrm{mol} / \mathrm{l}$ MPA und Guanosin/8-Aminoguanosin war wider Erwarten annähernd identisch mit der Fläche unter 100 mmol/l MPA. 


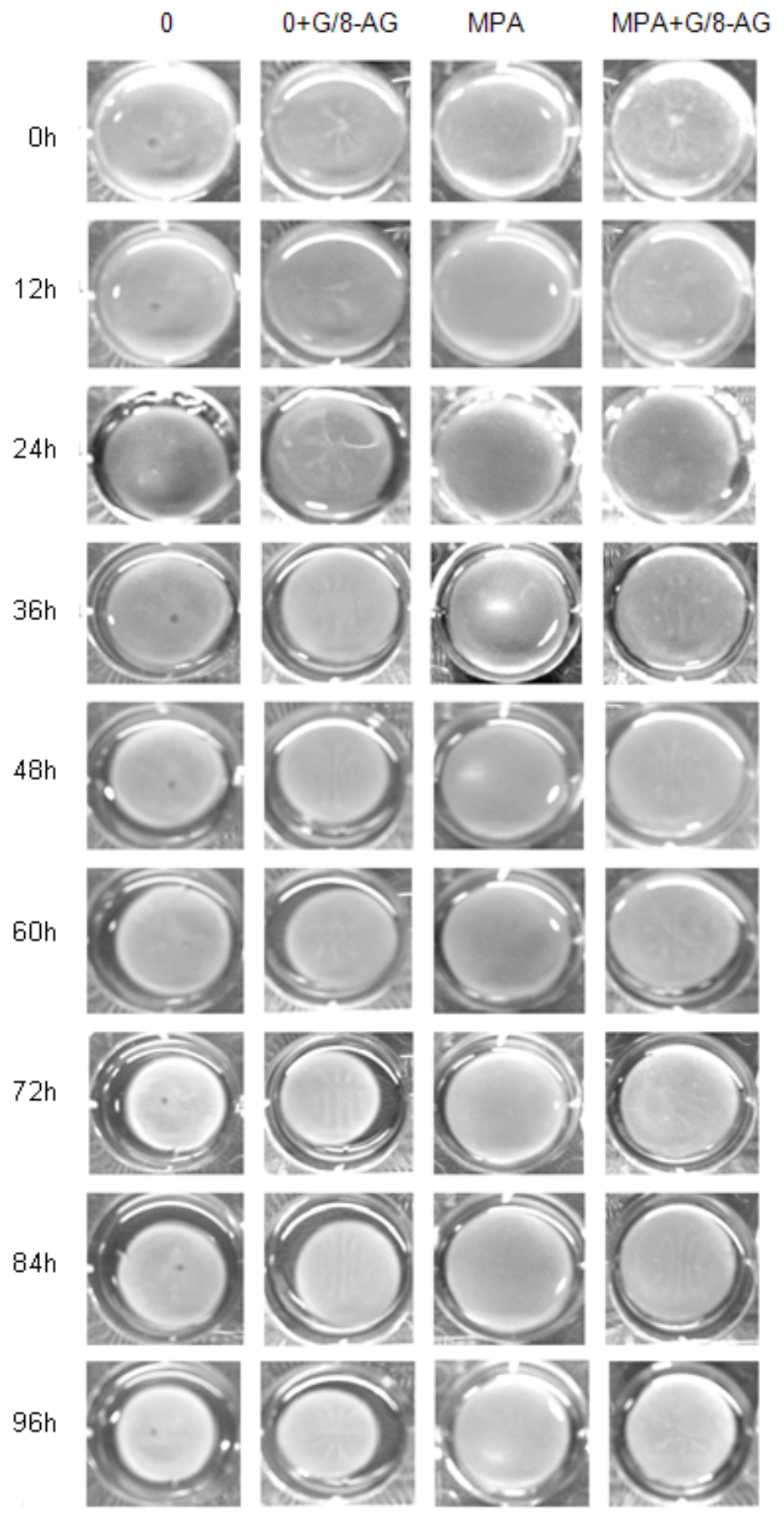

Abb. 7 Einfluss von $100 \mu \mathrm{mol} / \mathrm{l}$ MPA auf die Kollagen-Matrix-Kontraktion in An- und Abwesenheit von Guanosin/8-Aminoguanosin (G/8-AG)

Photographische Darstellung eines repräsentativen Experimentes. COS-7-Zellen, Kollagen und Medium mit 0 oder $100 \mu \mathrm{mol} / \mathrm{I}$ MPA jeweils in An- und Abwesenheit von Guanosin/8-Aminoguanosin 
(G/8-AG) waren in einer Matrix polymerisiert, welche unterschiedlich kontrahierte. Die Kontraktion der Matrix wurde nach $0,12,24,36,48,60,72,84$ und $96 \mathrm{~h}$ beurteilt und photographisch dokumentiert.

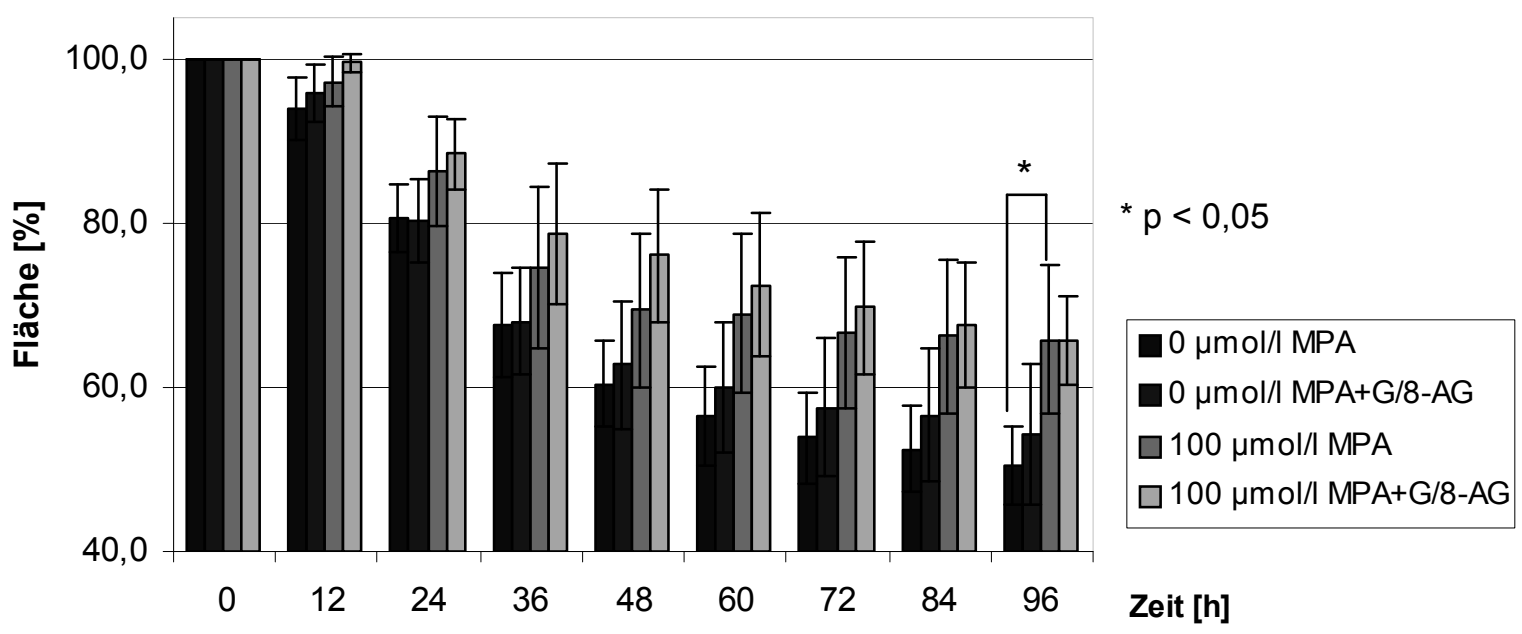

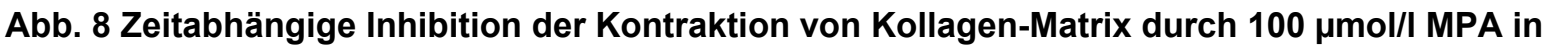
An- und Abwesenheit von Guanosin/8-Aminoguanosin (G/8-AG)

MPA inhibiert die Fähigkeit der Fibroblasten frei flottierende Kollagengitter zu kontrahieren. Die Fläche der Kollagen-Matrix wurde prozentual zum Ausgangswert beurteilt. Graphisch dargestellt sind die Ergebnisse als Mittelwerte mit Standardabweichung von $n=6$ Experimenten.

In Abb. 9 ist die Fläche unter der Kontraktions-Zeit-Kurve bei 6 Experimenten dargestellt (area under the curve, AUC). $100 \mu \mathrm{mol} / \mathrm{l} \mathrm{MPA}$ bewirkten eine statistisch signifikante Zunahme der AUC um 13,2 \% nach dem Beobachtungszeitraum von $96 \mathrm{~h}$ ( $p<0,05$ für $0 \mu \mathrm{mol} / / \mathrm{MPA}$ versus $100 \mu \mathrm{mol} / / \mathrm{MPA}$, Mann-Whitney-U-Test). Die $\mathrm{AUC}_{\text {Gesamt }}$ unter $100 \mu \mathrm{mol} / \mathrm{I} \mathrm{MPA}$ mit Guanosin/8-Aminoguanosin war im Vergleich etwas größer als die $\mathrm{AUC}_{\text {Gesamt }}$ unter $100 \mu \mathrm{mol} / / \mathrm{MPA}$ ( $\mathrm{p}>0,05$ für $100 \mu \mathrm{mol} / \mathrm{l} \mathrm{MPA}$ versus $100 \mu \mathrm{mol} / / \mathrm{MPA}+\mathrm{G} / 8-\mathrm{AG}$, Mann-Whitney-U-Test). 


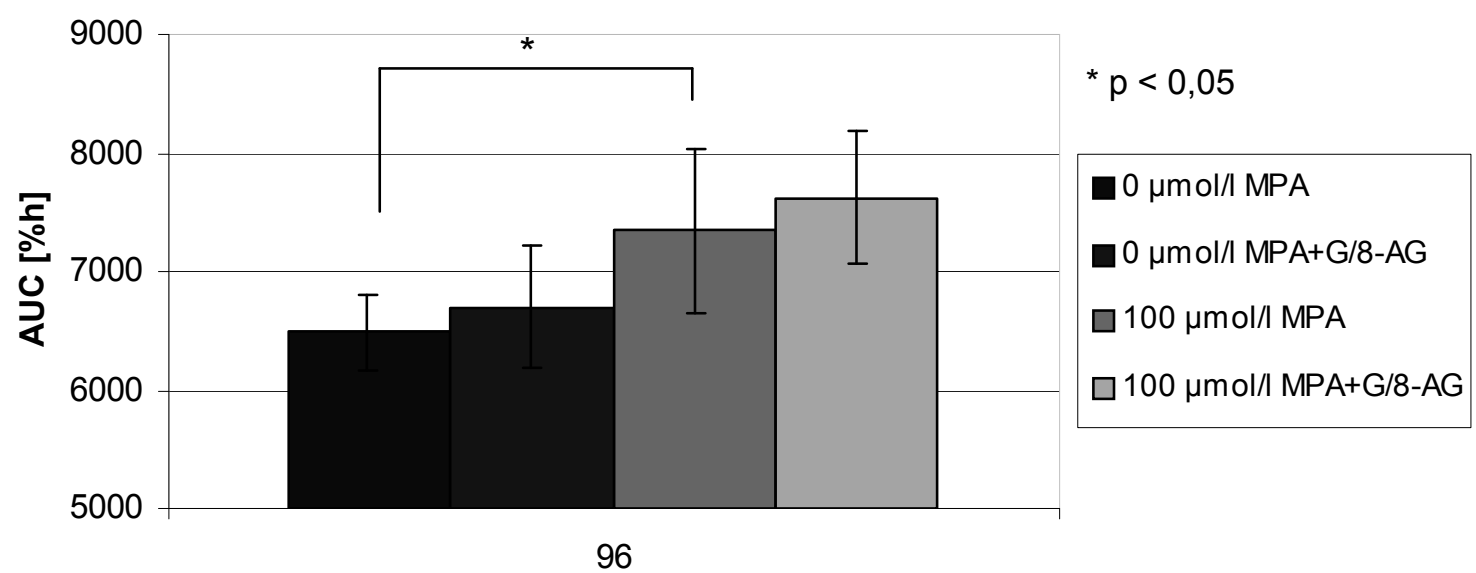

Zeit [h]

Abb. 9 Einfluss von $100 \mu \mathrm{mol} / \mathrm{I}$ MPA in An- und Abwesenheit von Guanosin/8-Aminoguanosin (G/8-AG) auf die AUC nach $96 \mathrm{~h}$

Graphisch dargestellt ist die area under the curve (AUC) nach $96 \mathrm{~h}$ als Mittelwert mit Standardabweichung von $n=6$ Experimenten. MPA bewirkt eine Zunahme der AUC. Durch die Zugabe von Guanosin/8-Aminoguanosin (G/8-AG) konnte der Effekt von MPA nicht aufgehoben werden.

\subsubsection{Ergebnisse der Genexpression von IL-6, TGFß1, COL1A1, CTGF und TNFa}

Der Einfluss von MPA auf die Genexpression von IL-6, TGFß1, COL1A1, CTGF und TNFa sowie die Umkehrbarkeit dieses Effektes durch die Zugabe von Guanosin/8Aminoguanosin im Verlauf wurde mittels quantitativer Real-Time-PCR untersucht. In Abb. 10 sind die Ergebnisse der einzelnen Genexpressionen normalisiert zur Expression des Elongationsfaktors-2 (EF-2) dargestellt. MPA bewirkte zu allen Zeitpunkten eine nicht signifikante Suppression der Expression von IL-6, wobei der maximale Effekt nach $6 \mathrm{~h}$ zu verzeichnen war. Durch die Zugabe von Guanosin/8Aminoguanosin wurde der Effekt von MPA vollständig aufgehoben. Im Gegensatz dazu bewirkte MPA eine Induktion der Expression von TGFß1 zu jedem Zeitpunkt. Das Effektmaximum lag bei $24 \mathrm{~h}$, hier verdoppelt sich nahezu die Anzahl der mRNAKopien, ebenso war nach $48 \mathrm{~h}$ eine starke Induktion von TGFß1 zu beobachten ( $p<0,05$ für $0 \mu \mathrm{mol} / / \mathrm{MPA}$ versus $100 \mu \mathrm{mol} / / \mathrm{MPA}$, Mann-Whitney-U-Test). Auch hier konnte die Reversiblität des Effektes von MPA auf die TGFß1-Expression durch die Zugabe von Guanosin/8-Aminoguanosin erzielt werden. 
Eine leichte Induktion der Expression zeigte sich ebenso bei COL1A1, welche jedoch zu keinem Zeitpunkt statistisch signifikant war. Durch die Zugabe von Guanosin/8Aminoguanosin ließen sich annähernd die gleichen Werte generieren wie ohne MPA. Bezüglich der Expression von CTGF bewirkte MPA initial eine starke Suppression um etwa $40 \%$ ( $p<0,05$ für $0 \mu \mathrm{mol} / /$ MPA versus $100 \mu \mathrm{mol} / \mathrm{I}$ MPA, Mann-Whitney-UTest). Im weiteren Verlauf zeigte sich dann eine deutliche Induktion der Expression, wobei die Effektmaxima nach $24 \mathrm{~h}$ und $48 \mathrm{~h}$ zu beobachten waren. Die Anzahl der mRNA-Kopien hatten sich annähernd verdreifacht $(p<0,01$ für $0 \mu \mathrm{mol} / \mathrm{I}$ MPA versus $100 \mu \mathrm{mol} / \mathrm{l}$ MPA, Mann-Whitney-U-Test). Auch hier bewirkte Guanosin/8Aminoguanosin die Reversibilität der MPA-bedingten Effekte. Des Weiteren war eine leichte, nicht signifikante Induktion der Expression bei TNFa zu beobachten, die wiederum durch Guanosin/8-Aminoguanosin antagonisiert werden konnte.

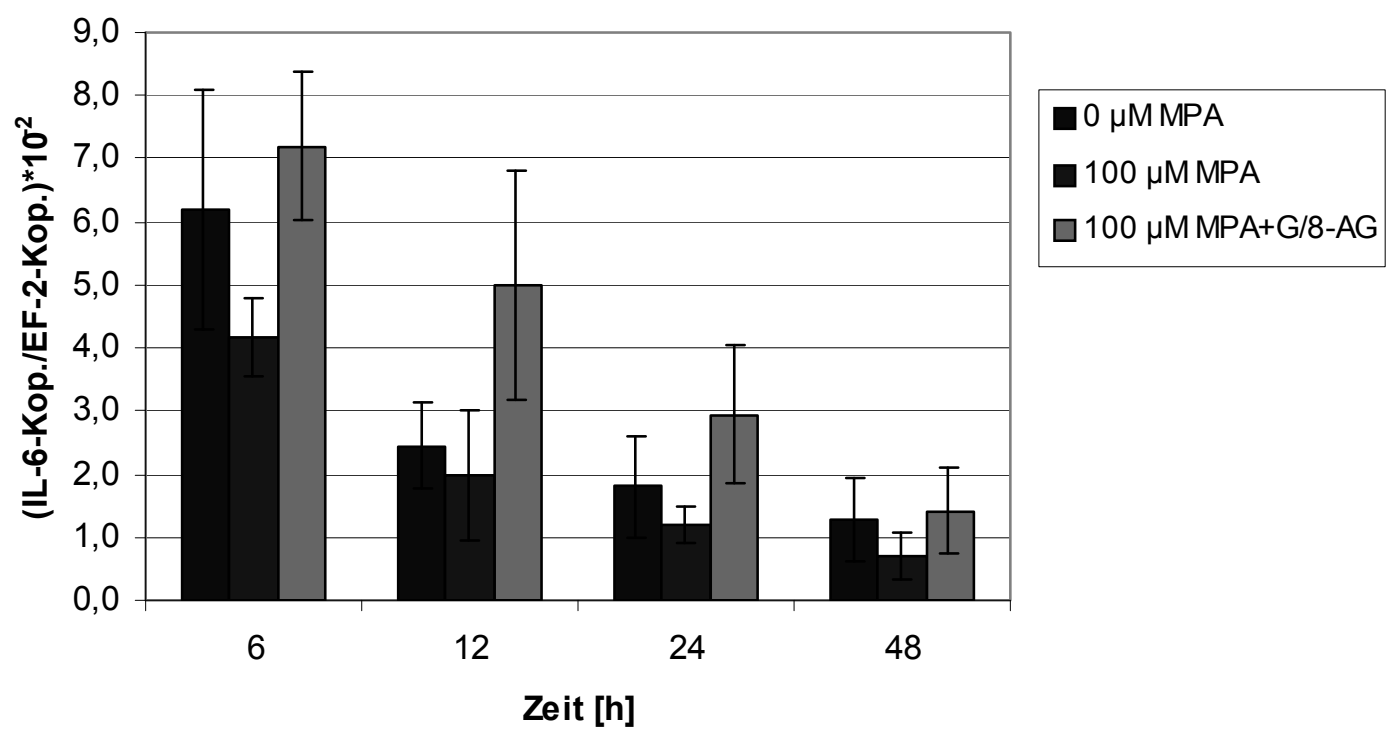



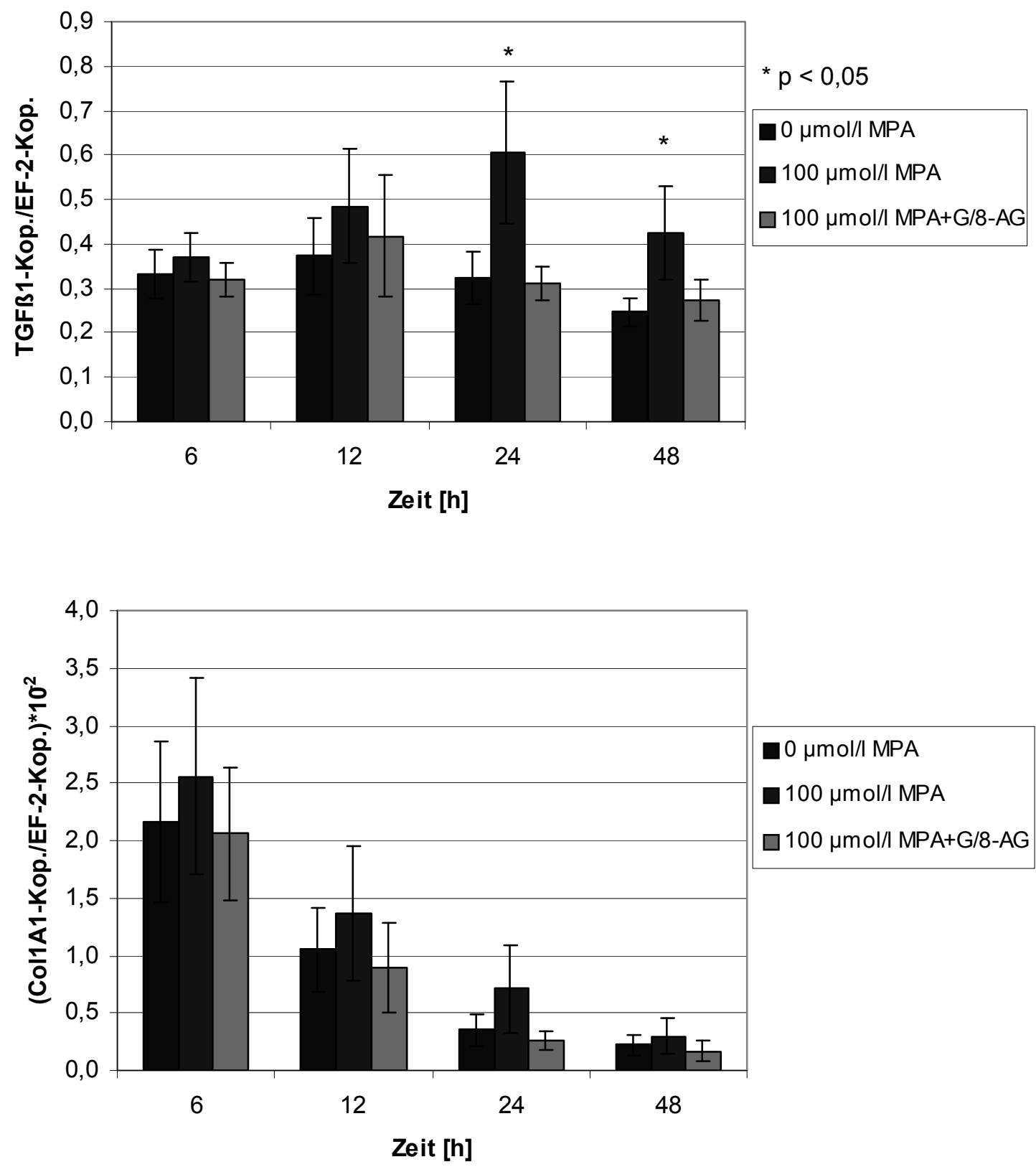

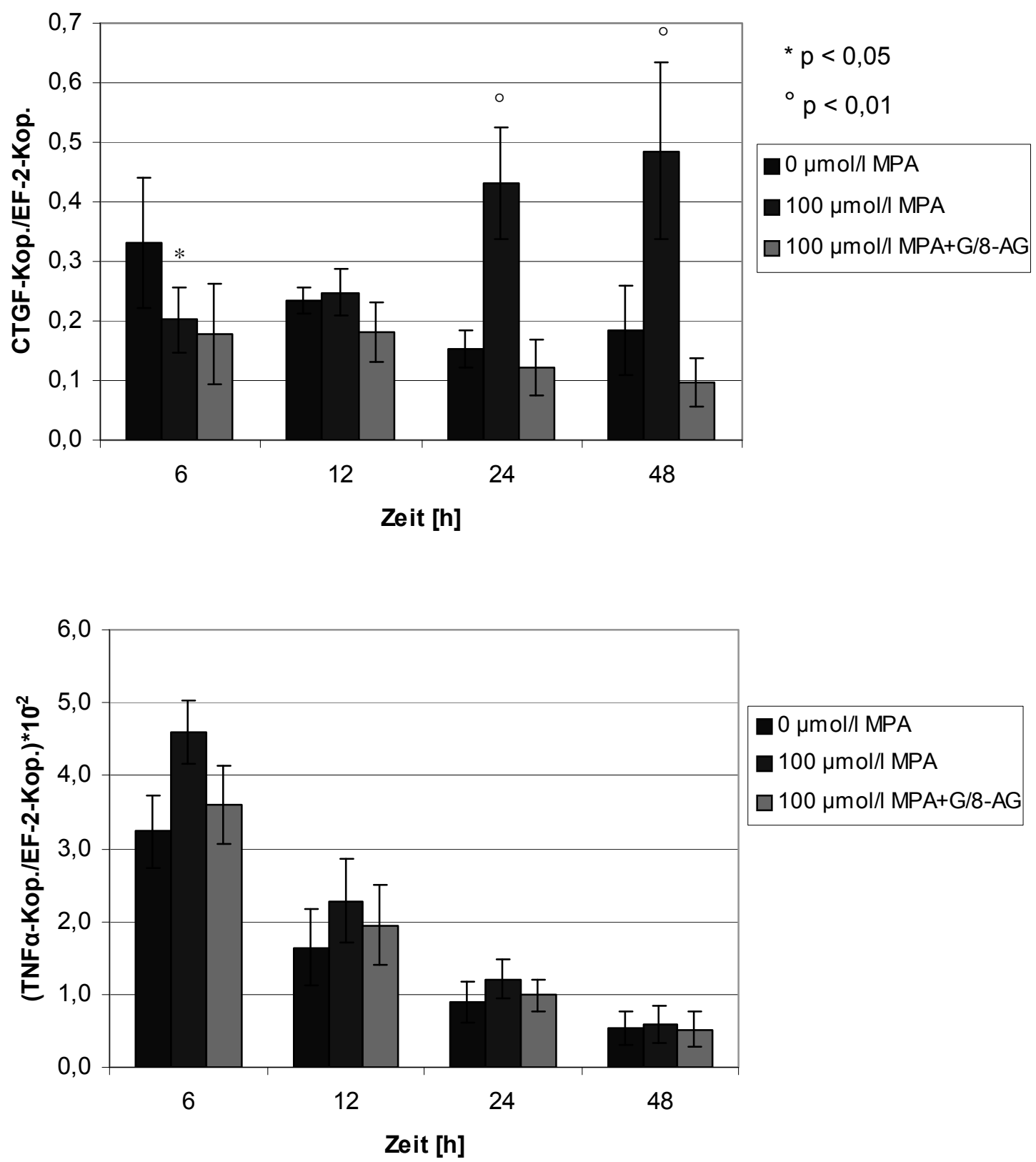

Abb. 10 Einfluss von $100 \mu \mathrm{mol} / \mathrm{I}$ MPA in An- und Abwesenheit von Guanosin/8-Aminoguanosin (G/8-AG) auf die Genexpression von IL-6, TGFß1, COL1A1, CTGF und TNFa zu unterschiedlichen Zeitpunkten

Dargestellt sind die Ergebnisse als Mittelwerte mit Standardabweichung von $n=6$ Experimenten pro Zeitpunkt. Hierfür wurden $1,5 * 10^{6}$ bzw. $3 * 10^{6}$ COS-7-Zellen mit 0 oder $100 \mu \mathrm{mol} / \mathrm{l} \mathrm{MPA} \mathrm{bzw.}$ $100 \mu \mathrm{mol} / \mathrm{l}$ MPA mit Guanosin/8-Aminoguanosin für 6, 12, 24 oder $48 \mathrm{~h}$ inkubiert. Die Anzahl der mRNA-Kopien wurde auf die EF-2-Expression normalisiert. MPA supprimiert die IL-6- und induziert die TGFß1-, COL1A1- und TNFa-Expression sowie die CTGF-Expression nach einer initialen Suppression. 


\subsubsection{Ergebnisse der Expression von TGFß1 und Annexin im Western Blot}

\subsubsection{Expression von TGFß1 im Western Blot}

Die Western-Blot-Analyse wurde durchgeführt, um zu überprüfen, ob es eine veränderte Expression von TGFß1 bei den behandelten Tieren im Gegensatz zu den unbehandelten Tieren auf Proteinebene gibt. Nachfolgend ist ein Western Blot exemplarisch dargestellt (Abb. 11). Die dafür verwendeten Proteine stammen aus dem Nierengewebe der Versuchstiere (2.13.1).

$25 \mathrm{kDa}$

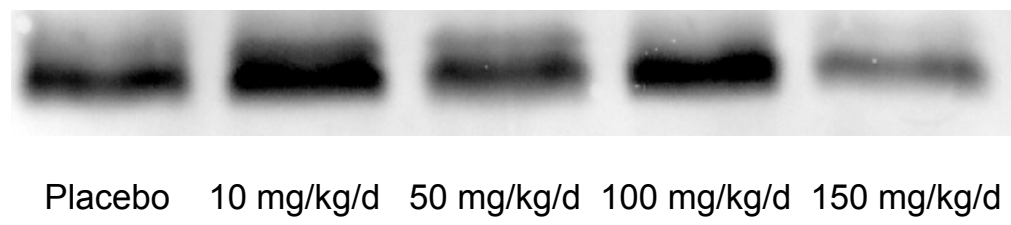

TGFß1

Abb. 11 Expression von TGFß1 in den Nieren der Mäuse im Western Blot stratifiziert nach Versuchsgruppen

Die Intensität der Proteinbanden wurde zur gesamten Proteinmenge auf der Ponceau-gefärbten Membran normalisiert (Abb. 12). Es zeigt sich ein abgeschwächtes Signal für TGFß1 bei den behandelten Versuchstieren im Gegensatz zu den unbehandelten Tieren, wobei die schwächsten Signale jeweils bei der Hochdosisgruppe und der $50 \mathrm{mg} / \mathrm{kg} / \mathrm{d}$-Gruppe zu verzeichnen waren (Mittelwerte TGFß1/Ponceau: $50 \mathrm{mg} / \mathrm{kg} / \mathrm{d}$ : 0,057 $(\mathrm{n}=6), 150 \mathrm{mg} / \mathrm{kg} / \mathrm{d}: 0,057(\mathrm{n}=5))$. Für die Gruppe mit der mittleren MMF-Dosis ist die Signalabschwächung für TGFß1 statistisch signifikant ( $p<0,05$ für $0 \mathrm{mg} / \mathrm{kg} / \mathrm{d}$ MMF versus $50 \mathrm{mg} / \mathrm{kg} / \mathrm{d}$ MMF, MannWhitney-U-Test). Zwar ist die Signalabschwächung für die Hochdosisgruppe statistisch knapp nicht signifikant $(p=0,051)$, dennoch scheint eine fallende Tendenz der Signalstärke für TGFß1 mit steigender MMF-Dosierung sichtbar ( $p>0,05$ für $0 \mathrm{mg} / \mathrm{kg} / \mathrm{d}$ MMF versus $150 \mathrm{mg} / \mathrm{kg} / \mathrm{d}$ MMF Mann-Whitney-U-Test). 


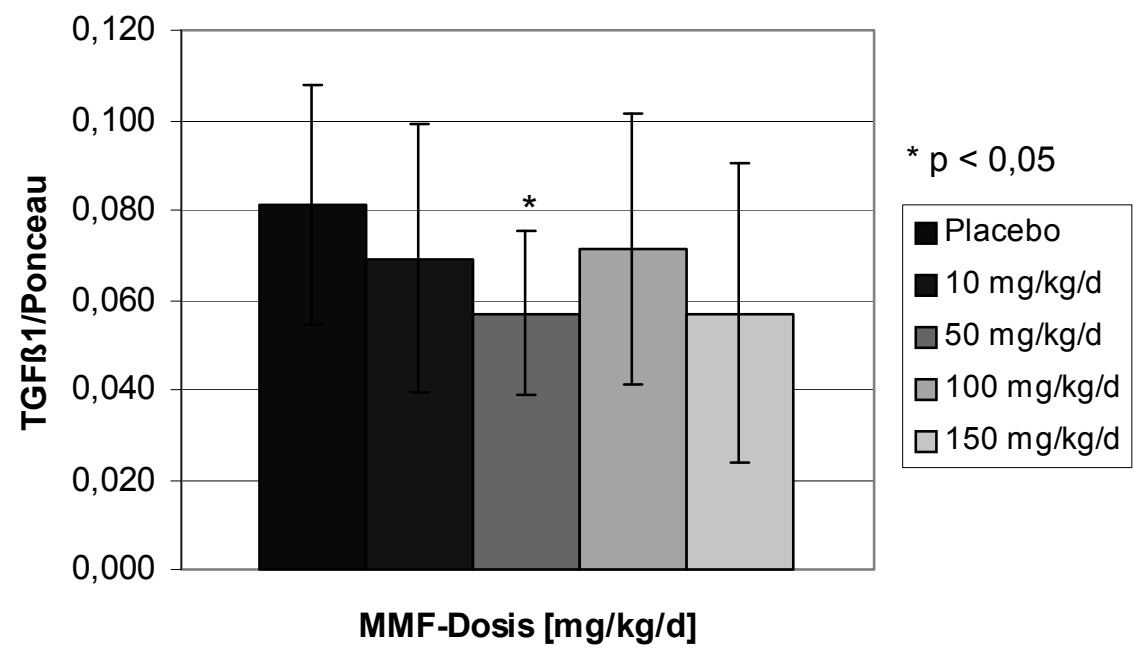

Abb. 12 Expression des Proteins TGFß1 in den Nieren der Mäuse normalisiert zur Ponceaufärbung

Dargestellt sind die Ergebnisse als Mittelwerte mit Standardabweichung von $\mathrm{n}=5$ (10; $150 \mathrm{mg} / \mathrm{kg} / \mathrm{d})$, $\mathrm{n}=6(50 \mathrm{mg} / \mathrm{kg} / \mathrm{d})$ und $\mathrm{n}=7(0 ; 100 \mathrm{mg} / \mathrm{kg} / \mathrm{d})$.

\subsubsection{Expression von Annexin A5 im Western Blot}

Zur Apoptosedetektion bei den behandelten und nicht behandelten Versuchstieren bzw. in den COS-7-Zellen dienten mit Annexin A5 (ANXA 5) als Zelltodmarker durchgeführte Western Blots. Nachfolgend sind 2 Western Blots exemplarisch dargestellt, wobei die Proteine zum einen aus den Nierengewebe der Versuchstiere, zum anderen aus den COS-7-Zellen stammen (Abb. 13, 14).

$33 \mathrm{kDa}$

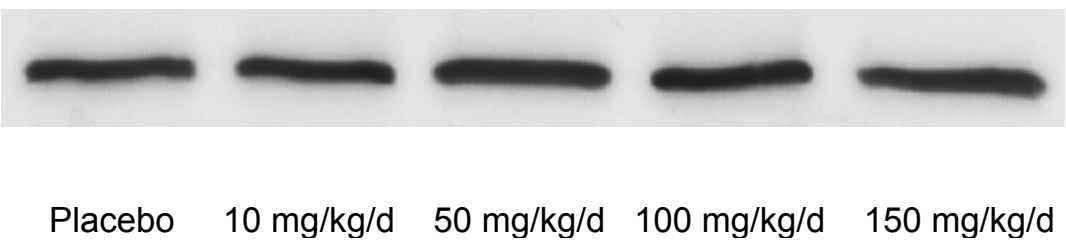

Abb. 13 Expression des Proteins ANXA 5 in den Nieren der Mäuse im Western Blot stratifiziert nach Versuchsgruppen 
$95 \mathrm{kDa}$

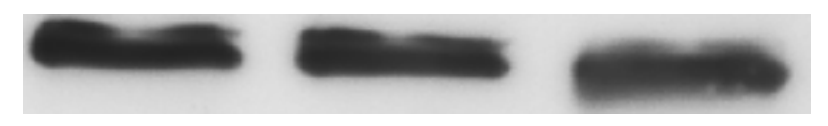

$33 \mathrm{kDa}$

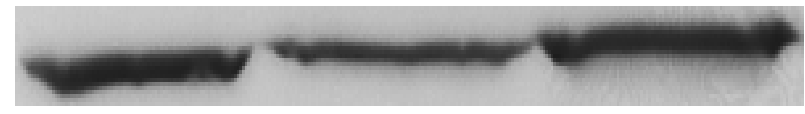

$0 \mu \mathrm{mol} / \mathrm{l} \mathrm{MPA} \quad 100 \mu \mathrm{mol} / \mathrm{l}$ MPA $100 \mu \mathrm{mol} / \mathrm{l} \mathrm{MPA}+\mathrm{G} / 8-\mathrm{AG}$

Abb. 14 Expression des Proteins ANXA 5 in COS-7-Zellen im Western Blot EEF-2 (95kDa) diente als Kontrolle.

Die Intensität der Banden der Nierenproteine wurde zur gesamten Proteinmenge auf der Ponceau-gefärbten Membran normalisiert (Abb. 15), die Banden der COS-7Zellproteine dagegen zur Intensität des eukaryotischen Elongationsfaktors EEF-2 (Abb. 16). Es zeigten sich keine signifikanten Unterschiede in der Signalstärke für ANXA 5 sowohl zwischen den Mäusen der Placebogruppe und den behandelten Mäusen unterschiedlicher Therapiegruppen ( $p>0,05$ für $0 \mathrm{mg} / \mathrm{kg} / \mathrm{d}$ MMF versus 10 , 50, 100 und $150 \mathrm{mg} / \mathrm{kg} / \mathrm{d}$ MMF, Mann-Whitney-U-Test) als auch in der Zellkultur zwischen 0 und $100 \mu \mathrm{mol} / \mathrm{l}$ MPA behandelten COS-7-Zellen $(p>0,05$ für $0 \mu \mathrm{mol} / \mathrm{l}$ MPA versus $100 \mu \mathrm{mol} / \mathrm{I}$ MPA, Mann-Whitney-U-Test).

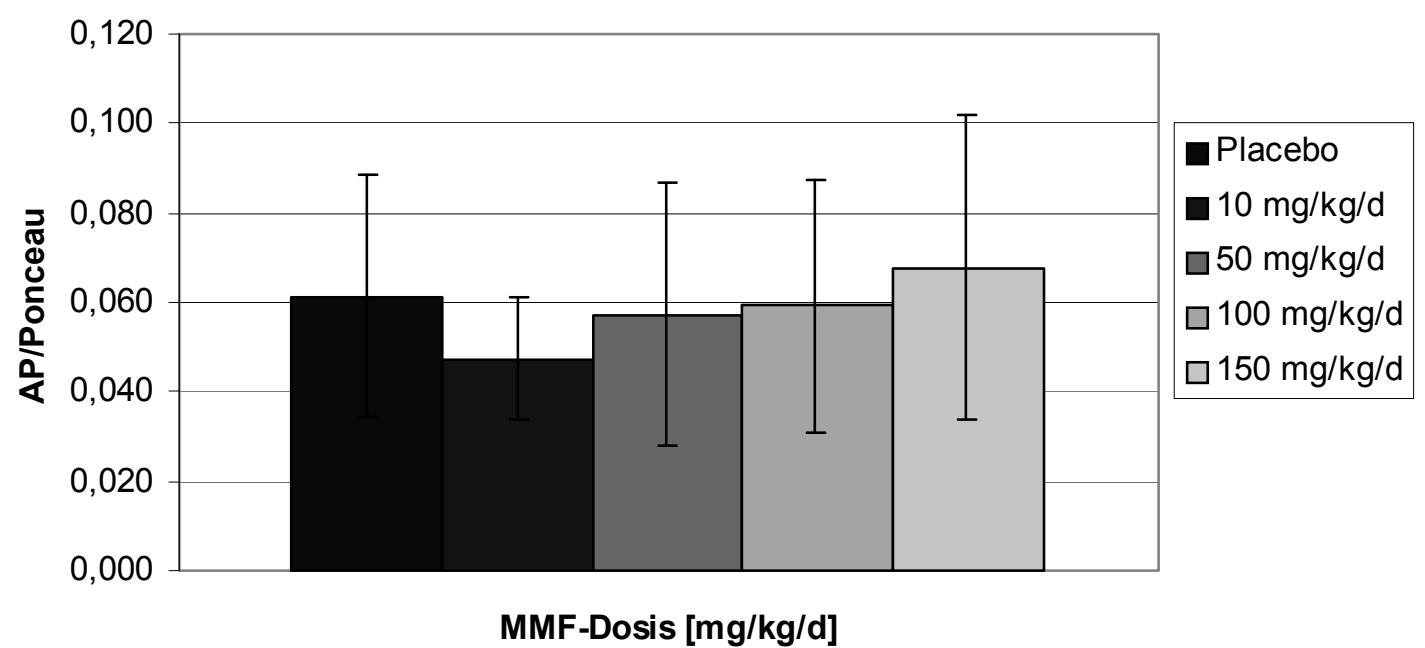

Abb. 15 Expression des Proteins ANXA 5 in den Nieren der Mäuse normalisiert zur Ponceaufärbung stratifiziert nach Versuchsgruppen

Dargestellt sind die Ergebnisse als Mittelwerte mit Standardabweichung von $n=5$ (10; $150 \mathrm{mg} / \mathrm{kg} / \mathrm{d})$, $\mathrm{n}=6(50 \mathrm{mg} / \mathrm{kg} / \mathrm{d})$ und $\mathrm{n}=7(0 ; 100 \mathrm{mg} / \mathrm{kg} / \mathrm{d})$ Experimenten. 


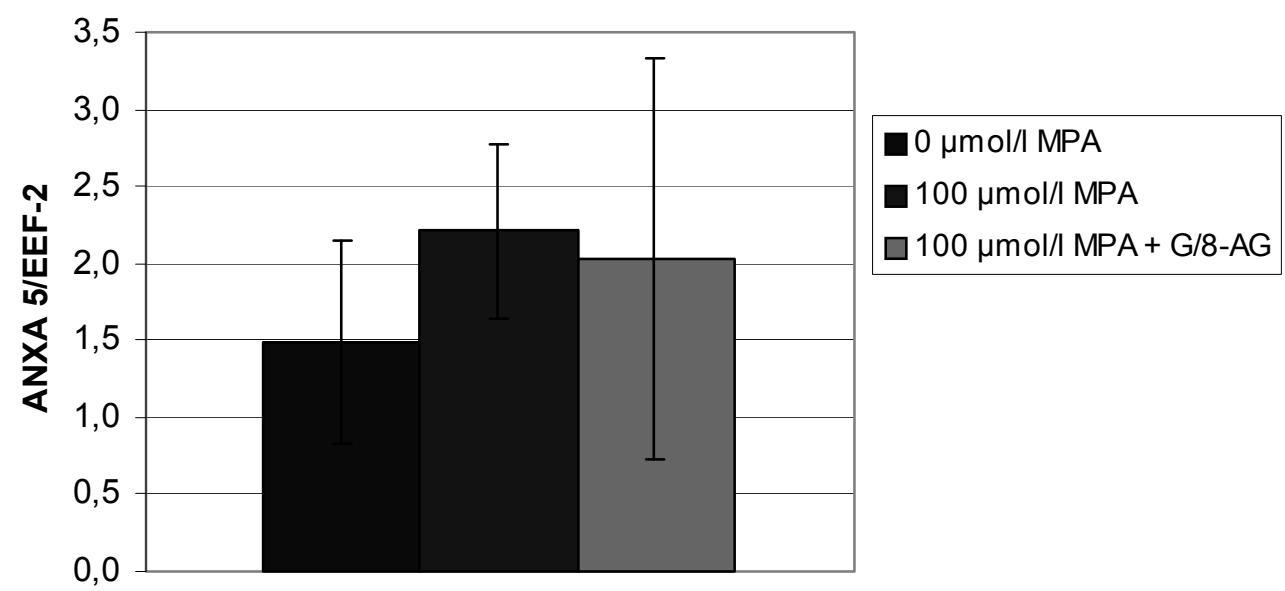

Abb. 16 Expression des Proteins ANXA 5 in COS-7-Zellen normalisiert zum Elongationsfaktor EEF-2

Dargestellt sind die Ergebnisse als Mittelwerte mit Standardabweichung von $n=4$ Experimenten. 1,5 x $10^{6}$ COS-7-Zellen inkubierten mit 0 oder $100 \mu \mathrm{mol} / \mathrm{IMPA}$ bzw. $100 \mu \mathrm{mol} / \mathrm{l}$ MPA mit Guanosin/8Aminoguanosin für $48 \mathrm{~h}$.

\subsection{Ergebnisse der in-vivo-Experimente}

Insgesamt 35 COL4A3-defiziente Versuchstiere wurden 5 verschiedenen MMFDosisgruppen $(0,10,50,100$ und $150 \mathrm{mg} / \mathrm{kg} / \mathrm{d})$ durch Randomisierung zugeordnet und entsprechend bis zum Eintreten der terminalen Niereninsuffizienz mit MMF behandelt.

\subsection{1 Überlebenszeit der COL4A3-defizienten Mäuse}

Die Auswertung der Überlebenszeit der Mäuse ist in Abb. 17 dargestellt. Es konnte kein signifikanter Unterschied zwischen den Mäusen der Placebo-Gruppe und den jeweiligen Therapiegruppen festgestellt werden ( $p>0,05$, Log-Rang-Test). Im Durchschnitt lebten die unbehandelten Mäuse 67,0 Tage, die durchschnittliche Überlebenszeit der behandelten Mäuse in den jeweiligen Therapiegruppen lag zwischen 63,6 (100 mg/kg/d) und 67,1 Tagen (150 mg/kg/d). 


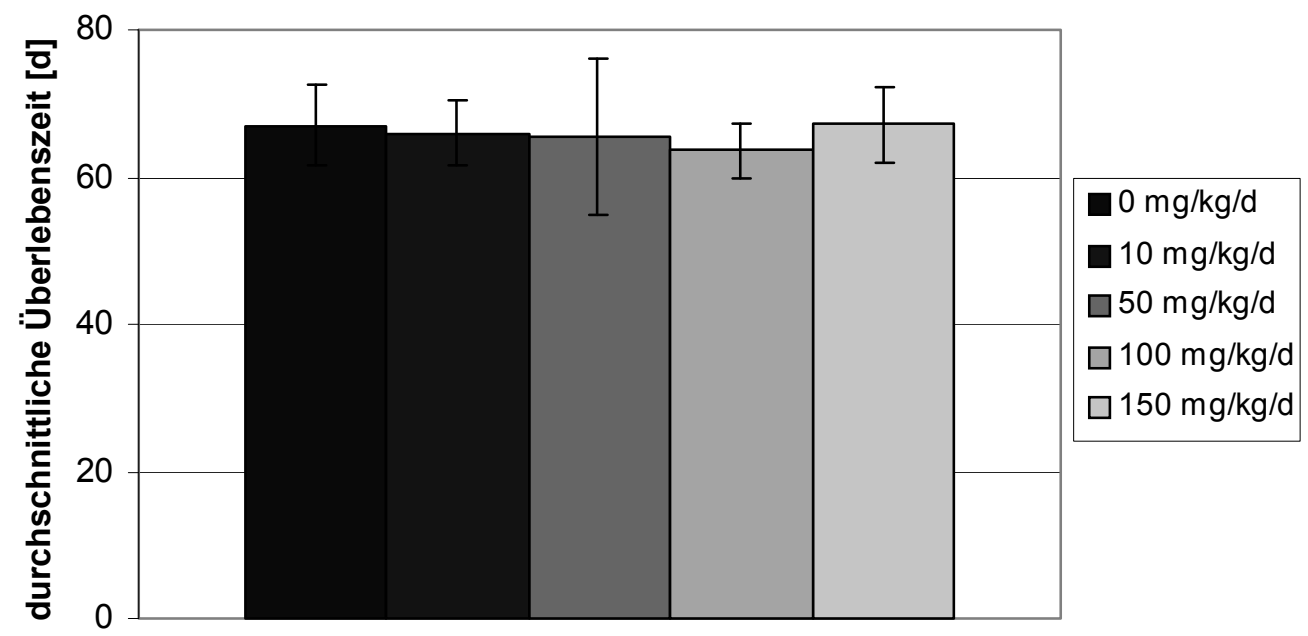

MMF-Dosis $[\mathrm{mg} / \mathrm{kg} / \mathrm{d}]$

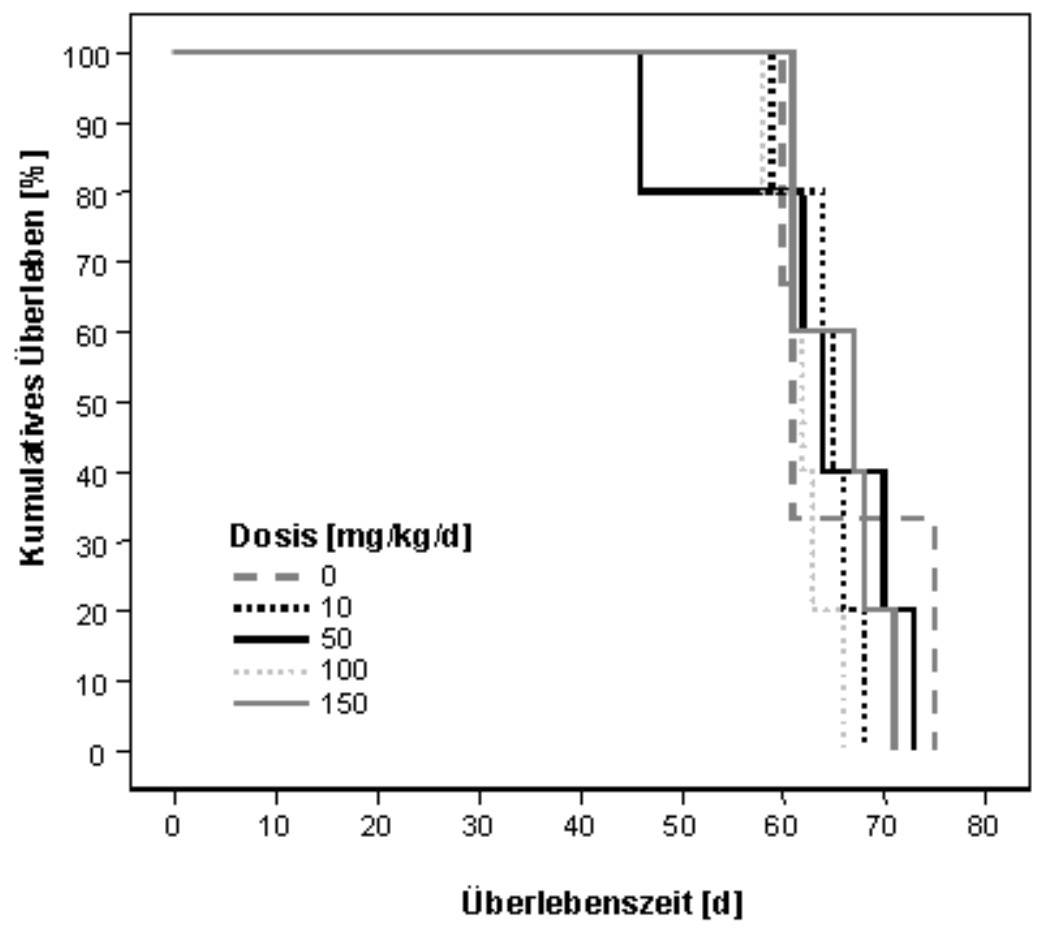

\section{Abb. 17 Überlebenszeit stratifiziert nach Versuchsgruppen}

Es konnte kein signifikanter Unterschied zwischen der Überlebenszeit der behandelten gegenüber den unbehandelten Versuchstieren nachgewiesen werden. Graphisch dargestellt sind die Überlebenszeiten als Mittelwerte mit Standardabweichung von 7 Mäusen pro Versuchsgruppe sowie als Kaplan-Meier-Kurven $(n=35)$. 


\subsubsection{Gewichtsverlauf}

Ab Beginn der tierexperimentellen Untersuchung wurden der Allgemeinzustand und das Gewicht der Versuchstiere täglich kontrolliert. Der Allgemeinzustand unter Therapie war bei allen Mäusen in den ersten Wochen unauffällig. Eine progrediente Verschlechterung des Allgemeinzustandes mit Aktivitäts- und Vigilanzminderung erfolgte sowohl in der Therapie- sowie der Placebogruppe mit dem Einsetzen der terminalen Niereninsuffizienz. Vor dem Einsetzen des terminalen Nierenversagens erfolgte mehrheitlich eine zunehmende Gewichtsabnahme, welche meist 7 bis 10 Tage vor dem Tod einsetzte (Abb. 18). Durchschnittlich verloren die Versuchstiere, einschließlich der Placebo-Gruppe, 21,8\% ihres Ausgangsgewichtes unter der Therapie, wobei der mittlere Gewichtsverlust zwischen 17,5\% (10 mg/kg/d) und 26,5\% (100 mg/kg/d) schwankte. Schwere Nebenwirkungen wie Erbrechen, Diarrhoe oder Sepsis als Zeichen einer Intoxikation mit MMF konnten während dieser Studie bei keinem der Versuchstiere festgestellt werden.

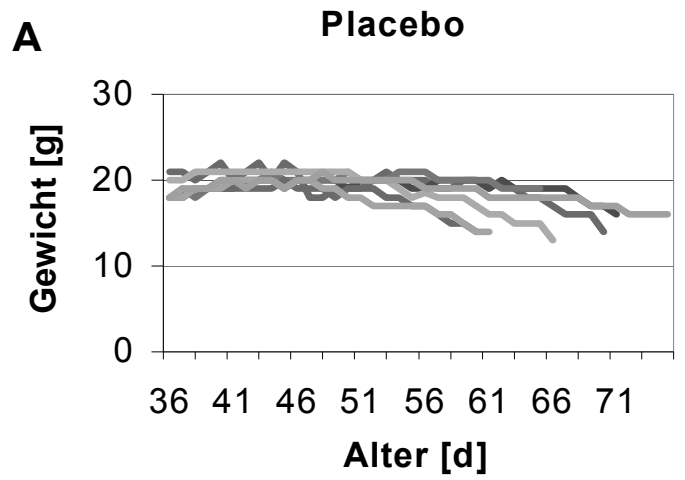

C

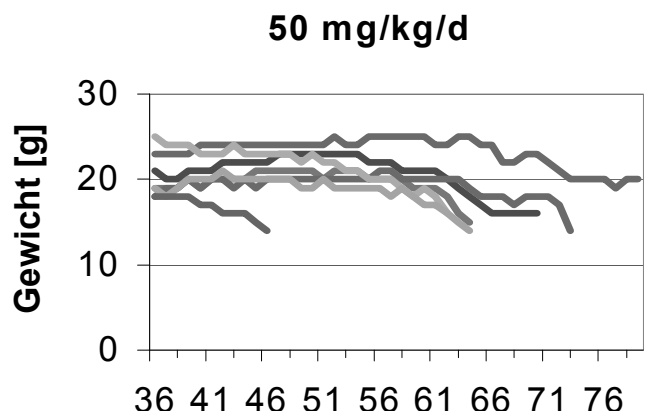

Alter [d]

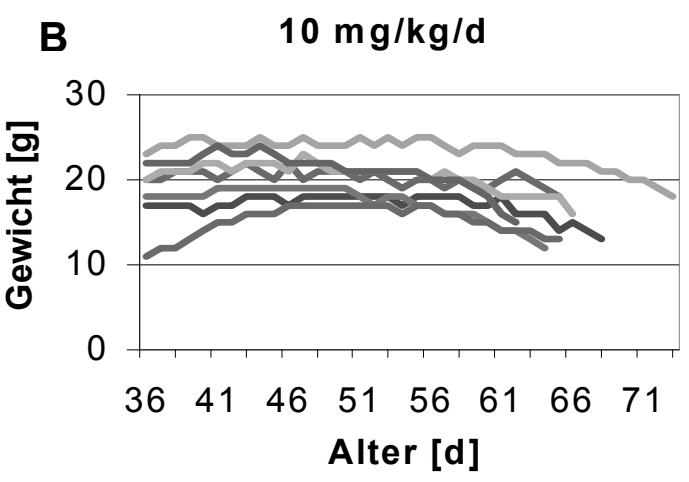

D

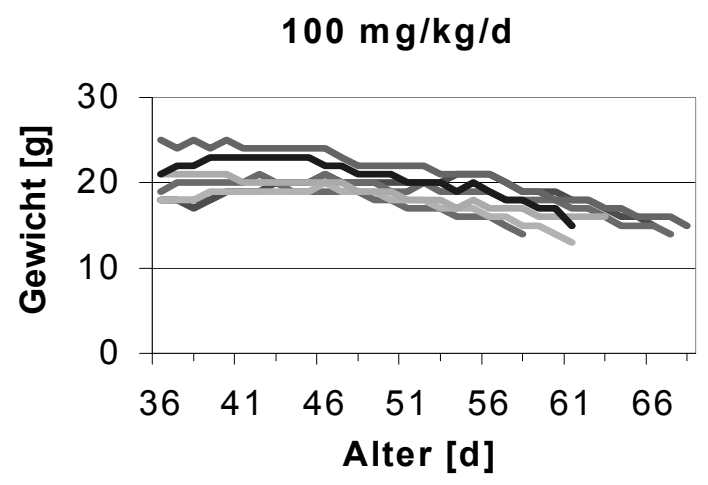




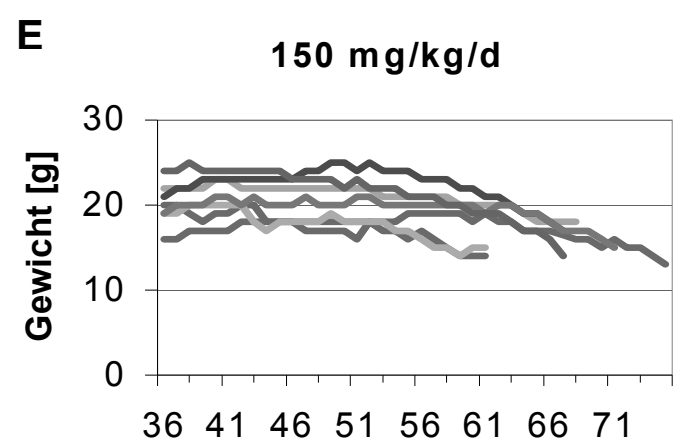

Alter [d]

Abb. 18 Gewichtsverläufe der Versuchstiere stratifiziert nach Versuchsgruppen

Die Diagramme zeigen den Gewichtsverlauf der Versuchstiere vom ersten Behandlungstag bis zum Todestag. Eine zunehmende Gewichtsabnahme erfolgte sowohl bei der Placebogruppe (A) als auch bei den jeweiligen Therapiegruppen (B-E).

\subsubsection{Auswertung der Blutwerte}

\subsubsection{MPA- und MPAG-Konzentration im Serum}

Aufgrund eines unerwarteten Todes einiger Versuchstiere oder eines ungenügenden Materialvolumens konnte nur von insgesamt 24 Versuchstieren unterschiedlicher Behandlungsgruppen Blut für weitere diagnostische Zwecke gewonnen werden. Da die Tötung der Tiere stets ohne eine weitere Gabe des MMF erfolgte, sind diese Werte als Talspiegel zu betrachten. Die Überlebenszeit in Abhängigkeit von der MPA-Serum-Konzentration ist in Abb. 19 dargestellt. Es ist keine Korrelation zwischen den gemessenen MPA-Talspiegeln und der Überlebenszeit der Versuchstiere feststellbar ( $p>0,05$, Spearman-Rangkorrelation). 


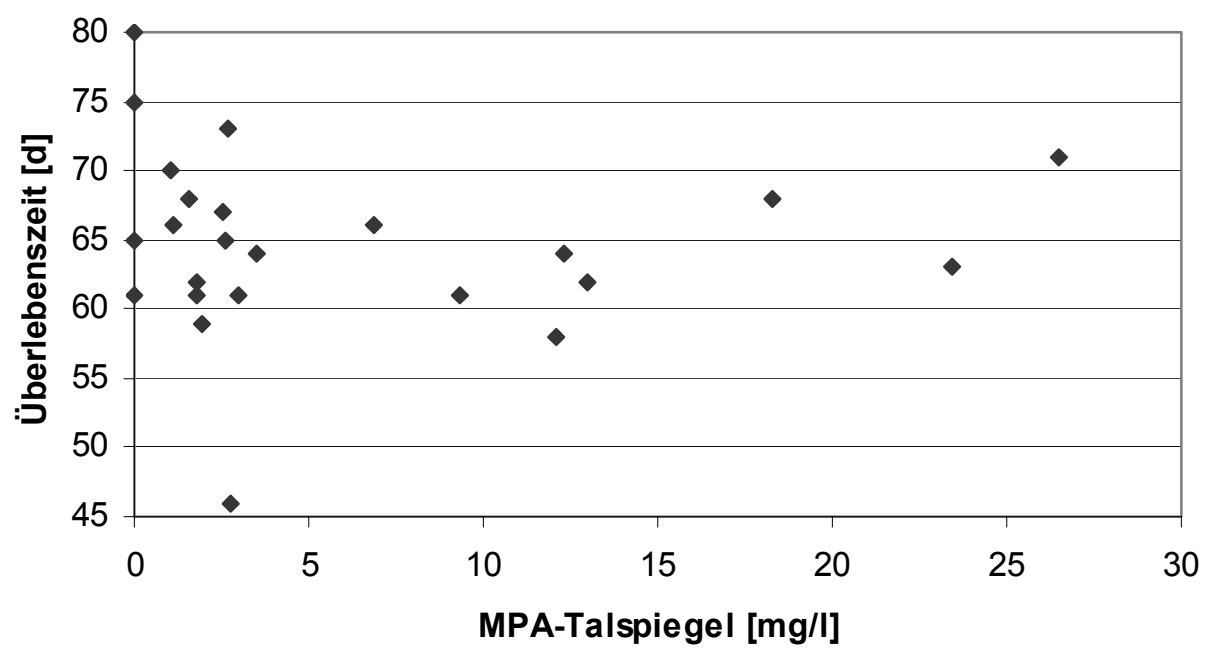

Abb. 19 Überlebenszeit der Versuchstiere in Abhängigkeit von MPA-Talspiegeln ( $n=24)$

Es besteht keine Korrelation zwischen den im Serum gemessenen MPA-Konzentrationen und der Überlebenszeit der Versuchstiere.

Die Serum-Konzentrationen für MPA und MPAG dieser 24 Versuchstiere in Abhängigkeit von der Versuchsgruppe sind in Abb. 20 dargestellt. Erwartungsgemäß konnte bei den 4 Versuchstieren der Placebo-Gruppe kein MPA oder MPAG im Serum nachgewiesen werden. Die durchschnittliche MPA-Konzentration nahm mit steigender MMF-Dosis zu. So lagen die durchschnittlichen MPA-Konzentrationen bei den Versuchstieren aus der Gruppe mit $10 \mathrm{mg} / \mathrm{kg} / \mathrm{d}$ bei 2,1 mg/l, mit $50 \mathrm{mg} / \mathrm{kg} / \mathrm{d}$ bei $4,1 \mathrm{mg} / \mathrm{l}$ und bei $100 \mathrm{mg} / \mathrm{kg} / \mathrm{d}$ bzw. $150 \mathrm{mg} / \mathrm{kg} / \mathrm{d}$ bei 11,4 mg/l bzw. 11,9 mg/l, d.h. es zeigt sich eine eindeutige Dosis-Konzentrations-Korrelation jedoch mit erheblicher interindividueller Variabilität ( $p<0,01$, Spearman-Rangkorrelation). Dies traf bedingt auch auf die im Serum gemessene MPAG-Konzentration zu. Die durchschnittliche Höchstkonzentration an MPAG mit 86,1 mg/l wurde hierbei mit einer MMF-Dosis von $100 \mathrm{mg} / \mathrm{kg} / \mathrm{d}$ erreicht. Die durchschnittliche MPAG-Konzentration betrug bei der Gruppe mit $10 \mathrm{mg} / \mathrm{kg} / \mathrm{d}$ 21,9 mg/l, mit $50 \mathrm{mg} / \mathrm{kg} / \mathrm{d}$ und $150 \mathrm{mg} / \mathrm{kg} / \mathrm{d}$ MMF wurden $36,3 \mathrm{mg} / \mathrm{l}$ und $46,1 \mathrm{mg} / \mathrm{l}$ erreicht ( $p<0,01$, Spearman-Rangkorrelation). 

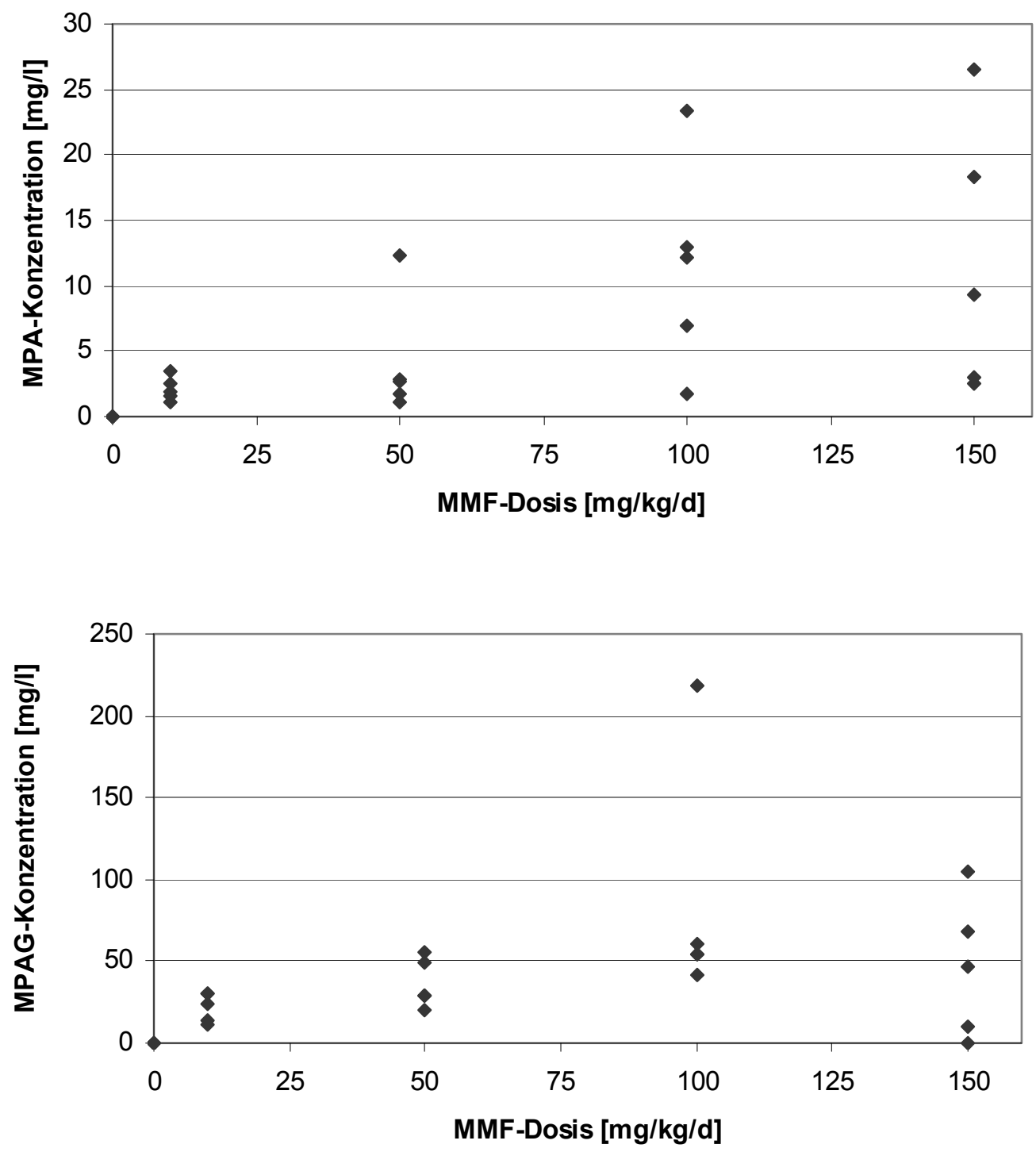

Abb. 20 MPA- und MPAG-Konzentrationen stratifiziert nach Versuchsgruppen $(n=24)$

Es konnte eine hochsignifikante Dosis-Konzentrations-Korrelation mit erheblicher interindividueller Variabilität festgestellt werden ( $p<0,01$, Spearman-Rangkorrelation).

\subsubsection{Parameter der klinischen Chemie}

Aus den gewonnenen Seren der Versuchstiere wurden weiterhin Gesamtprotein, Kreatinin und Harnstoff-N bestimmt (Abb. 21). Der hochdosierte Einsatz von MMF ging mit statistisch signifikanten niedrigeren Kreatinin- und Harnstoff-NKonzentrationen einher ( $p<0,05$ für Placebo versus $150 \mathrm{mg} / \mathrm{kg} / \mathrm{d}$, Mann-Whitney-UTest). Die Dosis von $150 \mathrm{mg} / \mathrm{kg} / \mathrm{d}$ MMF bewirkte eine Verringerung der mittleren Kreatinin-Konzentration von 54,2\% und eine Verringerung der mittleren Harnstoff-N- 
Konzentration von 60,5 \% im Vergleich zur Placebogruppe. Geringere Dosen von MMF zeigten jedoch keinen relevanten Effekt auf die Kreatinin- und Harnstoff-NKonzentrationen. Ebenso ließ sich keine statistisch relevante Wirkung des MMF auf das gemessene Gesamtprotein im Serum nachweisen ( $p>0,05$ für Placebo versus 10, 50, 100 und $150 \mathrm{mg} / \mathrm{kg} / \mathrm{d}$, Mann-Whitney-U-Test).
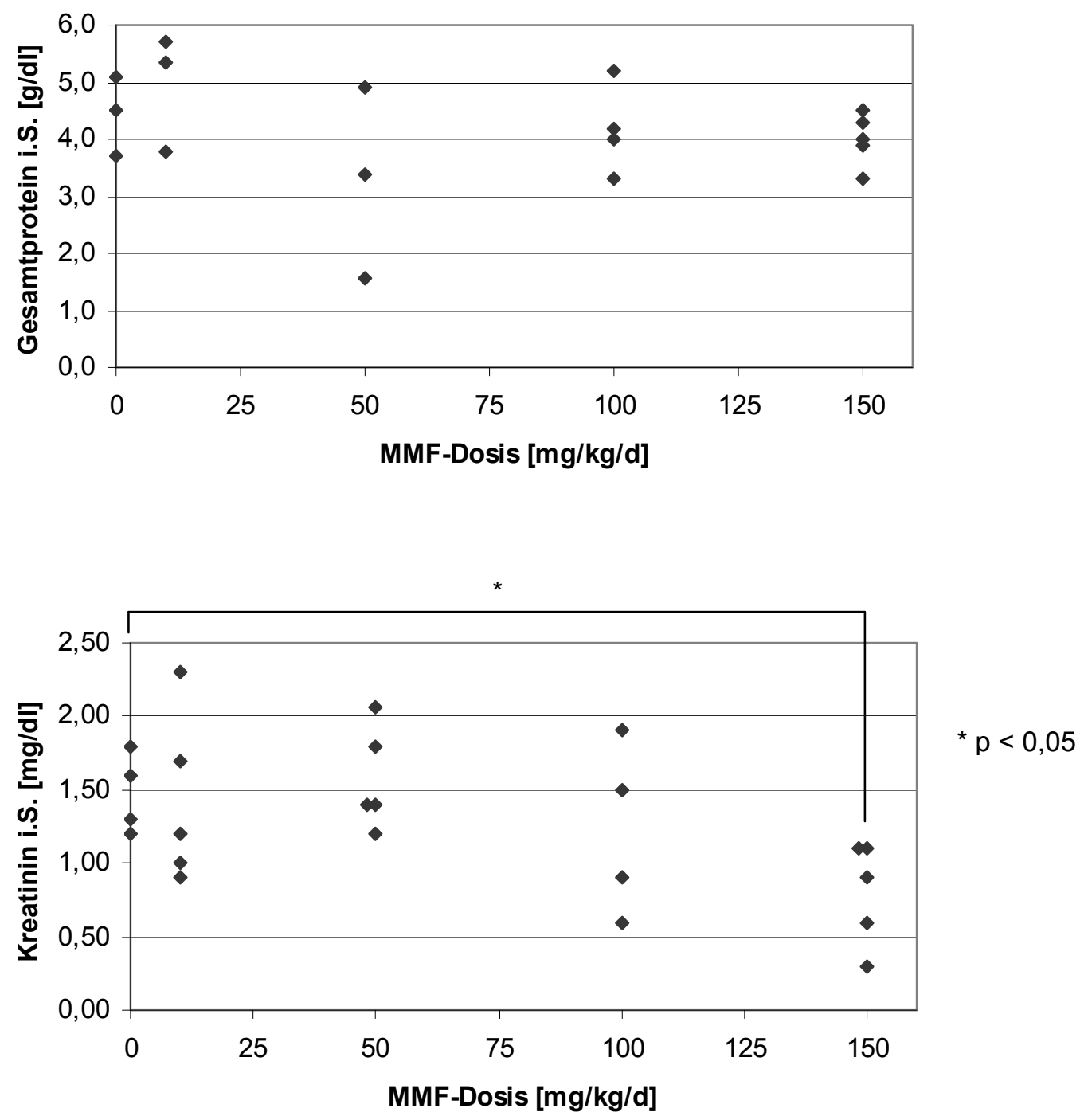


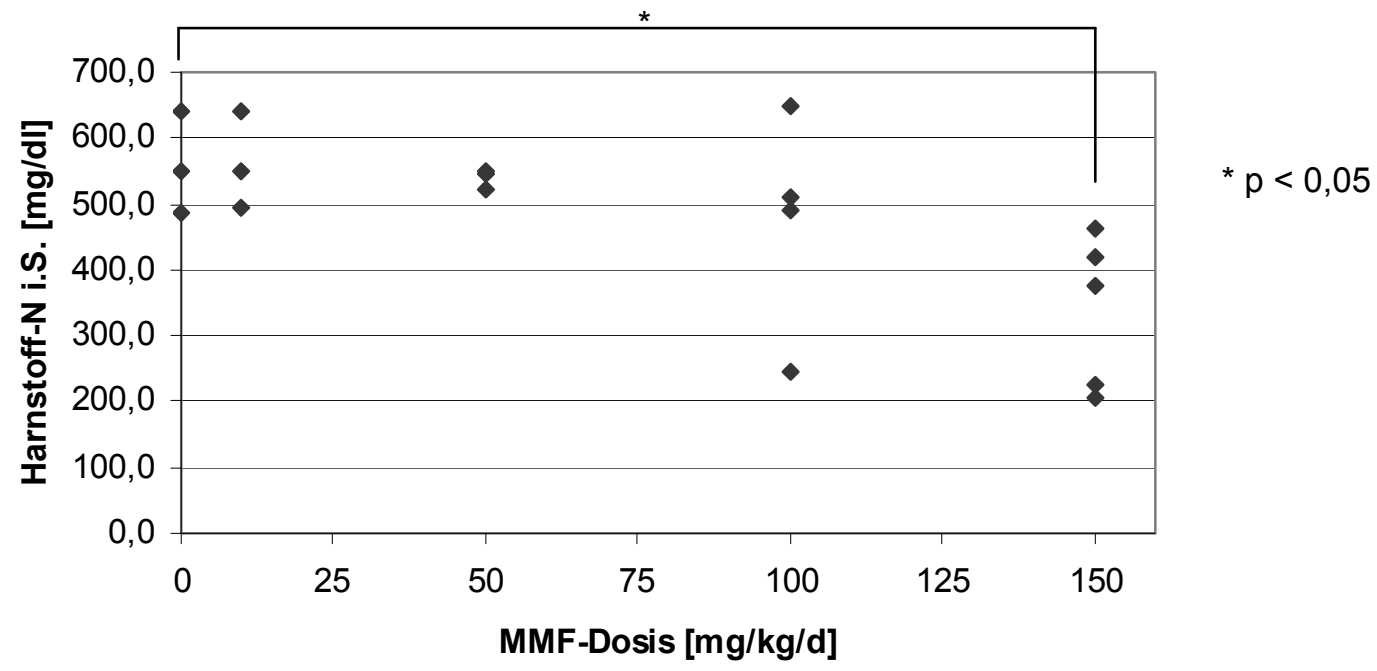

Abb. 21 Gesamtprotein, Kreatinin und Harnstoff-N im Serum als Einzelpunktmesswerte stratifiziert nach Versuchsgruppen

MMF-Hochdosistherapie bewirkte eine signifikante Erniedrigung der Retentionsparameter Kreatinin und Harnstoff-N ( $p<0,05$ für Placebo versus $150 \mathrm{mg} / \mathrm{kg} / \mathrm{d}$, Mann-Whitney-U-Test; Kreatinin: $\mathrm{n}=23$, Gesamtprotein/Harnstoff-N: $n=18)$.

In Abb. 22 ist der Zusammenhang zwischen den Kreatinin- und den MPAKonzentrationen im Serum der Versuchstiere dargestellt. Es ließ sich eine hochsignifikante reziproke Korrelation zwischen den MPA-Konzentrationen und den Serum-Kreatinin-Konzentrationen feststellen ( $p<0,01$, Spearman-Rangkorrelation). Bei den unbehandelten Mäusen, die keine im Serum messbaren MPAKonzentrationen aufwiesen, betrug das gemessene Kreatinin 1,5 $\pm 0,3 \mathrm{mg} / \mathrm{dl}$. Bei allen Mäusen mit einem Kreatinin oberhalb von 1,5 mg/dl waren die gemessenen MPA-Konzentrationen stets kleiner als $2 \mathrm{mg} / \mathrm{l}$, wogegen bei einem maximalen Kreatinin von 0,9 mg/dl MPA-Konzentrationen größer als $15 \mathrm{mg} / \mathrm{l}$ beobachtet wurden. Das heißt je höher die MPA-Konzentration im Serum, desto geringer das Kreatinin. 


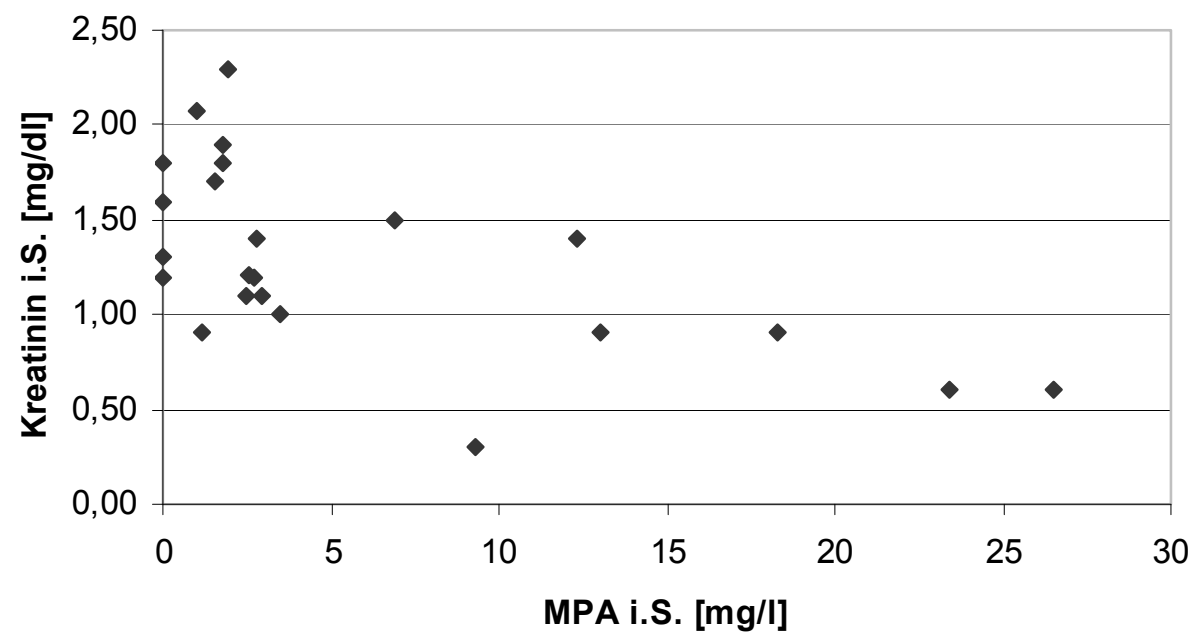

Abb. 22 Kreatinin-Werte im Serum der Versuchstiere in Abhängigkeit von der MPAKonzentration ( $\mathrm{n}=\mathbf{2 3})$

Es zeigte sich eine hochsignifikante reziproke Korrelation zwischen den MPA- und den KreatininKonzentrationen ( $p<0,01$, Spearman-Rangkorrelation).

\subsubsection{Auswertung der Urinwerte}

Aus dem zum Zeitpunkt des Todes entnommenen Urin wurden des Weiteren das Gesamtprotein $(n=12)$ und Albumin $(n=14)$ bestimmt (Abb. 23). Die begrenzte Anzahl der Proben lässt keine statistische Prüfung $\mathrm{zu}$, jedoch scheint zumindest beim Gesamtprotein eine fallende Tendenz der Konzentration im Urin mit steigender MMF-Dosierung sichtbar.

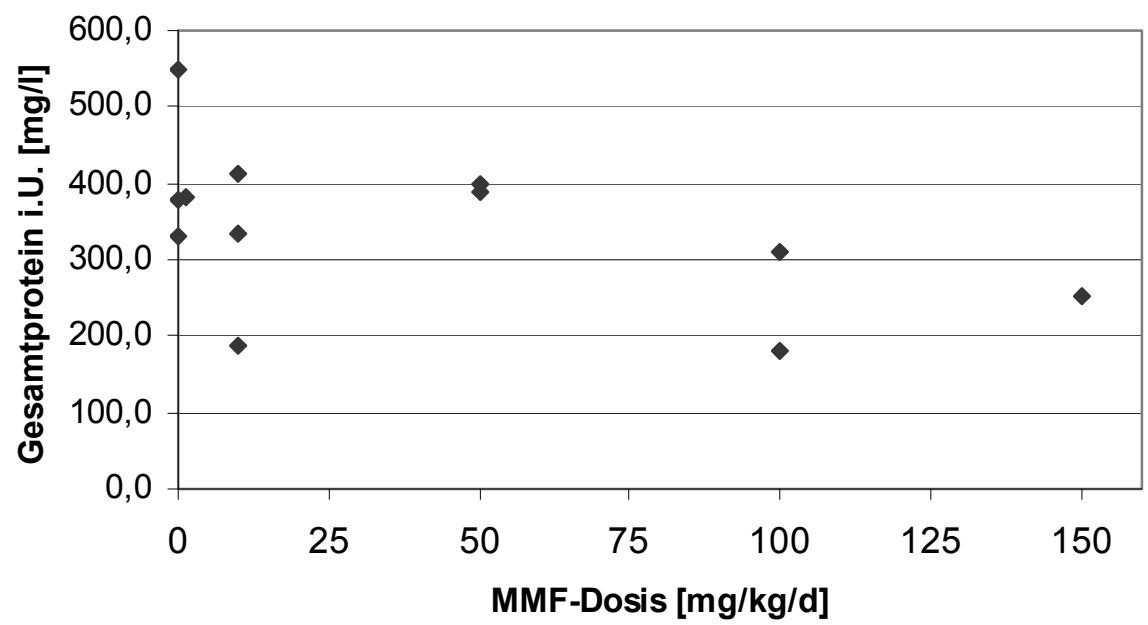




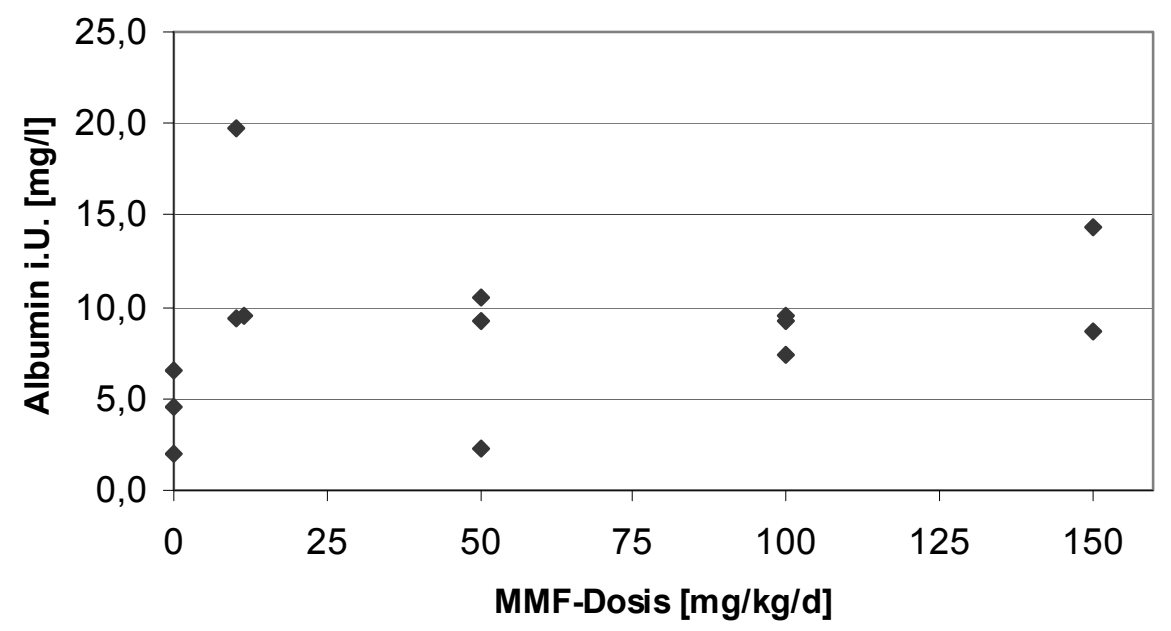

Abb. 23 Im Urin gemessenes Gesamtprotein und Albumin als Einzelpunktmesswerte stratifiziert nach Versuchsgruppen

\subsection{Ergebnisse der histologischen Methoden}

\subsubsection{Ergebnisse der Lichtmikroskopie}

Für die lichtmikroskopische Untersuchung wurden die Hämatoxylin-Eosin- (H.E.) sowie zur Bindegewebsdarstellung die Trichrom-Färbung nach Masson-Goldner durchgeführt. Die H.E.-Methode ist die gebräuchlichste Übersichtsfärbung zur Darstellung von Zellkernen und zytoplasmatischen Bestandteilen. Durch den positiv geladenen Farbstoff Hämatoxylin werden die negativ geladenen (basophilen) Nukleinsäuren blau angefärbt, so dass die Kerne dunkel imponieren. Das Zytoplasma und die kollagenen Fasern erscheinen durch den Gegenfarbstoff Eosin rot, elastische Fasern blassrot. In der Trichrom-Färbung nach Masson-Goldner imponieren die Kerne durch das Eisenhämatoxylin nach Weigert braun-schwarz, durch Azophloxin und Orange $G$ erscheinen das Zytoplasma ziegelrot und die Erythrozyten orange-gelb. Die kollagenen Fasern werden durch die Gegenfärbung mit Lichtgrün grün dargestellt, die elastischen Fasern erscheinen blassgrün bzw. bleiben ungefärbt.

Bereits die lichtmikroskopischen Übersichtsaufnahmen der Hämatoxylin-Eosingefärbten Nieren sowohl der behandelten als auch der unbehandelten Versuchstiere 
zeigten im Vergleich zu der HE-gefärbten Niere einer gesunden Maus große Unterschiede auf (Abb. 24 A-E). Aufgrund der Fibrose waren die Organe der Mäuse, einschließlich der Placebo-Gruppe, stark geschrumpft und der geregelte histologische Aufbau verändert. Bei den Nieren der behandelten und unbehandelten Versuchstiere, bei denen die Trichrom-Färbung nach Masson-Goldner zur Bindegewebsdarstellung erfolgte, fiel bereits makroskopisch die nahezu vollständige Grünfärbung des gesamten Präparates auf, was eine stark ausgeprägte renale Fibrose impliziert. In den folgenden lichtmikroskopischen Übersichtsaufnahmen wird dies deutlich (Abb. 24 B-E).

\section{Dosis MMF}

$[\mathrm{mg} / \mathrm{kg} / \mathrm{d}]$
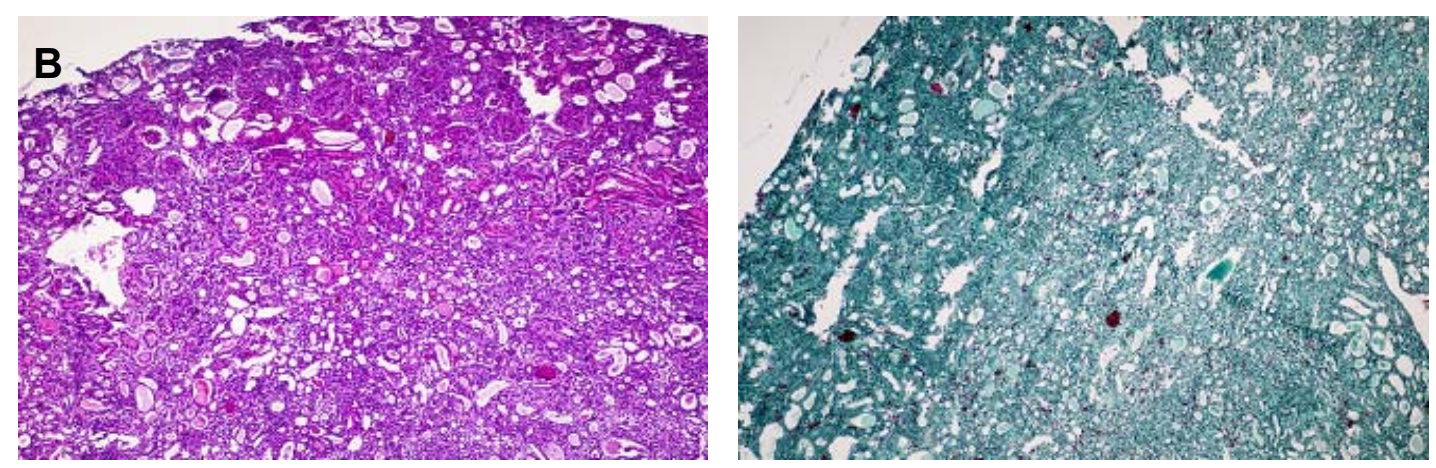

10

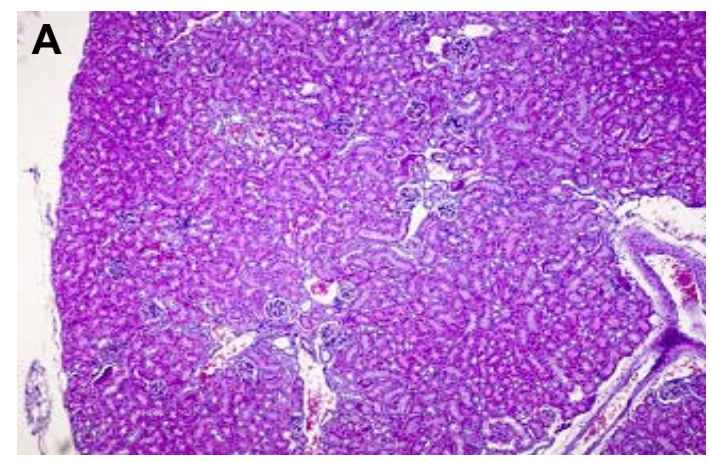

0
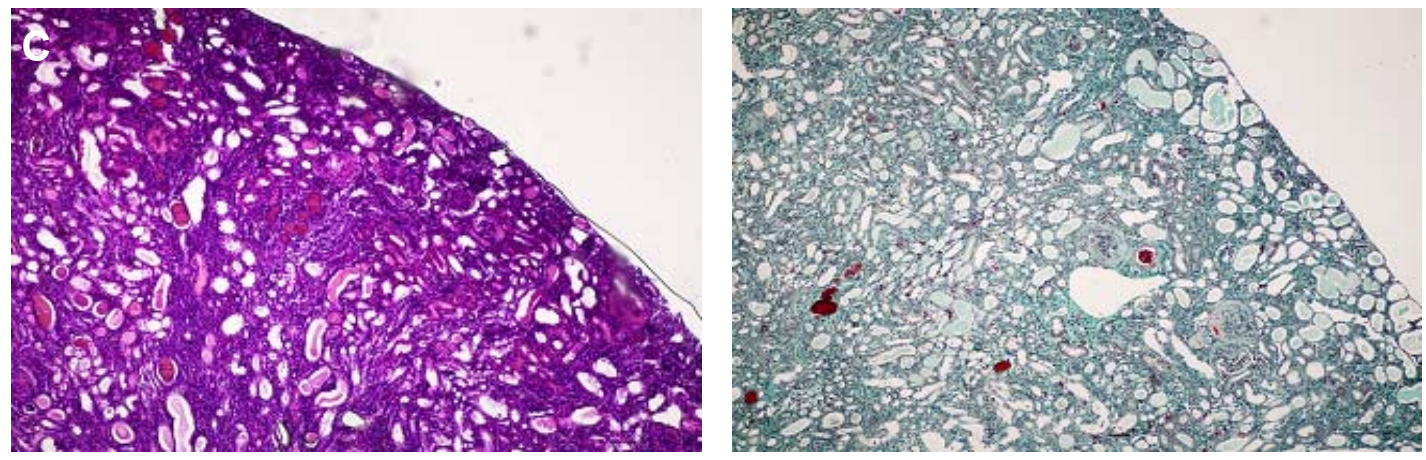
50
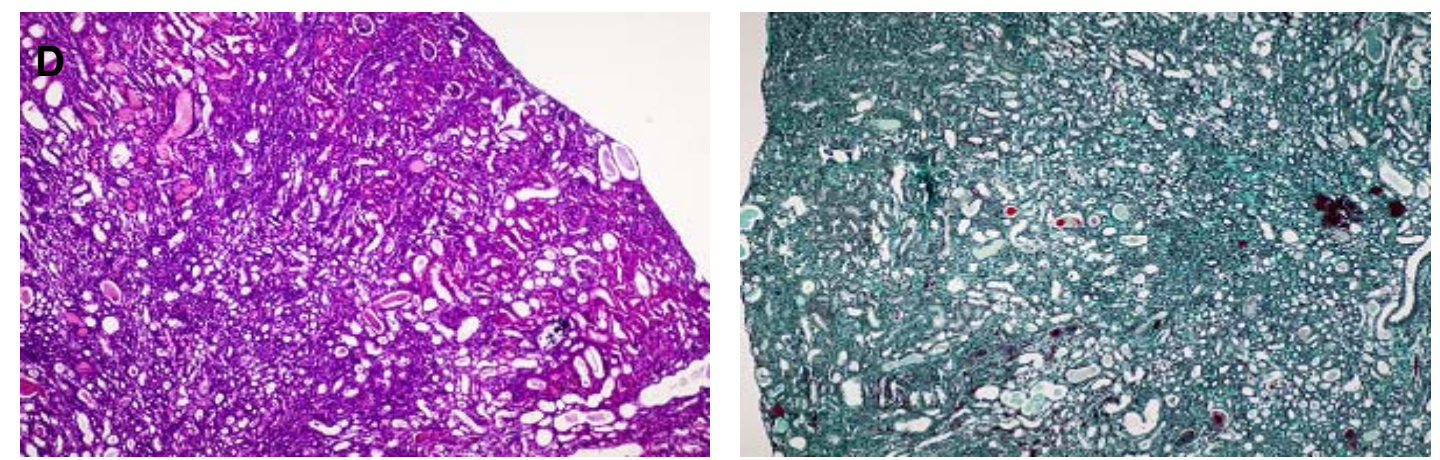

100
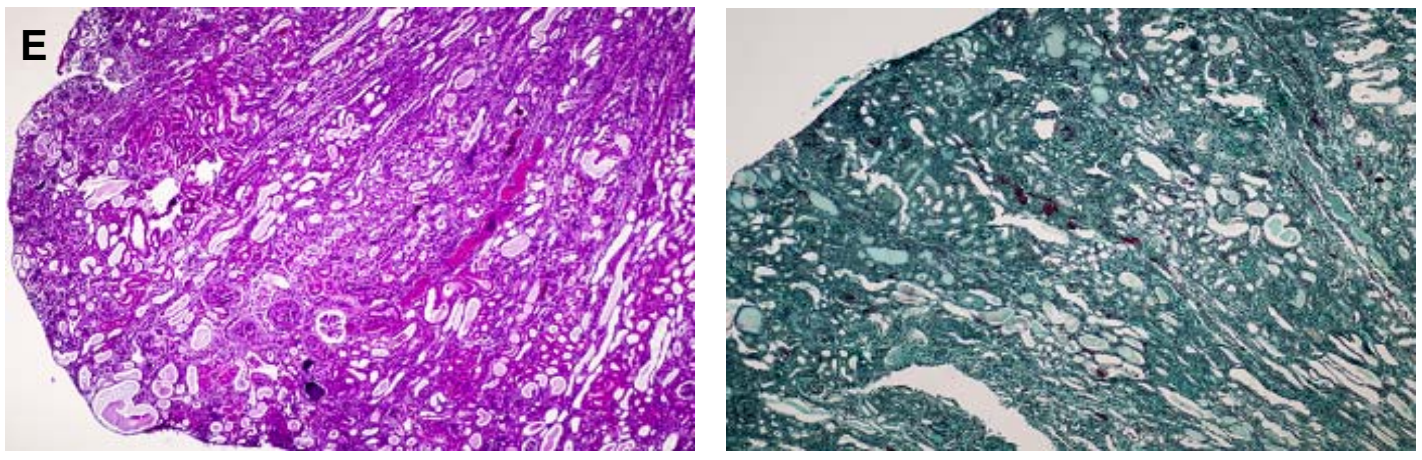

150
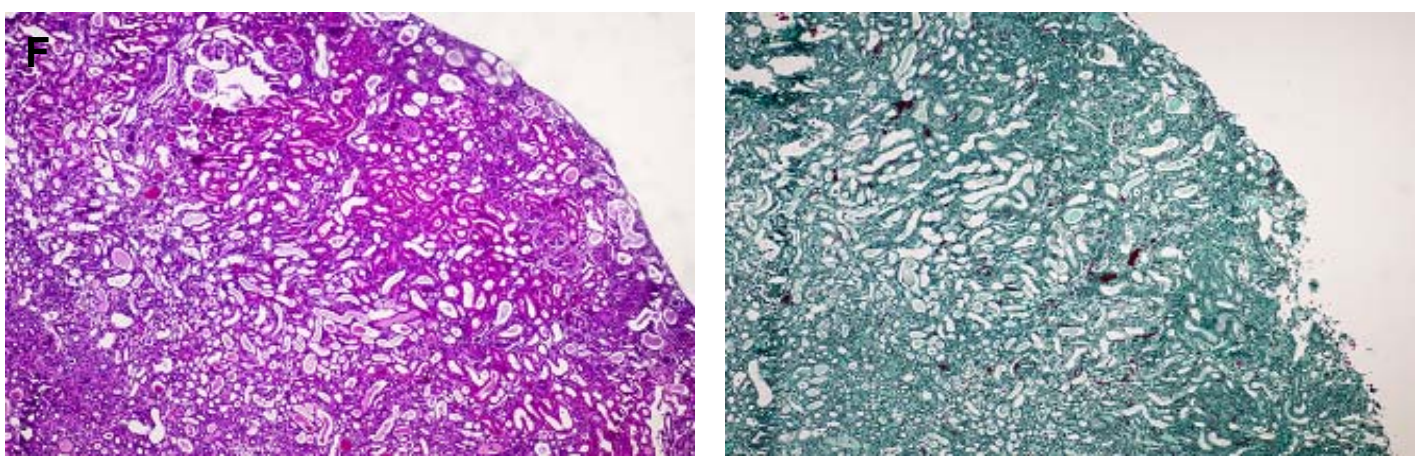

Abb. 24 Gegenüberstellung der lichtmikroskopischen Übersichtsaufnahmen HE- und Trichromgefärbter Nieren

Dargestellt sind eine gesunde HE-gefärbte Niere (A), sowie in HE- und Trichrom-Färbung die Niere einer Placebo-Maus (B) und Nieren behandelter Mäuse unterschiedlicher Therapiegruppen (C-E): $10 \mathrm{mg} / \mathrm{kg} / \mathrm{d}$ (C), $50 \mathrm{mg} / \mathrm{kg} / \mathrm{d}(D), 100 \mathrm{mg} / \mathrm{kg} / \mathrm{d}$ (E), $150 \mathrm{mg} / \mathrm{kg} / \mathrm{d}$ (F). 10x Vergrößerung.

In den Abb. 25A-E sind exemplarisch einzelne HE- und Trichrom-gefärbte Nierenausschnitte der Versuchstiere dargestellt. In allen untersuchten Versuchstieren, einschließlich der Placebo-Gruppe, finden sich zum Zeitpunkt des Todes stark sklerotisch veränderte Glomerula, deutlich durch die Verbreiterung der mesangialen Matrix und der mesangialen Zelldichte, mit bereits einsetzendem Untergang einzelner Glomerula. 
MMF-Dosis

HE

Trichrom

[mg/kg/d]

0

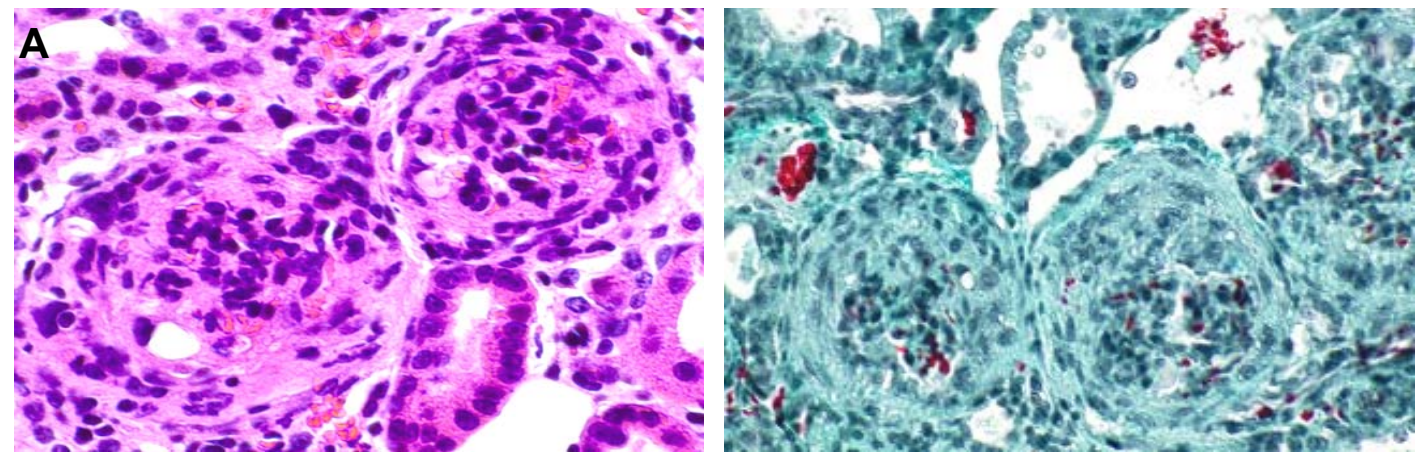

10
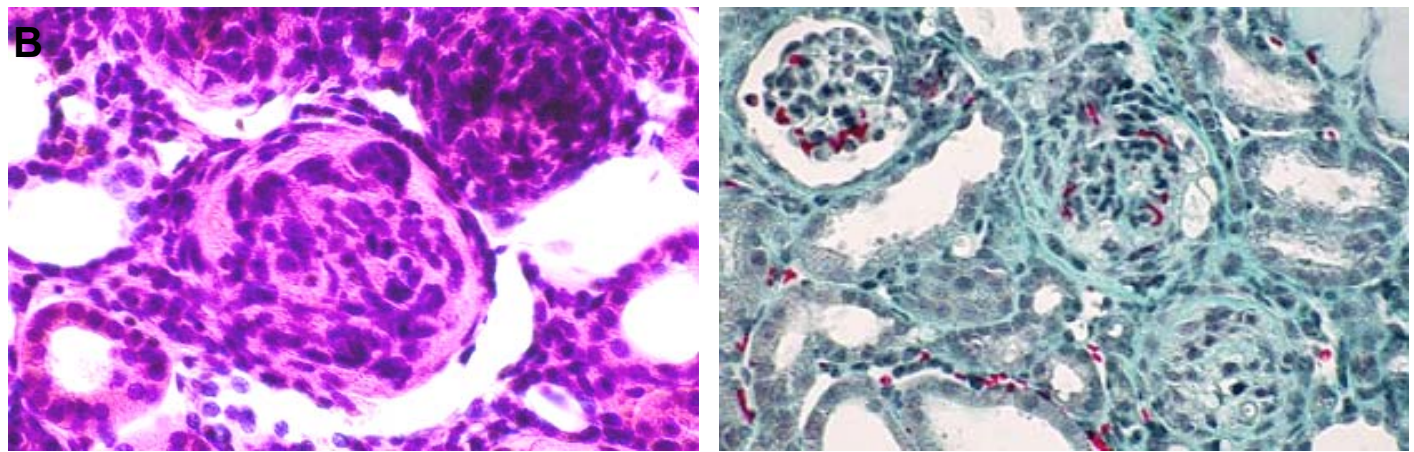

50
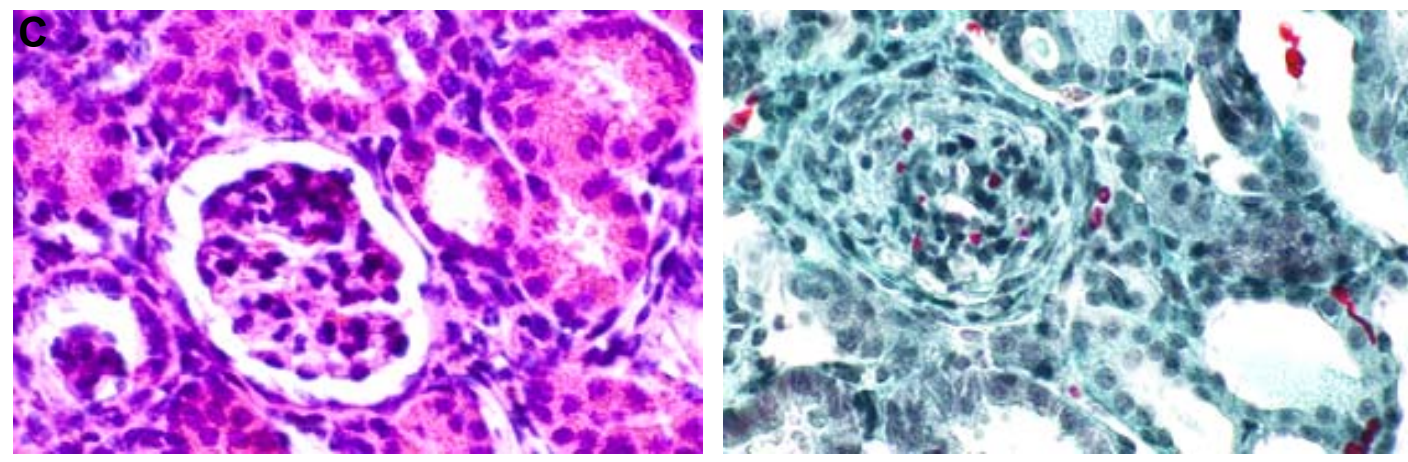

100
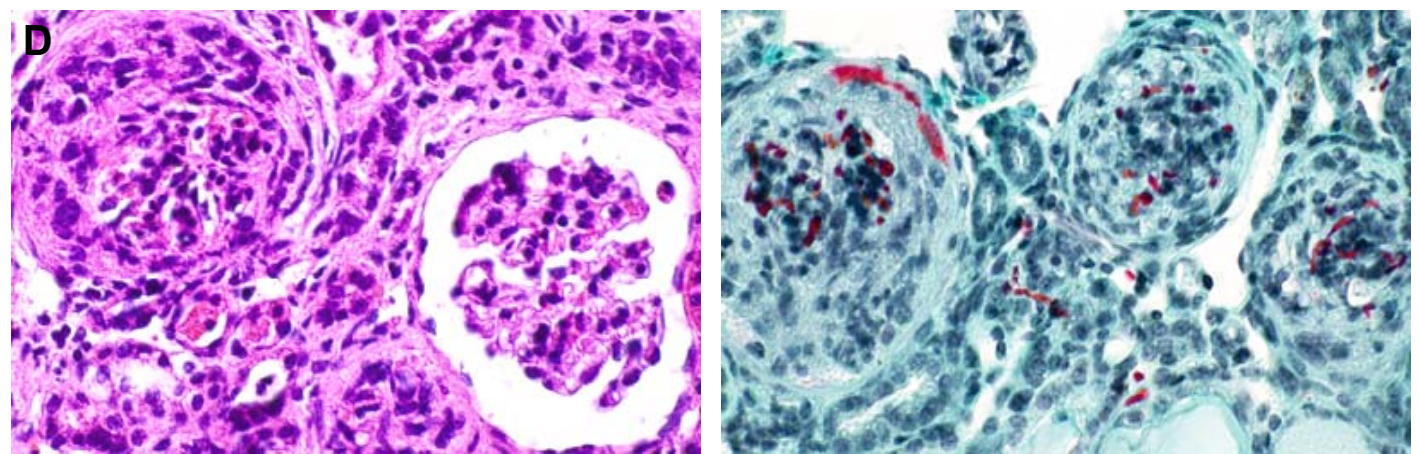
150
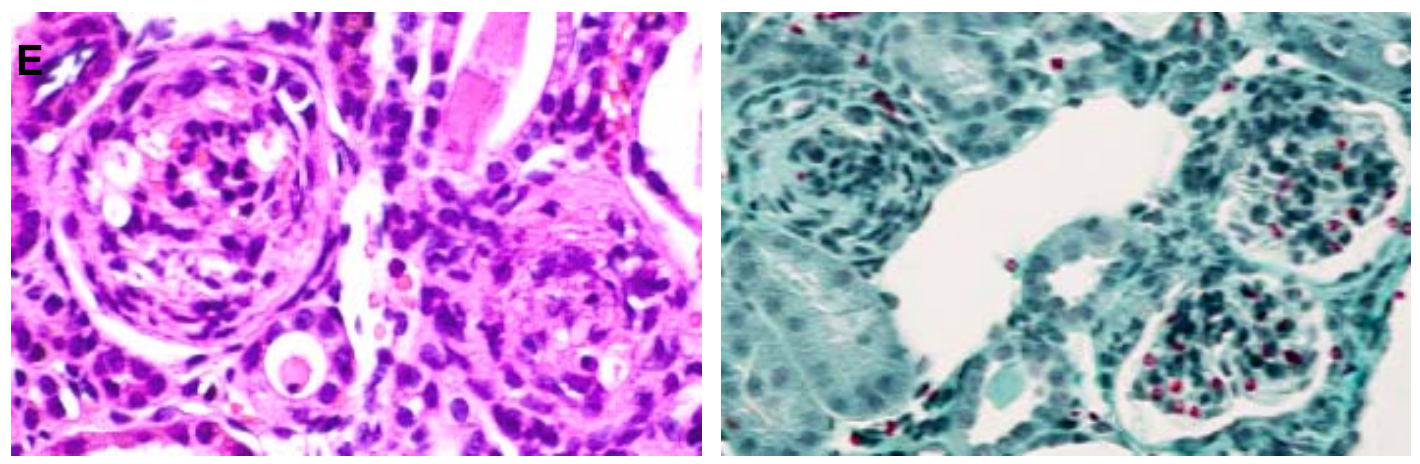

Abb. 25 Exemplarische Gegenüberstellung einzelner Ausschnitte HE- und Trichrom-gefärbter Nieren

Dargestellt sind die Glomerula behandelter Mäuse unterschiedlicher Therapiegruppen (A-E): $0 \mathrm{mg} / \mathrm{kg} / \mathrm{d}$ (A), $10 \mathrm{mg} / \mathrm{kg} / \mathrm{d}$ (B), $50 \mathrm{mg} / \mathrm{kg} / \mathrm{d}$ (C), $100 \mathrm{mg} / \mathrm{kg} / \mathrm{d}$ (D) und $150 \mathrm{mg} / \mathrm{kg} / \mathrm{d}$ (E). Sämtliche photographierte Glomerula stammen aus dem apikalen Rindenbereich. 60x Vergrößerung.

Die Auszählung der Glomerula und deren Einstufung in unterschiedliche Fibrosierungsgrade zeigt keine erheblichen Unterschiede zwischen den behandelten Versuchstieren im Vergleich zu den unbehandelten Versuchstieren auf $(p>0,05$, ChiQuadrat-Test). Der ermittelte Glomerulumsklerose-Score betrug in der unbehandelten Gruppe 2,62 und lag in den jeweiligen Therapiegruppen zwischen 2,42 (150 mg/kg/d) und 2,62 (50 mg/kg/d). Der relative Anteil der massiv fibrosierten Glomerula (Grad 3+), die in den Organen der unbehandelten Versuchstiere quantitativ dominierten, nahm mit steigender MMF-Dosis ab, gleichzeitig stieg der relative Anteil der mäßig geschädigten Glomerula (Grad 2+). Letztendlich waren jedoch alle Nieren von einer massiven Glomerulumsklerose betroffen. 


\begin{tabular}{|c|c|c|c|c|}
\hline \multicolumn{2}{|c|}{ Grad der Glomerulumsklerose } & $\mathbf{1 +}$ & $\mathbf{2 +}$ & $\mathbf{3 +}$ \\
\hline $\begin{array}{c}\text { MMF-Dosis } \\
\text { [mg/kg/d] }\end{array}$ & rel. Anteil [\%] & rel. Anteil [\%] & rel. Anteil [\%] & rel. Anteil [\%] \\
\hline $\mathbf{0}$ & 2 & 6 & 20 & 72 \\
\hline $\mathbf{1 0}$ & 2 & 6 & 26 & 66 \\
\hline $\mathbf{5 0}$ & 0 & 6 & 26 & 68 \\
\hline $\mathbf{1 0 0}$ & 0 & 10 & 30 & 60 \\
\hline $\mathbf{1 5 0}$ & 2 & 8 & 36 & 54 \\
\hline
\end{tabular}

Tab. 3 Semiquantitative Auswertung der Glomerulumsklerose

Pro Präparat wurden 50 Glomerula ausgezählt und entsprechend ihres Fibrosierungsausmaßes in unterschiedliche Grade eingeteilt. $0=$ keine Veränderungen, $1+=<25 \%$ des Glomerulums, $2+=25-$ $50 \%$ des Glomerulums, 3+ = > $50 \%$ des Glomerulums sind betroffen.

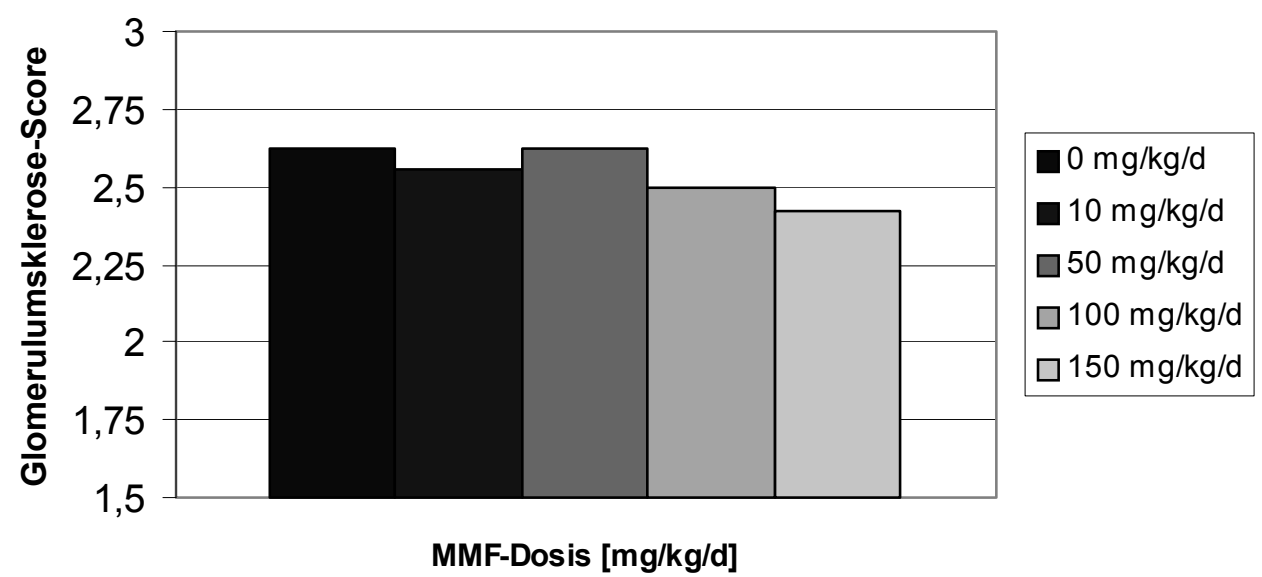

Abb. 26 Glomerulumsklerose-Score der jeweiligen Behandlungsgruppen $(n=5)$

Die Multiplikation des jeweiligen Grades mit dem prozentualen Anteil der Glomerula ergab den Glomerulumsklerose-Score. Es konnte kein signifikanter Unterschied zwischen den einzelnen Behandlungsgruppen festgestellt werden ( $p>0,05$, Chi-Quadrat-Test).

Die Auswertung der tubulointerstitiellen Fibrose ist in Tab. 4 und Abb. 27 dargestellt. In den unbehandelten Versuchstieren dominierte eine massive tubulointerstitielle Fibrose (Grad 3+), welche zudem mit einer ausgeprägten Tubulusatrophie 
einherging. Der tubulointerstitielle Fibrose-Score betrug bei der Placebo-Gruppe 2,01. Mit zunehmender MMF-Dosis nahm der Schweregrad der tubulointerstitiellen Fibrose deutlich ab, so dass mittels Hochdosisgabe ein Score von 1,43 erreicht werden konnte und insgesamt eine geringe bis mäßige tubulointerstitielle Fibrose vorherrschte $(p<0,001$, Chi-Quadrat-Test). Auch die Zahl der atrophierten Tubuli nahm ebenso mit steigender MMF-Dosis ab. Zwar konnte in allen Präparaten eine Fibrose des Interstitiums festgestellt werden, dennoch ist das Ausmaß der Schädigung mit steigender MMF-Konzentration deutlich abgeschwächt.

\begin{tabular}{|c|c|c|c|c|}
\hline \multicolumn{2}{|l|}{$\begin{array}{l}\text { Grad der tubulointerstitiellen } \\
\text { Veränderung: }\end{array}$} & $\mathbf{0}$ & $\mathbf{1 +}$ & $\mathbf{2 +}$ \\
\hline $\begin{array}{l}\text { MMF-Dosis } \\
\text { [mg/kg/d] }\end{array}$ & rel. Anteil [\%] & rel. Anteil [\%] & rel. Anteil [\%] & rel. Anteil [\%] \\
\hline $\mathbf{0}$ & 8 & 19 & 39 & 35 \\
\hline $\mathbf{1 0}$ & 11 & 20 & 35 & 34 \\
\hline $\mathbf{5 0}$ & 8 & 31 & 39 & 23 \\
\hline $\mathbf{1 0 0}$ & 11 & 39 & 34 & 16 \\
\hline $\mathbf{1 5 0}$ & 16 & 39 & 31 & 14 \\
\hline
\end{tabular}

Tab. 4 Semiquantitative Auswertung der tubulointerstitiellen Fibrose

Die Tubuli wurden entsprechend ihres Abstands zueinander aufgrund von Fibrosierungsprozessen und des Vorhandenseins von Tubulusatrophie in unterschiedliche Grade eingeteilt. $0=$ keine tubulointerstitiellen Veränderungen Fibrose, $1+=<25 \%$ der Fläche, $2+=25-50 \%$ der Fläche, 3+ = $>50 \%$ der Fläche sind betroffen $(n=5)$. Pro Präparat wurden mindestens 15 Felder ausgewertet. 


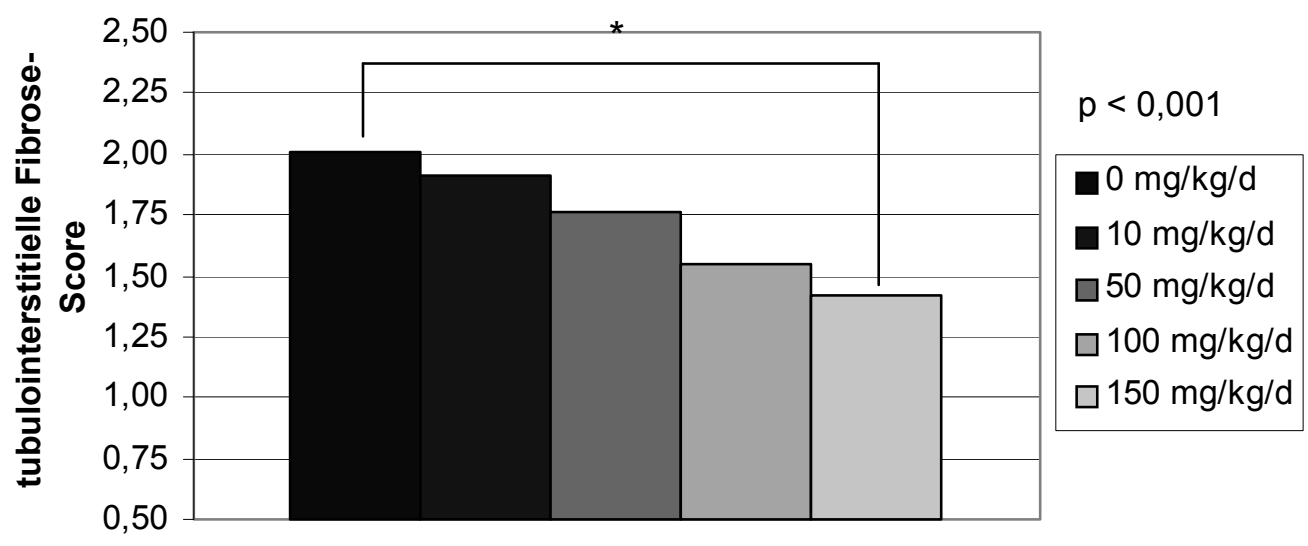

MMF-Dosis [mg/kg/d]

Abb. 27 Tubulointerstitieller Fibrose-Score der jeweiligen Behandlungsgruppen $(n=5)$

Die Multiplikation des jeweiligen Grades mit dem prozentualen Anteil ergab den tubulointerstitiellen Fibrose-Score. Das Ausmaß der tubulointerstitiellen Schädigung nimmt mit steigender MMFKonzentration signifikant ab ( $p<0,001$, Chi-Quadrat-Test).

\subsubsection{Ergebnisse der Elektronenmikroskopie}

In Abb. 28 sind exemplarisch die Nieren einiger ausgewählter Versuchstiere nach Organverfügbarkeit und Qualität der Aufnahmen demonstriert. Dargestellt sind elektronenmikroskopische Aufnahmen einer gesunden, nicht therapierten Maus sowie 4 behandelter Versuchstiere (10, 50 und 2x $100 \mathrm{mg} / \mathrm{kg} / \mathrm{d})$. In der als Kontrolle dienenden Niere der gesunden Maus lassen sich deutlich das fenestrierte Endothel der Kapillaren, die gleichmäßig breite glomeruläre Basalmembran von homogener Elektronendichte mit der typischen trilaminären Struktur mit einer zentralen Lamina densa und 2 Laminae rarae, sowie die Sekundärfortsätze der Podozyten („Füsschen“) mit Filtrationsschlitzen, welche alle zusammen die Filtrationsbarriere bilden, erkennen. Im Gegensatz dazu erscheint bei allen hier exemplarisch dargestellten behandelten Versuchstieren die Basalmembran inhomogen und unregelmäßig breit, überwiegend verdickt und ausgefranst (Abb. 28E, K). Die Podozyten sind in ihrer Struktur kaum noch zu erkennen, die Füße sind stark verbreitert, so dass keine Filtrationsschlitze mehr vorhanden sind und in Abb. $28 \mathrm{E}$ wird sogar das komplette Fehlen der Podozytenfortsätze deutlich. Des Weiteren fällt das wellig-konturierte und z. T. verdickte Endothel der Blutgefäße auf, beispielsweise 
in Abb. 28F, G oder L, auch ist die Fenestrierung größtenteils aufgehoben. Ebenso auffällig ist die verminderte Blutversorgung der Glomerula (Abb. 28G). Die normale Struktur der Tubuli ist ebenfalls z. T. deutlich aufgehoben. Im linken Bildrand von Abb. 28F ist ein zugrunde gehender Tubulus dargestellt und in Abb. 28L erkennt man, dass der Tubulus bereits z. T. stark von kollagenen Fasern durchsetzt ist. Alles in allem ließen sich im groben Vergleich der Aufnahmen der hier exemplarisch dargestellten behandelten Versuchstiere untereinander keine wesentliche Unterschiede im Fibrosierungsgrad feststellen.
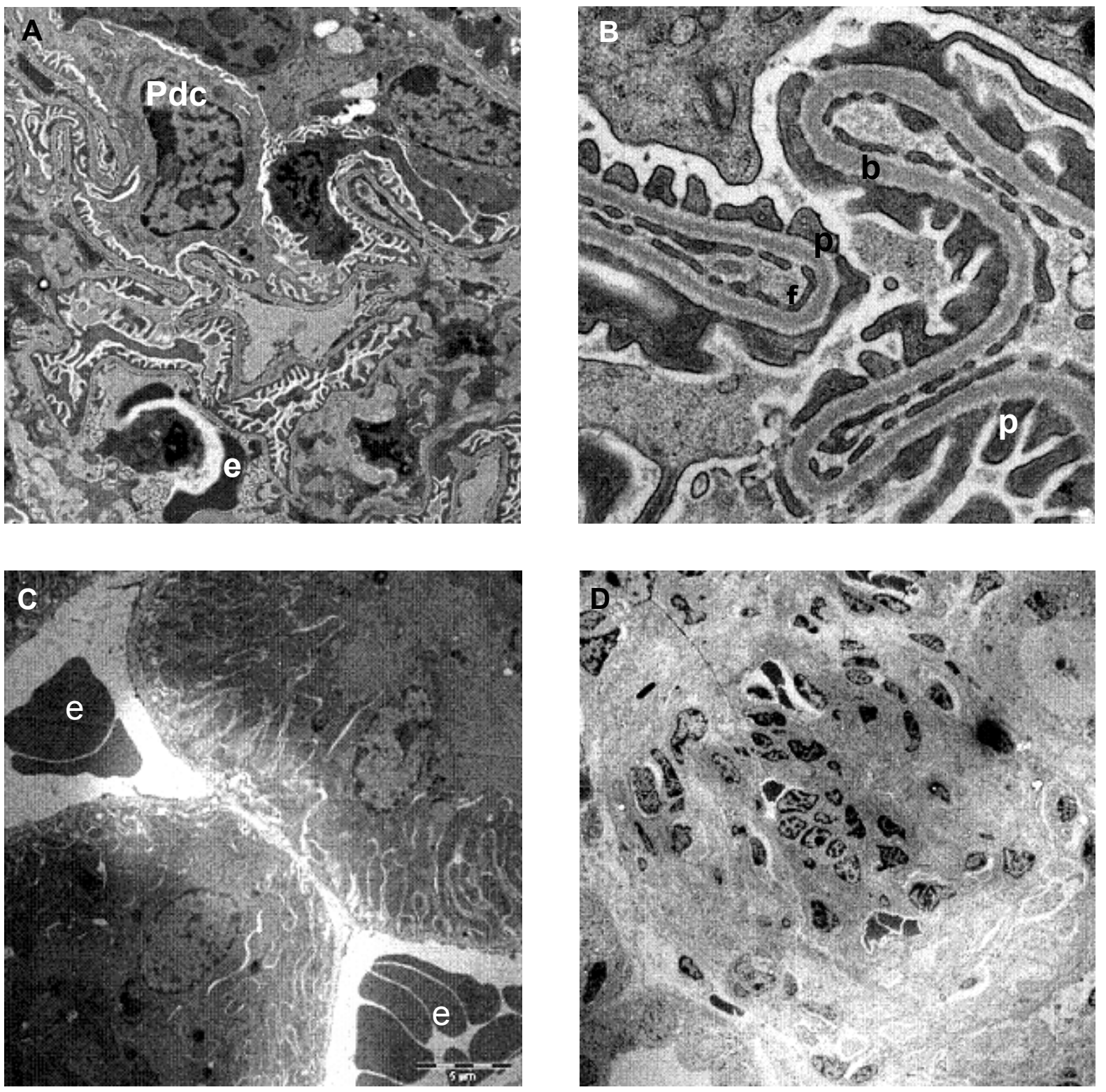

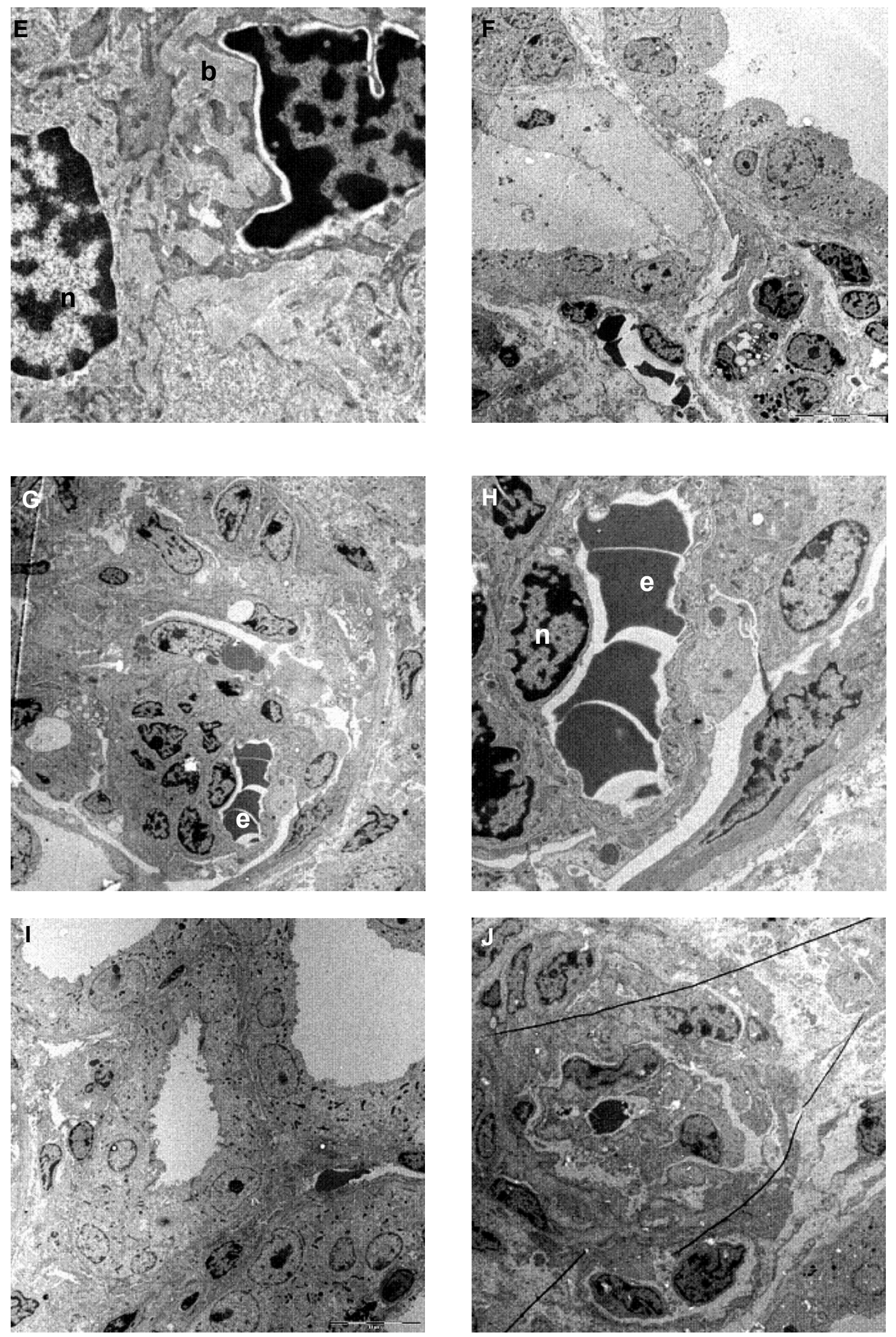

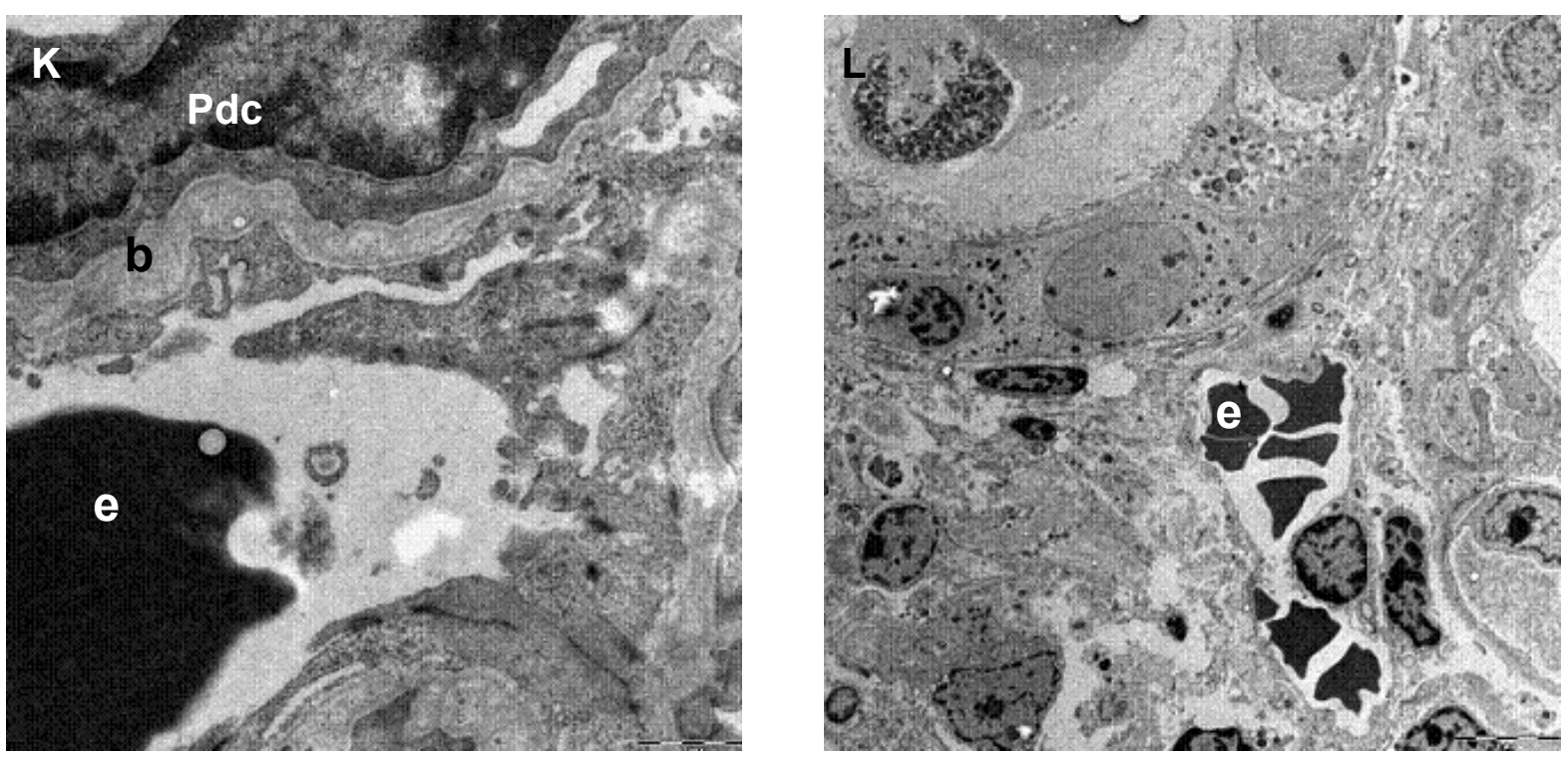

Abb. 28 Exemplarische Darstellung elektronenmikroskopischer Aufnahmen von renalem Gewebe

Dargestellt sind Ausschnitte aus dem Nierengewebe einer gesunden Maus (A-C) und behandelter Mäuse unterschiedlicher Therapiegruppen (D-L): $10 \mathrm{mg} / \mathrm{kg} / \mathrm{d}$ (D-F), $50 \mathrm{mg} / \mathrm{kg} / \mathrm{d}$ (G-I) und $100 \mathrm{mg} / \mathrm{kg} / \mathrm{d}$ $(J-L) . b=$ Basalmembran, $e=$ Erythrozyt, $f=$ fenestriertes Endothel einer Glomerulumkapillare, $n=$ Nucleus einer Endothelzelle, $p=$ Podozytenfortsätze, Pdc= Podozyt

In Abb. 29 ist exemplarisch die interstitielle Synthese der kollagenen Fasern dargestellt. In den Nieren aller Versuchstiere fanden sich Fibroblasten und wie bereits in der Trichrom-Färbung nach Masson-Goldner zu sehen, massenhaft kollagene Fasern, welche in ihrer Menge im visuellen Vergleich keine Unterschiede aufwiesen. Auffällig in Abb. 29A ist die Vielzahl der Mitochrondrien im angeschnittenen Tubulus. In Abb. 29C wird der große Abstand zwischen der Kapillare und dem Tubulus deutlich, verursacht durch das dazwischen liegende proliferierte Bindegewebe. Der Fibroblast in Abb. 29F weist im Gegensatz zu den Fibroblasten der anderen Versuchstiere einen relativ kleinen Nucleus auf, dafür ist jedoch sehr viel raues endoplasmatisches Retikulum im Zytoplasma vorhanden. Zusammengefasst ließen sich hier im groben Vergleich der einzelnen Aufnahmen in Abhängigkeit von der Behandlung der Tiere mit MMF keine wesentlichen Unterschiede im Ausmaß der kollagenen Fasern feststellen. 

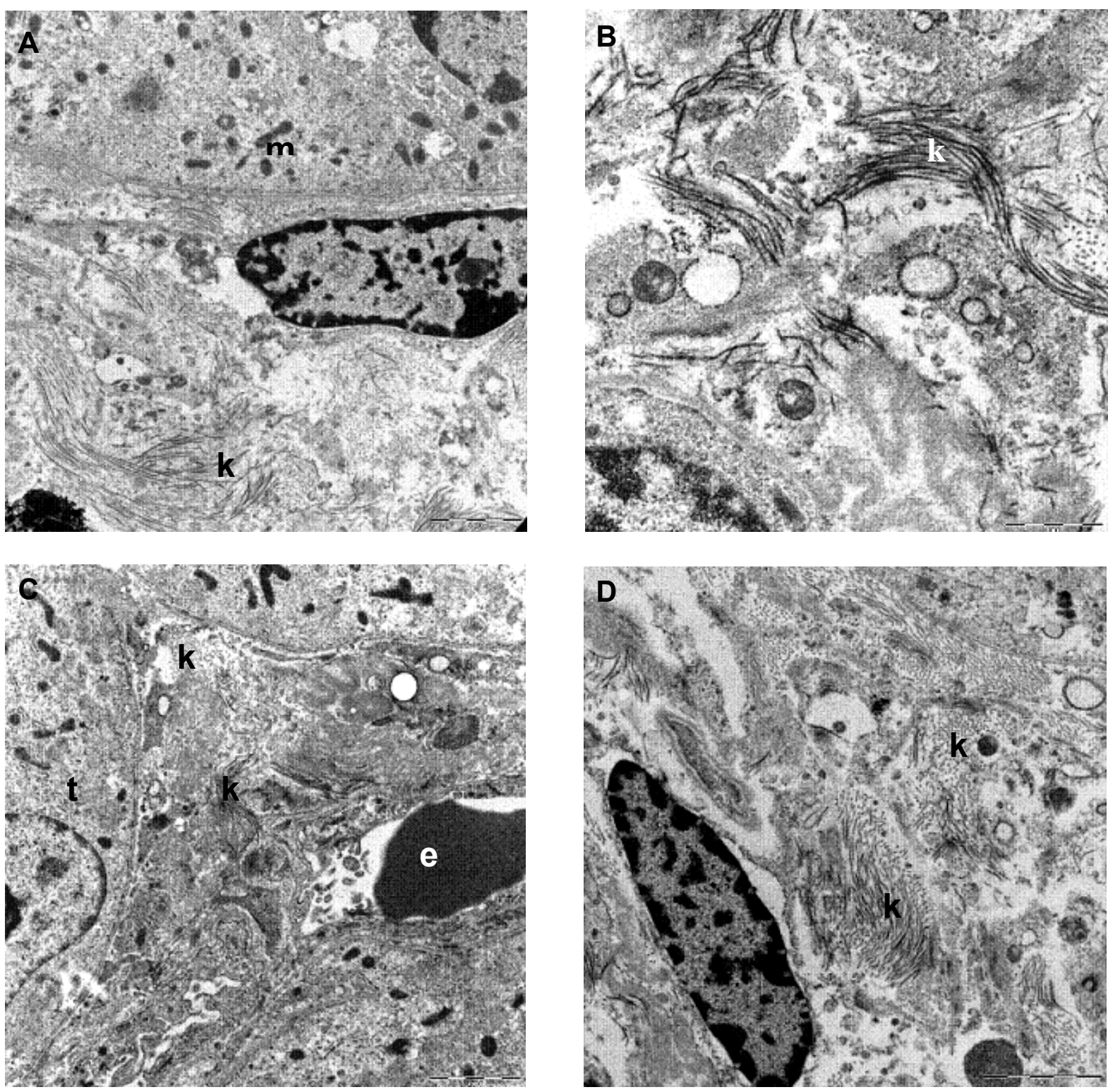

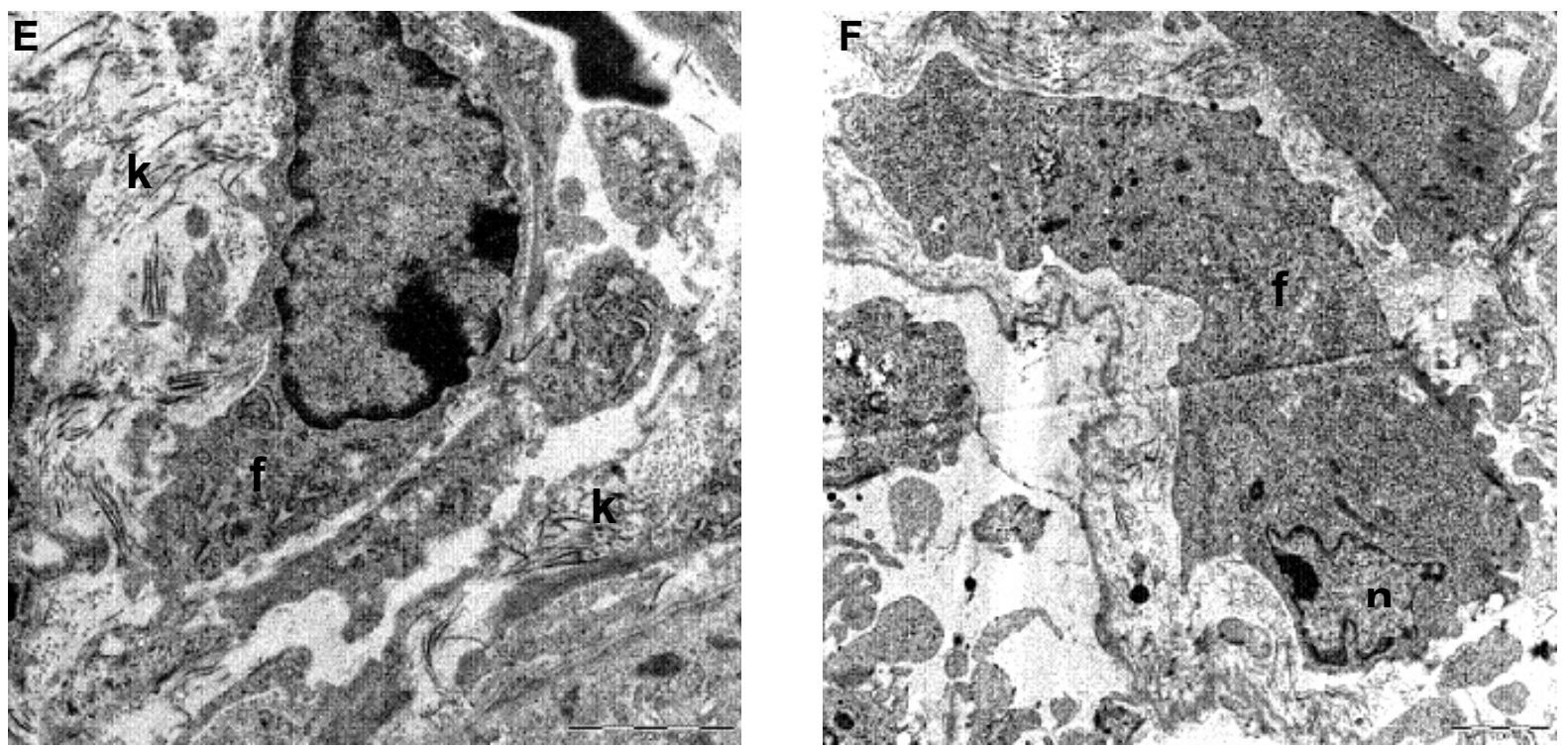

Abb. 29 Exemplarische Darstellung elektronenmikroskopischer Aufnahmen. Ausmaß der Synthese kollagener Fasern im Interstitium der Nieren der Versuchstiere

Dargestellt sind Ausschnitte aus dem Nierengewebe behandelter Mäuse unterschiedlicher Therapiegruppen: $10 \mathrm{mg} / \mathrm{kg} / \mathrm{d}$ (A), $50 \mathrm{mg} / \mathrm{kg} / \mathrm{d}$ (B,C), $100 \mathrm{mg} / \mathrm{kg} / \mathrm{d}$ (D-F). Die kollagenen Fasern sind z. T. quer, z. T. längs angeschnitten. $F=$ Fibroblast, $k=$ kollagene Fasern, $m=$ Mitochrondrien, $n=$ Nucleus, $\mathrm{t}=$ Tubulus.

\subsubsection{Ergebnisse der immunhistochemischen Untersuchung}

Die immunhistochemische Untersuchung wurde zur Überprüfung möglicher Unterschiede zwischen den unbehandelten und behandelten Versuchstieren bezüglich ihrer renalen Expression von Laminin, einem Glykoprotein und Bestandteil sämtlicher Basalmembranen, durchgeführt. Laminine dienen als Zelladhäsionsproteine, indem sie Bindungsstellen für Zelloberflächenrezeptoren aufweisen und stellen somit eine wichtige Komponente der extrazellulären Matrix dar.

Die dargestellten tubulointerstitiellen Aufnahmen der mit Laminin gefärbten Nieren je eines unbehandelten und eines mit der Höchstdosis von $150 \mathrm{mg} / \mathrm{kg} / \mathrm{d}$ MMF behandelten Versuchstieres erlauben einen repräsentativen Eindruck über den jeweiligen Grad der renalen Schädigung (Abb. 30 A, B). Sowohl die Niere der Placebo- als auch der behandelten Maus weisen deutliche Zeichen einer bereits fortgeschrittenen Organfibrose auf. Während gesunde Nieren durch eine dünne 
glomeruläre und tubuläre Basalmembran gekennzeichnet sind, lassen sich bei beiden Präparaten eine vermehrte Ablagerung extrazellulärer Matrixbestandteile durch die Laminin-Färbung darstellen. Dennoch erscheint das Nierenparenchym der behandelten Maus im Vergleich zu der unbehandelten Maus weniger stark geschädigt, impliziert durch ein insgesamt schwächeres fluoreszierendes Signal. Das Tubulussystem der behandelten Maus imponiert insgesamt dünnwandiger und damit weniger stark fibrotisch. Im Gegensatz zur behandelten Maus, bei der das Interstitium in seiner Menge reduziert erscheint, ist bei der unbehandelten Maus der Abstand zwischen den einzelnen Tubuli deutlich größer, d.h. eine interstitielle Substanzvermehrung liegt hier vor. Insgesamt konnten in den exemplarisch dargestellten Aufnahmen allenfalls andeutungsweise Unterschiede im Fibrosierungsgrad festgestellt werden.

\section{Dosis MMF}

\section{$0 \mathrm{mg} / \mathrm{kg} / \mathrm{d}$}

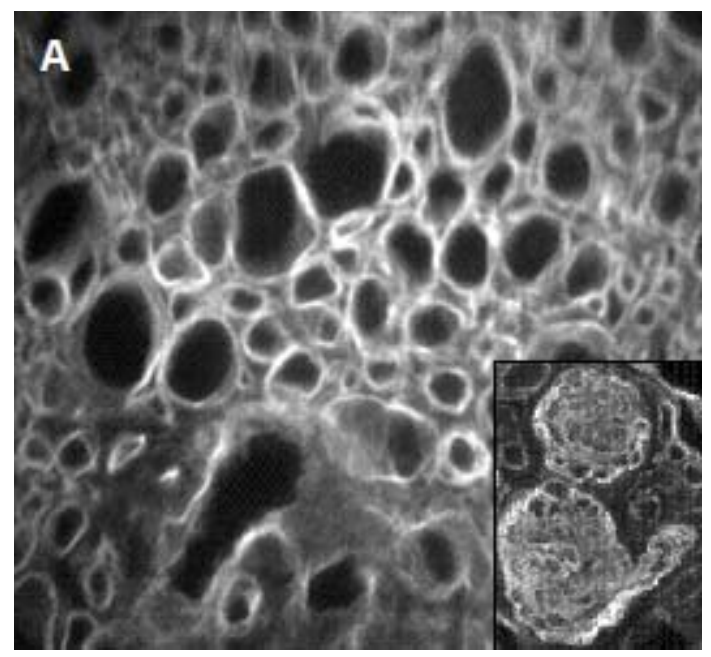

$150 \mathrm{mg} / \mathrm{kg} / \mathrm{d}$

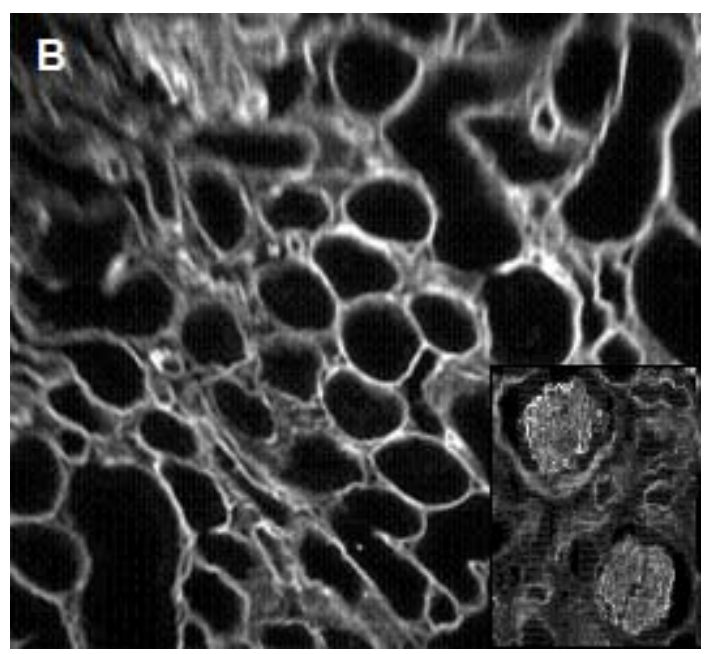

Abb. 30 Immunhistochemie. Exemplarische Gegenüberstellung repräsentativer Aufnahmen einer unbehandelten und einer behandelten Maus

In der Übersichtsaufnahme dargestellt ist die tubulointerstitielle Ablagerung extrazellulärer Matrix mittels Laminin-1-Färbung in einer unbehandelten Maus (A) und einer mit $150 \mathrm{mg} / \mathrm{kg} / \mathrm{d}$ MMF behandelten Maus (B), sowie vergrößert je zwei Glomerula einer unbehandelten (A) und einer behandelten Maus (B). 40 x Vergrößerung. 


\section{Diskussion}

Wie bereits beschrieben konnte in zahlreichen in-vitro-Experimenten das antifibrotische Potential von MPA erfolgreich nachgewiesen werden (Badid et al. 2000, Baer et al. 2000, Dubus et al. 2002). Diese antiproliferativen und antifibrotischen Effekte von MPA konnten in mehreren tierexperimentellen Studien bestätigt werden (Fujihara et al. 1998, Romero et al. 1999, Badid et al. 2000). Im Kontext der beschriebenen Literatur können folgende antifibrotische und protektive Effekte von MMF auf die Organfunktion zusammengefasst werden:

1.) Inhibition der Lymphozytenproliferation und -infiltration mit konsekutiver Inhibition der Makrophagenakkumulation im Nierenparenchym (Fujihara et al. 1998)

2.) verminderte Expression von Adhäsionsmolekülen und dadurch bedingt reduzierte Infiltration von Lymphozyten und Monozyten (Romero et al. 1999)

3.) verringerte Produktion von Zytokinen und Wachstumsfaktoren vor allem von TGFß, platelet-derived growth factor und TNF $\alpha$ (Romero et al. 1999)

4.) Reduktion der Myofibroblasteninfiltration und folglich reduzierte interstitielle Akkumulation von Kollagen Typ III (Badid et al. 2000).

All diese Erkenntnisse führten erstmals zu der Hypothese, dass MMF die Entwicklung einer Fibrose hemmen und somit therapeutisch bei einer progredienten Organfibrosierung eingesetzt werden könnte.

Im Rahmen dieser Arbeit wurde das antifibrotische Potential von MycophenolatMofetil bzw. seines aktiven Metaboliten Mycophenolsäure unter der Verwendung von renalen Fibroblasten (COS-7-Zellen) in vitro und anhand COL4A3-defizienter Mäuse als Modell für eine progrediente renale Fibrose in vivo untersucht.

\subsection{Die antifibrotische Wirkung von MMF auf COS-7-Zellen}

In COS-7-Zellen, einem Modell für Nierenfibroblasten, wurden die Effekte von MPA auf die Proliferation und Funktion sowie daran beteiligte Signalwege untersucht. 
Im Rahmen dieser Experimente bestätigte sich das dosisabhängige inhibitorische Potential von MPA auf die Fibroblastenproliferation (3.1.1). Die maximale Inhibition lag hierbei bei ca. $50 \%$ und wurde mit einer MPA-Konzentration von $10 \mu \mathrm{mol} / /$ und höher erreicht. Bereits in humanen Lungenfibroblasten konnte das antiproliferative Potential von MPA nachgewiesen werden, wobei die $50 \%$ Inhibition der Fibroblastenproliferation hierbei mit einer MPA-Konzentration von 0,3 mg/l ( $1 \mu \mathrm{mol} / \mathrm{l})$ erreicht worden war (Azzola et al 2004). In anderen in-vitro-Experimenten mit Rattenfibroblasten aus der Haut wurde in Übereinstimmung mit unseren Ergebnissen eine $50 \%$ Inhibition der Proliferation mit einer MPA-Konzentration von $10 \mu \mathrm{mol} / \mathrm{l}$ und höher erreicht (Badid et al. 2000). Dies entspricht üblicherweise auch der Therapie der mit MMF erreichten MPA-Spiegel. Des Weiteren konnte im Rahmen unserer Experimente die proliferationsinhibitorische Wirkung auch für den Metaboliten AcMPAG nachgewiesen werden, jedoch waren höhere Konzentrationen von AcMPAG nötig, um vergleichbare Effekte zu erzielen. Dies ist vereinbar mit Angaben in der Literatur, in denen postuliert wurde, dass das Acylglucuronid zwar ebenso wie MPA über eine nicht-kompetitive Inhibition der IMPDH wirkt, jedoch mit geringerer Potenz (Gensburger et al. 2009). Weiterhin konnte die vollständige Antagonisierbarkeit der MPA- und AcMPAG-vermittelten Effekte auf die Fibroblastenproliferation durch die Zugabe von Guanosin/8-Aminoguanosin gezeigt werden.

Mit Hilfe des Wundverschluss-Assays konnte die inhibitorische Wirkung des MPA auf die Fibroblastenfunktion demonstriert werden, indem MPA die Fibroblastenmotilität hemmte (3.1.2). Dieser Effekt konnte durch Guanosin/8-Aminoguanosin ebenfalls vollständig aufgehoben werden. Die Reversibilität der Wirkung von MPA auf die Zellproliferation durch die Zugabe von Guanin bzw. Guanylat konnte bereits in vorherigen Experimenten mit anderen Zelllinien demonstriert werden (Franklin und Cook 1969, Lowe et al. 1977); die Reversibilität der Inhibition des Wundverschlusses durch Guanosin/8-Aminoguanosin konnte jedoch hier erstmalig gezeigt werden.

Der Einfluss von MPA auf die Fähigkeit der Fibroblasten zur Kontraktion der frei flottierenden Kollagenfasern wurde mittels des Kollagen-Kontraktionstestes untersucht (3.1.3). MPA hemmte hierbei die Fibroblasten zur adäquaten Kontraktion der Kollagenfasern. Nach einem Beobachtungszeitraum von $96 \mathrm{~h}$ war die Fläche der Kollagenmatrix mit einer MPA-Konzentration von $100 \mu \mathrm{mol} / \mathrm{l}$ etwa $30 \%$ größer als die Kontrollfläche ohne MPA. Im Gegensatz zu den vorherigen Experimenten auf die 
Zellproliferation und -funktion konnte hierbei die Wirksamkeit von MPA nicht vollständig durch Guanosin/8-Aminoguanosin aufgehoben werden. Bis dato wird angenommen, dass MPA einzig über die unkompetitive Inhibition der IMPDH wirkt. Die vorliegenden Ergebnisse legen im Gegensatz dazu nahe, dass die Effekte des MPA auf die Kontraktionsfähigkeit der Fibroblasten nicht durch Guanosin/8Aminoguanosin aufgehoben werden konnten. Dies ist ein Hinweis auf einen möglichen IMPDH-unabhängigen Wirkungsmechanismus.

Zusammenfassend belegen diese Ergebnisse eine IMPDH-abhängige Inhibition der Fibroblastenproliferation und des Wundverschlusses durch MPA sowie eine unerwartete IMPDH-unabhängige Inhibition der Kollagen-Kontraktion.

Zur Identifizierung der zellulären Signale, die an einer möglichen IMPDHunabhängigen Wirkung beteiligt sein könnten, wurden die Genexpressionen von unterschiedlichen Zytokinen in Abhängigkeit von MPA und Guanosin/8Aminoguanosin untersucht (3.1.4).

Maßgeblich an der Pathogenese der Fibrose beteiligt, sind vor allem die Zytokine TGFß1 und CTGF. Da bereits gezeigt werden konnte, dass CTGF die renale Fibroblastenproliferation und die Synthese extrazellulärer Matrix induziert (Frazier et al. 1996) und MPA die Zellproliferation inhibiert, wurde die Supprimierung der mRNA-Expression von CTGF durch MPA hypothetisiert. Interessanterweise bestätigte sich zunächst die signifikante IMPDH-unabhängige Suppression der Expression von CTGF nach $6 \mathrm{~h}$. Im Gegensatz dazu zeigte sich im Verlauf und deutlich nach $24 \mathrm{~h}$ eine signifikante Induktion der Genexpression, welche zudem IMPDH-abhängig zu sein scheint. Daher ist vor allem eine antifibrotische Wirkung des MPA innerhalb der ersten $6 \mathrm{~h}$ auf die Zellen anzunehmen.

TGFß1 stellt durch seine Fähigkeit zur Induktion von Zellproliferation und differenzierung sowie zur Bildung extrazellulärer Matrix ein wichtiges fibroseassoziiertes Zytokin dar. In mehreren Experimenten konnte bereits gezeigt werden, dass das antifibrotische Potential von MPA durch eine Suppression der TGFß1-Expression bedingt war (Waller et al. 2005, Copeland et al. 2007). Im Gegensatz dazu führte im Rahmen unserer Experimente die Behandlung mit MPA erstaunlicherweise zu allen Zeitpunkten zur Induktion der Genexpression von TGFß1, die vor allem spätzeitig ( $\geq 24 \mathrm{~h}$ ) eindeutig signifikant war. 
Des Weiteren bewirkte MPA eine leichte Induktion der Genexpression von COL1A1. Diese verstärkte Genexpression steht jedoch einerseits im Gegensatz zu der gezeigten signifikanten Hemmung der Fibroblasten zum Wundverschluss unter der Behandlung mit MPA, anderseits $\mathrm{zu}$ der in der Literatur beschriebenen MMFbedingten Abnahme der Genexpression von COL1A1 und einer verringerten Bildung von Kollagen 1 (Ross et al. 2007).

IL-6 ist als multifunktionelles Zytokin an immunologischen Prozesse beteiligt und wird vor allem unter inflammatorischen Bedingungen verstärkt exprimiert (Hirano et al. 1990). Es konnte bereits gezeigt werden, dass IL-6 die Proliferation von Mesangiumzellen induziert und mit der Entstehung einer Fibrose assoziiert ist (Horii et al. 1989, Kovacs 1991). Inhibitorische Effekte von MPA auf die IL-6-Expression von humanen renalen Tubulusepithelzellen und Mausfibroblasten konnten ebenso bereits gezeigt werden (Miljkovic et al. 2002, Baer et al. 2004). Im Rahmen unserer Experimente zeigte sich ebenso eine leichte, zu keinen Zeitpunkten jedoch signifikante Suppression der IL-6-Expression. Ebenso proinflammatorisch wirkt TNFa. MPA bewirkte im Gegensatz zur supprimierten Expression von IL-6 eine leichte Induktion der Genexpression von TNFa .

Zusammenfassend lässt sich feststellen, dass unsere Ergebnisse bezüglich der Expression profibrotischer Gene teilweise gegensätzlich zu den bereits veröffentlichten Daten sind. Daraus lässt sich ableiten, dass im Rahmen der Fibrogenese die Regulierung der Genexpressionen und die sich anschließenden Proteinsynthesen viel komplexer zu sein scheinen als bisher angenommen.

\subsection{Die antifibrotische Wirkung von MMF auf COL4A3-defiziente Mäuse}

Zur Untersuchung des antifibrotischen Potentials von MPA in vivo dienten homozygot COL4A3-defiziente Mäuse (COL4A3-/-) als Modell für eine chronisch progrediente renale Fibrose analog zur autosomalen Form des humanen AlportSyndroms (Cosgrove et al. 1996). Dieses Tiermodell ist seit 1996 etabliert und bietet zahlreiche Vorteile. In relativ kurzer Zeit kann eine große Anzahl von Versuchstieren generiert werden, die Genotypisierung mittels Schwanzbiopsie und anschließender PCR ist bereits vor dem Krankheitsausbruch möglich und durch die begrenzte Überlebenszeit der Versuchstieren von 10 Wochen sind zeitnahe Ergebnisse 
möglich. Das Mausmodell zeigt ein ähnliches Krankheitsgeschehen wie das AlportSyndrom im Zeitraffermodell. Ab der 4. Woche kommt es zur Hämaturie, ab der 6. Woche zur Proteinurie und ab der 8 . Woche setzt die progrediente Niereninsuffizienz bis zum Erreichen des terminalen Organversagens ein. Da bei diesem Mausmodell die Nierenfibrose zuverlässig durch den genetischen Defekt verursacht wird, sind im Gegensatz zu anderen etablierten Tiermodellen, wie beispielsweise dem Remnant Kidney Model oder dem Modell der unilateralen Ureterobstruktion (UUO), keine vorherigen operativen Interventionen notwendig. Das COL4A3-defiziente Mausmodell stellt außerdem das einzige nicht-hypertensive, nicht-inflammatorische Tiermodell der chronisch progredienten Nierenerkrankung dar (Gross et al. 2004). Beim Alport-Syndrom als hereditäre Nephropathie führen Mutationen in den Genen COL4A3-A5, welche für die $\alpha 3-\alpha 5-K e t t e n$ des Typ IV-Kollagens kodieren, zum defekten Kollagen Typ IV, einem Hauptbestandteil der glomerulären Basalmembran. Der normale trilamelläre Aufbau der glomerulären Basalmembran ist gestört und es imponieren Aufsplitterungen und Lamellierungen der ebenfalls verbreiterten glomerulären Basalmembran (Cangiotti et al. 1996). Daraus resultiert vermutlich kompensatorisch eine überschießende Produktion der extrazellulären Matrix und folglich eine Organfibrose, welche letztendlich zur terminalen Niereninsuffizienz führt. Der genaue Pathomechanismus von der defekten glomerulären Basalmembran über Fibrose zum Untergang der einzelnen Nephrone ist allerdings noch nicht eindeutig geklärt (Gross und Weber 2005). Da die $\alpha 3-\alpha 5-K e t t e n$ neben den Glomerula auch im Innenohr und Auge exprimiert werden, zählen zu den weiteren Symptomen des Alport-Syndroms neben Hämaturie und Proteinurie die bilaterale Innenohrschwerhörigkeit sowie Augenveränderungen (Hudson et al. 2003).

\subsubsection{Der Einfluss von MMF auf die Überlebenszeit}

$\mathrm{Ab}$ der 6. Woche postnatal wurden die Versuchstiere bis zum Erreichen der terminalen Niereninsuffizienz mit unterschiedlichen Dosen oral verabreichtem MMF gewichtsadaptiert behandelt. Die unbehandelten Versuchstiere zeigten eine mittlere Überlebenszeit von 67 Tagen mit nur geringer Standardabweichung, was mit der in der Literatur genannten Überlebenszeit COL4A3-defizienter Mäuse übereinstimmt und somit die Reproduzierbarkeit dieses Tiermodells bestätigt (Gross et al. 2003). 
Eine progrediente Gewichtsabnahme erfolgte dabei fast ausnahmslos bei allen Versuchstieren, wobei keine Unterschiede zwischen den einzelnen Gruppen beobachtet werden konnten. Eine signifikante Verlängerung der Überlebenszeit durch MMF behandelter Versuchstiere gegenüber den unbehandelten Tieren konnte nicht festgestellt werden (3.2.1, S. 59-60).

\subsubsection{Der Einfluss von MMF auf die Nierenhistologie}

Die histologische Untersuchung ausgewählter Nieren behandelter als auch unbehandelter Versuchstiere zeigte im groben Vergleich zueinander bezüglich der Glomerulumsklerose keine wesentlichen Unterschiede auf. Der Anteil der massiv fibrotisch geschädigten Glomerula (Grad 3+) nahm mit steigender MMF-Dosis geringfügig um etwa $18 \%$ ab (3.3.1, S. 72), letztendlich konnte jedoch bei allen Versuchstieren eine glomeruläre Fibrose festgestellt werden. Erstaunlicherweise nahm der Schweregrad der tubulointerstiellen Fibose mit zunehmender MMFKonzentration signifikant ab, so dass insgesamt bei der Hochdosisgruppe eine leichte bis mäßige tubulointerstitielle Fibrose dominierte. Die immunhistochemische Untersuchung der Nieren bezüglich ihrer Expression von Laminin, einem Bestandteil der Basalmembranen, ergab lediglich andeutungsweise Unterschiede im Fibrosierungsgrad (3.3.3, S. 80). Alles in allem ist daher insgesamt davon ausgehen, dass es zum Zeitpunkt des Todes der Versuchstiere keine wesentliche Unterschiede im Ausmaß der glomerulären Schädigung gab, wogegen die tubulointerstitielle Schädigung durch MMF deutlich reduziert werden konnte.

\subsubsection{Der Einfluss von MMF auf die Nierenfunktion}

Von insgesamt 24 Versuchstieren konnte Blut für weitere diagnostische Zwecke gewonnen werden. So erfolgte die Bestimmung von Gesamtprotein, Kreatinin und Harnstoff-N in den gewonnenen Seren (3.2.3.2, S. 64). Erstaunlicherweise ging der hochdosierte Einsatz von MMF mit signifikant niedrigeren Kreatinin- und Harnstoff-NKonzentrationen einher. So konnte durch die tägliche Gabe von MMF im Vergleich zu den unbehandelten Versuchstieren die mittlere Kreatinin-Konzentration um mehr als $50 \%$, die mittlere Harnstoff-N-Konzentration sogar um mehr als $60 \%$ reduziert 
werden, wobei sich interessanterweise eine hochsignifikante reziproke Korrelation zwischen den MPA-Konzentrationen und den Kreatinin-Konzentrationen feststellen ließ. Die eindeutig verringerten Retentionsparameter sind Hinweise auf eine verbesserte Nierenfunktion durch die Behandlung mit MMF.

Demnach konnte ein positiver therapeutischer Effekt von MMF auf die Nierenfunktion, nicht jedoch auf die Überlebenszeit der COL4A3-defizienten Mäuse festgestellt werden. Dies könnte durch mehrere Ursachen erklärbar sein. Zum einen ist es denkbar, dass das Ausmaß des Nierenschadens bereits bei Therapiebeginn in der 6. Woche postnatal zu groß war. Im Rahmen der präventiven Therapie COL4A3defizienter Mäuse mit dem ACE-Hemmer Ramipril konnte gezeigt werden, dass die nephroprotektive Wirkung entscheidend vom Zeitpunkt des Therapiebeginns abhängt. Während die Behandlung ab der 4. Lebenswoche durch Hemmung der Proteinurie und interstitiellen Fibrose zur signifikanten Überlebenszeitverlängerung führte, konnte durch die Behandlung ab der 7. Lebenswoche zwar eine verringerte Proteinurie, aber keine Verbesserung der interstitiellen Fibrose und des Gesamtüberlebens erreicht werden (Gross et al. 2003). Ebenso führte in einem invivo-Modell der membranösen Glomerulopathie nur die frühzeitige Behandlung mit MMF zur Verhinderung einer massiven Proteinurie, nicht jedoch bei Therapiebeginn 4 Wochen nach Krankheitsinduktion und später (Penny et al. 1998). Daher ist es denkbar, dass im Rahmen dieses Projektes die Therapieeinleitung zum Erreichen der MMF-vermittelten antifibrotischen Effekte möglicherweise zu spät statt fand. Eine Therapieeinleitung vor Manifestation der Proteinurie erscheint erstrebenswert.

Eine weitere mögliche Ursache für das Fehlen einer Wirksamkeit des MMF auf das Überleben der Versuchstiere ist eine zu gering gewählte Höchstdosis. Bei Mäusen beträgt die mittlere letale Dosis (LD 50) der Mycophenolsäure bei peroraler bzw. intraperitonealer Darreichung über $1000 \mathrm{mg} / \mathrm{kg}$ (Williams et al. 1968), anderswo wird die LD 50 sogar mit $2500 \mathrm{mg} / \mathrm{kg}$ angegeben (Weidenbörner 1999). Die hier verwendete Höchstdosis von MMF betrug $150 \mathrm{mg} / \mathrm{kg} / \mathrm{d}$, demnach könnten im Rahmen dieses Experimentes die Versuchstiere unterdosiert sein. Weiterführende Experimente mit höheren Dosen sind denkbar, da gezeigt werden konnte, dass Mäuse im Gegensatz zu anderen Tieren wie Ratten oder Hunde unempfindlicher gegenüber dem MMF sind (Platz et al. 1990, Heller et al. 2008). Bei Ratten führte bereits die Gabe von MMF in einer Dosis von $40 \mathrm{mg} / \mathrm{kg} / \mathrm{d}$ zu Diarrhoe, Dehydratation und Gewichtsverlust. Die von uns gewählten Dosen von MMF im Tiermodell waren 
im Vergleich zu den therapeutisch eingesetzten Dosen am Menschen verhältnismäßig hoch. So erhalten beispielsweise nierentransplantierte Patienten zur Prävention einer akuten Abstoßungsreaktion MMF in einer Dosis von typischerweise 2-3 g/d, was bei einem durchschnittlich männlichen Erwachsenen mit 75 kg etwa 26$40 \mathrm{mg} / \mathrm{kg} / \mathrm{d}$ entspricht. Demnach erhielten die Versuchstiere in der Hochdosisgruppe nahezu die 4-fache Dosis, ohne jedoch dass es dabei zu relevanten Nebenwirkungen kam. Auch die beobachteten MPA-Konzentrationen im Serum waren sehr hoch. Die Werte sind dabei als Predose-Konzentrationen zu betrachten, da die Versuchstiere vor der nächsten Gabe getötet wurden. Der vorläufige therapeutische Bereich der Predose-MPA-Konzentration in der frühen Phase nach erfolgter Nierentransplantation in Kombination mt Cyclosporin liegt bei 1,0-3,5 mg/l (Shaw et al. 2001). In unseren Experimenten lag dagegen die maximale beobachtete MPA-Konzentration bei $26,5 \mathrm{mg} / \mathrm{l}$, ohne dass nennenswerte Nebenwirkungen beobachtet wurden. Auch die Untersuchung der Proteinexpression von ANXA 5, einem Apoptosemarker, ergab keine Unterschiede zwischen den einzelnen Versuchsgruppen. Nach unseren Ergebnissen ist nicht von einem Apoptoseinduzierenden Effekt des MMF bis zu einer Konzentration von 150 mg/kg/d auszugehen. Auch in einer Studie, welche antiproliferative Effekte von MMF auf Mesangiumzellen zeigte, ließ sich keine Apoptose nachweisen (Hauser et al. 1999). Dies steht im Gegensatz zu der oftmals beschriebenen Zelltod-induzierenden Wirkung von MPA auf gewisse Zelllinien (Jonsson und Carlsten 2001, Heller et al. 2009).

Da die Löslichkeit des MMF in seiner Trägersubstanz jedoch begrenzt ist, könnte die Verabreichung des MMF in höheren Dosen per os aber auch mittels intraperitonealer bzw. intragastraler Injektion ein schwieriges Problem darstellen. Alternativ ist die Kombination des MMF mit einem weiteren antifibrotisch wirksamen Medikament, z. B. einem ACE-Hemmer oder AT1-Antagonisten, zu erwägen. So wäre eine additive oder synergistische Potenz der antifibrotischen Wirkung ohne erhöhte Toxizität möglich. 


\subsubsection{Der Einfluss von MMF auf die Proteinexpression von TGFß1}

Konnte bei den COS-7-Zellen eine gesteigerte TGFß1-Genexpression durch MPA gezeigt werden, bewirkte MMF bei allen behandelten Versuchstieren im Vergleich zur Placebogruppe eine herabgesetzte Expression von TGFß1. Zwar war die Supprimierung der Proteinexpression nur für die $50 \mathrm{mg} / \mathrm{kg} / \mathrm{d}$ Gruppe statistisch signifikant, dennoch scheint eine fallende Tendenz der reduzierten Proteinsynthese mit steigenden MMF-Konzentrationen sichtbar. Die fehlende statistische Relevanz vor allem für die Hochdosisgruppe $(p=0,051)$ ist womöglich durch eine verminderte Zahl an zur Verfügung stehenden Organen durch unerwarteten Tod der Versuchstiere erklärbar. Möglicherweise könnte die verstärkte Expression von TGFß1 auf mRNA-Ebene einen reflektorischen Kompensationsmechanismus zur abgeschwächten Proteinsynthese darstellen.

\subsection{MMF und seine mögliche Bedeutung in der antifibrotischen Therapie}

Obwohl die Organfibrose und deren Pathogenese nun schon mehr als zwei Dekaden intensiv erforscht wird, gibt es momentan noch keine etablierten Behandlungsmöglichkeiten, die direkt in den Pathomechanismus der Fibrose eingreifen. Zum einen gehen unerwünschte Fibrose und erwünschte Wundheilung ineinander über, zum anderen sind die zugrundeliegenden Regulierungswege komplex und betreffen eine Vielzahl von unterschiedlichen Zelltypen und Mediatoren. Im Gegensatz zur physiologischen Wundheilung terminiert die Fibrose nicht. Hat der entstandene Schaden erst einmal ein gewisses Ausmaß erreicht, ist die Progression des Fibroseprozesses stetig, irreversible und weitgehend unabhängig von der initialen Ursache (Nangaku 2002). Die Neusynthese an Kollagen übertrifft dessen Degradation, so dass eine exzessive Matrixakkumulation und folglich eine Verschlechterung der renalen Funktion bis zur terminalen Organinsuffizienz resultiert. 


\subsubsection{Strategien in der antifibrotischen Therapie}

Fibrose wird als Folge chronisch inflammatorischer Reaktionen angesehen, wobei die induzierenden Reize vielfältig sein können (Wynn 2007). Den meisten chronisch fibrotischen Erkrankungen liegt ein persistierender Schädigungsreiz (z. B. Hypertonie, Hyperglykämie, Infektionen, Autoimmunreaktionen etc.) zugrunde, der die kontinuierliche Produktion von profibrotischen Zytokinen und Wachstumsfaktoren aufrechterhält und somit zur inadäquat gesteigerten Matrixakkumulation und damit zur progressiven Zerstörung der physiologischen Gewebsarchitektur führt. Dies resultiert in einer progredienten Organinsuffizienz und letztendlich in terminalem Organversagen. Derzeitige antifibrotische Behandlungen zielen daher typischerweise auf die Entzündungsreaktion. So werden beispielsweise zur Therapie der Lungenfibrose vorwiegend Glukokortikoide und Immunsuppressiva wie Cyclophosphamid oder Azathioprin zur Entzündungshemmung und damit der Prävention einer progredienten Fibrosierung eingesetzt; dies gelingt jedoch nur mit geringfügiger Wirksamkeit (Lasky und Ortiz 2001). Obwohl typischerweise inflammatorische Prozesse der Fibrosebildung vorausgehen, ist anzunehmen, dass die Fibrose nicht immer durch eine persistierende Inflammation gekennzeichnet ist (Wynn 2008). Dies impliziert deutliche Unterschiede zwischen den fibrose- und inflammationsregulierenden Mechanismen.

Grundsätzlich gibt es im Rahmen der antifibrotischen Therapie zwei Angriffspunkte: zum einen die Bindegewebs-produzierenden Zellen per se, zum anderen den an der Fibrogenese beteiligten Signalweg. Diverse Zytokine, Chemokine, Wachstumstumsfaktoren und angiogenetische Faktoren konnten als wichtige Regulatoren der Fibrose identifiziert werden und stellen somit potentielle Angriffspunkte zur Inhibierung oder Modulierung des Signalweges dar.

\subsubsection{Therapeutische Optionen bei renaler Fibrose}

In den letzten Dekaden sind mehrere Behandlungsmöglichkeiten zur Aufhaltung bzw. Verlangsamung der Progredienz chronischer Nephropathien bis hin zum terminalen Nierenversagen untersucht worden. Für immunologisch-vermittelte Nephropathien wie der Lupus-Nephritis oder der IgA-Nephritis stehen Immunsuppressiva zur Verfügung, um die Proliferation der inflammatorischen Zellen zu hemmen. Dem 
gegenüber stehen die nichtimmunologisch-vermittelten Nephropathien, die ohne Vorliegen einer immunologischen Ursache progredient verlaufen. Hierzu zählen beispielsweise die diabetische und hypertensive Nephropathie sowie die fokalsegmentale Glomerulumsklerose, die zusammen bereits mehr als $80 \%$ der terminalen Niereninsuffizienzen in den Vereinigten Staaten ausmachen (Zatz et al. 2002). Es konnte gezeigt werden, dass hämodynamischer Stress einen bedeutenden proinflammatorischen Stimulus darstellt, welcher die Proliferation von Mesangiumzellen, die Produktion von extrazellulärer Matrix sowie die gesteigerte Synthese von Wachstumsfaktoren fördert (Zatz 1996). Derzeitige therapeutische Strategien zur Verhinderung der Progredienz nichtimmunologisch-vermittelter Nephropathien zielen daher vor allem auf eine Verbesserung der hämodynamischen Bedingungen. Es konnte gezeigt werden, dass Angiotensin II eine entscheidende Rolle in der Entwicklung der renalen Fibrose spielt (Mezzano et al. 2001). Derzeit steht als antifibrotische Option bei fibroseassoziierten renalen Erkrankungen einzig die Blockierung des Angiotensin II zur Verfügung. Dies kann zum einen durch ACEHemmer erreicht werden, welche das ACE (Angiotensin-converting-enzyme) blockieren und damit die Umwandlung von Angiotensin I in Angiotensin II inhibieren; zum anderen durch Angiotensin-II-Antagonisten, die die Wirkung von Angiotensin II am AT1-Rezeptor inhibieren. Durch Angiotensin-II-Blockade konnte eine Verlangsamung der Progredienz chronischer Nierenerkrankungen, nicht jedoch eine Beendigung des Krankheitsgeschehens erreicht werden (Maschio et al. 1999, Yu et al. 2002). Die Kombination von Medikamenten lieferte erste therapeutische Vorteile gegenüber der alleinigen Angiotensin-II-Blockade. So gelang eine verstärkte Abschwächung der renalen interstitiellen Fibrose durch die Kombination aus Gentherapie mit HGF (hepatocyte growth factor) und Angiotensin-II-Blockade im Tierexperiment (Yang et al. 2002) sowie ein verstärkter antifibrotischer Effekt durch die Kombination aus TGFß1-neutralisierenden Antikörpern (1D11) und AngiotensinIl-Blockade im Rahmen des Anti-Thy1-Modell der Glomerulonephritis (Yu et al. 2004). Aber auch hier mißlang die vollständige Beendigung des Fibroseprozesses.

Ein weiterer Pfeiler in der antifibrotischen Therapie stellt die Restriktion der täglichen Proteinzufuhr dar. Die dabei empfohlene Proteinzufuhr beträgt dabei je nach Literaturquelle zwischen 0,6 bis $0,8 \mathrm{~g} / \mathrm{kg} \mathrm{KG/d}$. Eine Proteinurie beschleunigt das Fortschreiten der Niereninsuffizienz, da es die Entwicklung einer Glomerulumsklerose durch direkte zytotoxische Wirkungen, aber auch durch 
Aktivierung von Mesangiumzellen und Aufrechterhaltung einer Inflammation über Zytokine und Komplementfaktoren fördert (Abbate et al. 2006).

Die Vermeidung von potentiell nephrotoxischen Medikamenten und anderer Noxen wie beispielsweise Kontrastmittel sind ebenfalls wichtige Bestandteile der konservativen antifibrotischen Therapie.

\subsubsection{Stellenwert des TGFß in der antifibrotischen Therapie}

In der Pathogenese der Fibrose nimmt vor allem TGFß1 als profibrotisches Antigen eine Schlüsselposition ein (Zeisberg et al. 2001). Die Überproduktion dieses Zytokins resultiert in einer gesteigerten Matrixsynthese und verminderten -degradation sowie in einer vermehrten Produktion von Integrinen, welche die Vernetzung von Zellen mit der extrazellulären Matrix ermöglichen. Daher ist anzunehmen, dass die Höhe der TGFß1-Konzentration mit dem Ausmaß der Fibrose korreliert. Der protektive Effekt der Inhibition des Renin-Angiotensin-Systems in experimentellen und humanen Nierenerkrankungen war eng mit der Suppression der TGFß-Produktion verbunden (Okuda et al. 1991, Ohta et al. 1994, Border und Noble 1998). Dies suggerierte TGFß1 als potentiellen Angriffspunkt in der antifibrotischen Therapie. Die Vermittlung der Effekte von TGFß1 erfolgt über äußerst komplexe Signalwege. Diese Komplexität bietet auf der anderen Seite aber auch mehrere potentielle Angriffspunkte für antifibrotische Therapien. In mehreren tierexperimentellen Modellen renaler Fibrose wurden unterschiedliche Strategien untersucht, um TGFß zu blockieren. Dabei gelang eine verminderte Progression der chronischen Nierenerkrankungen durch spezifische Inhibition von TGFß1 durch AntisenseOligonukleotide (Isaka et al. 2000), durch lösliche TGFß Typ-II-Rezeptoren (Isaka et al. 1999) oder durch das Proteoglykan Dekorin, welches TGF bindet (Isaka et al. 1996). Ebenso konnte eine reduzierte renale Fibrose durch Überexpression von Smad7, einem TGFß1-Rezeptor-Antagonisten und damit potenten Inhibitor der Signaltransduktion von TGFß, erreicht werden (Lan et al. 2003, Hou et al. 2005). Der TGFß1/Smad-Signalweg ist in der Pathogenese der renalen Fibrose von großer Bedeutung. Durch die Fähigkeit von Smad7 zur Abschwächung der renalen und vaskulären Sklerose könnte die Smad7-Gentherapie demnach eine sinnvolle therapeutische Strategie in der Prävention der renalen Fibrose darstellen. Eine 
vollständige Blockade des TGFß1-Signalweges scheint dagegen mit schweren Nebenwirkungen einhergehen. So starben beispielsweise homozygot TGFßdefiziente Mäuse an einem multifokalen Inflammationssyndrom (Shull et al. 1992).

Zusammenfassend lässt sich feststellen, dass die Komplexität der TGFßRegulierung und seiner nachgeschalteten Signalwege zahlreiche spezifische Angriffspunkte zur Unterdrückung bzw. Modulation des Fibroseprozesses eröffnet und in den letzten Jahren erfolgsversprechende Strategien in unterschiedlichen Tiermodellen bereits untersucht werden konnten und derzeit untersucht werden.

\subsubsection{Mycophenolat-Mofetil und die Prävention der renalen Fibrose}

In einigen Arbeiten wurde bereits das antifibrotische Potential von MMF postuliert. So konnte gezeigt werden, dass MPA in vitro die Proliferation und Aktivierung von hepatischen Sternzellen hemmt, welche maßgeblich an fibrotischen Prozessen in der Leber beteiligt sind (Greupink et al. 2005). Aber auch im Bereich der diffusen Sklerodermie, charakterisiert durch eine progressive Fibrose der Haut und der inneren Organe, konnten antifibrotische Effekte des MMF beobachtet werden. Die Behandlung mit MMF bewirkte eine signifikante Verbesserung des Hautscores (Stratton et al. 2001) sowie eine Verringerung der pulmonalen Fibrose (Nihtyanova et al. 2007). Ebenso steht MMF bei der Behandlung der idiopathischen Lungenfibrose schon länger in Diskussion, zum einen durch seine antiinflammatorischen Fähigkeiten, zum anderen durch seine potente Inhibition der Proliferation von Lungenfibroblasten (Altschuler 2001).

Vielversprechende Ergebnisse zur Behandlung der renalen Fibrose konnten bereits in mehreren tierexperimentellen Modellen chronischer Nierenerkrankungen mit MMF als Kombinationspartner gezeigt werden. So führte die Kombinationstherapie aus Angiotensin-II-Blockade und MMF zur verstärkten renalen Protektion, indem über zwei verschiedene pathogenetische Mechanismen die Progredienz der Nierenschädigung gehemmt werden konnte (Remuzzi et al. 1999, Fujihara et al. 2000).

Unsere in-vitro-Experimente demonstrieren eindeutig das inhibitorische Potential von MMF auf die Proliferation und Funktion renaler Fibroblasten. In vivo konnte zwar keine verlängerte Überlebenszeit der behandelten Alport-Mäuse beobachtet werden, 
dennoch zeigte sich eine verbesserte Nierenfunktion, verdeutlicht durch die signifikant niedrigeren Kreatinin- und Harnstoff-N-Konzentrationen in der MMFHochdosisgruppe sowie tendenziell verbesserte Fibrose-Scores. Daher ist anzunehmen, dass MMF in der Lage ist, die Nierenfunktion zu verbessern bzw. aufrechtzuerhalten und stellt somit ein potentielles Medikament zur Erhaltung der Nierenfunktion bei progredient-fibrotischen Nierenerkrankungen dar.

Eine wichtige Rolle bei der renalen Fibrosebildung spielen die Ras-GTPasen. Sie gehören zur Ras-Superfamilie der kleinen GTP-bindenden Proteine und kontrollieren Zellproliferation, -differenzierung, -wachstum sowie deren Apoptose durch intrazelluläre Signaltransduktionswege (Martínez-Salgado et al. 2008). Diese Proteine werden durch GTP-Bindung aktiviert und durch Hydrolyse des gebundenen GTP zu GDP inaktiviert. Nach ihrer Aktivierung können intrazelluläre Signale übertragen werden. Es konnte gezeigt werden, dass renale Fibroblasten und Mesangiumzellen aktivierte Ras exprimieren, so dass sie eventuell ein Rolle als Mediatoren der renalen Fibrose spielen. Ebenso konnte gezeigt werden, dass die Hemmung der Ras-Signalwege in Fibroblasten eine Fibrose verhindern könnte. Die Aktivierung von Ras erfolgt über eine Reihe von Zytokinen, u.a. über TGFß1. Dadurch, dass MPA zum einen eine GTP-Depletion, zum anderen auch eine verringerte TGFß1-Expression bewirkt, wären MPA-bedingte antifibrotische Effekte denkbar. Eine verringerte Gen- und Proteinexpression von RhoA, einem Mitglieder der Ras-Familie, durch MMF konnte bereits gezeigt werden (Song et al. 2008).

MMF vereinigt mehrere wichtige Eigenschaften: es inhibiert die de-novoPurinsynthese und damit die Fibrosebildung, des Weiteren vermag MMF effektiv in die Fibrogenese einzugreifen. Damit ist MMF möglicherweise in der Lage, frühzeitig Entzündungsvorgänge zu reduzieren, welche maßgeblich an der Initiierung bzw. Progression der Fibrose über inflammatorische Zytokine beteiligt sind. Im Gegensatz zu anderen Immunsuppressiva verfügt MMF über eine relativ geringe Toxizität, außerdem ist seine Wirkung nicht auf Lymphozyten begrenzt, sondern involviert auch andere Zellen wie Fibroblasten, Mesangiumzellen und diverse Zytokine.

Zusammenfassend resultiert die potentiell antifibrotische Wirkung von MMF durch folgende Funktionen: 
1.) Inhibition der T- und B-Lymphozytenproliferation sowie des Recruitments von Lymphozyten und Monozyten

2.) IMPDH-abhängige und IMPDH-unabhängige Effekte auf die Proliferation und Funktion renaler Fibroblasten

3.) Effekte auf die Signalübertragung in renalen Fibroblasten mit konsekutiv veränderten Proteinexpressionen, vor allem auf TGFß1 und CTGF

4.) Inhibition der Proliferation von glatten Gefäßmuskelzellen und Mesangiumzellen.

In den letzten Jahren verdichtete sich die Annahme, dass inflammatorische Prozesse bei der Entwicklung und Aufrechterhaltung von sowohl immunologisch- als auch bei nichtimmunologisch-vermittelten chronischen Nephropathien eine entscheidende Rolle spielen. Die Lymphozytenproliferation und die gesteigerte Expression von Adhäsionsmolekülen stellen dabei frühzeitige Ereignisse dar. Daher wäre der alleinige Einsatz von MMF als antilymphozytäres Medikament vor allem in der Frühphase des Krankheitsgeschehens denkbar. Auch in späteren Phasen, die vor allem klinisch relevant sind, ist ein nephroprotektiver Effekt von MMF denkbar.

Zusammenfassend lässt sich feststellen, dass die Fibrogenese einen äußerst komplexen und hochregulierten Prozess darstellt. Das genaue Verstehen der Mechanismen ist jedoch essentiell, um neue therapeutische Strategien für die Behandlung der renalen Fibrose bzw. deren Prävention zu ergründen. Weiterführende Experimente sind notwendig, um die antifibrotische Wirkung von MMF im Rahmen der chronischen Allograft-Nephropathie umfassend beurteilen zu können. Da Fibrose eine Vielzahl von verschiedenen Zelltypen und Mediatoren vor allem TGFß1 und CTGF involviert, empfiehlt sich in anschließenden Experimenten die Kombination von MMF mit anderen antifibrotisch wirksamen Medikamenten, beispielsweise ACE-Inhibitoren. Zum einen wären damit synergistische antifibrotische Effekte über verschiedene Mechanismen denkbar, zum anderen eine Reduktion der Medikamentendosis und -toxizität. Zukünftige Untersuchungen vor allem in vivo werden zeigen, ob MMF eine Fibrose bei humanen Nierenerkrankungen behandeln und verhindern kann. 


\section{Zusammenfassung}

Im Rahmen der vorliegenden Arbeit wurde das antifibrotische Potential von Mycophenolat-Mofetil bzw. seines aktiven Metaboliten Mycophenolsäure in vitro unter Verwendung von renalen Fibroblasten und in vivo anhand COL4A3-defizienter Mäuse als Modell für eine progrediente renale Fibrose untersucht.

Die in-vitro-Experimente bestätigten die inhibitorische Wirkung von MPA sowohl auf die Fibroblastenproliferation als auch auf die Fibroblastenfunktion hinsichtlich ihrer Fähigkeit zum Wundverschluss und zur Kollagen-Kontraktion. Es konnte gezeigt werden, dass die Wirkung von MPA auf die Fibroblastenproliferation durch die Zugabe von Guanosin/8-Aminoguanosin vollständig reversibel ist. Mittels des Wundverschluss-Assays konnte die inhibitorische Wirkung von MPA auf die Motilität der Fibroblasten nachgewiesen werden. MPA führte hierbei zur zeit- und dosisabhängigen verzögerten Wundheilung. Die Zugabe von Guanosin/8Aminoguanosin bewirkte wiederum eine weitestgehend vollständige Aufhebung der Wirkung von MPA. Im Rahmen des Kollagen-Kontraktions-Assays, bei dem die Auswirkungen von MPA bezüglich einer veränderten Kontraktion der extrazellulären Matrixbestandteile untersucht wurde, bestätigte sich ebenfalls das hemmende Potential von MPA auf die Fibroblastenfunktion. Im Gegensatz zu den vorherigen Experimenten konnte hier allerdings der MPA-vermittelte Effekt durch die Zugabe von Guanosin/8-Aminoguanosin nicht antagonisiert werden. Bis dato wird angenommen, dass die Wirkungen der Mycophenolsäure allein auf die Hemmung der de-novo-Synthese der Purinbasen durch Blockierung des Schlüsselenzyms Inosinmonophosphat-Dehydrogenase zurückzuführen sind. Hier konnte jedoch der Effekt des MPA auf die Kontraktionsfähigkeit der Fibroblasten nicht durch Guanosin/8-Aminoguanosin aufgehoben werden. Dies impliziert erstmals eine mögliche IMPDH-unabhängige Wirkung der Mycophenolsäure. Allerdings konnte dieser IMPDH-unabhängige Effekt auf die Expression profibrotischer Gene und Proteine mehrheitlich nicht bestätigt werden. Eine signifikant IMPDH-unabhängige Wirkung von MPA auf eine veränderte CTGF-Genexpression zeigte sich nur nach den ersten 6 h. Im weiteren Verlauf verliefen die MPA-bedingten Effekte wiederum IMPDH-abhängig. Des Weiteren führte MPA erstaunlicherweise initial zu einer 
supprimierten Genexpression von CTGF, später jedoch zur gesteigerten Expression. Insgesamt waren die Ergebnisse der Expression profibrotischer Gene zum Teil konform, zum anderen Teil jedoch gegensätzlich zu dem heutigen Erkenntnisstand. Daher ist anzunehmen, dass im Rahmen der Fibrogenese die Regulierung der Genexpressionen um ein Vielfaches komplexer zu sein scheint als allgemein bisher angenommen. Weiterführende Untersuchungen zur Erforschung der Fibrogenese sollten vor allem die Wachstumfaktoren TGFß und CTGF, aber auch TGFßunabhängige Signalwege beinhalten.

Die in-vivo-Experimente zur Untersuchung der antifibrotischen Wirkung von MPA erfolgten an homozygot COL4A3-defizienten Mäusen, welche als Modell für eine progrediente renale Fibrose analog zum humanen Alport-Syndrom dienten. Die tägliche gewichtsadaptierte Gabe von MMF ab der 6. Woche postnatal bewirkte keine Verlängerung der Überlebenszeit der behandelten Versuchstiere gegenüber der Placebo-Gruppe ( $p>0,05$, Log-Rang-Test). Ebenso ließ sich keine Korrelation zwischen den im Serum gemessenen MPA-Konzentrationen und der Überlebenszeit der Versuchstiere feststellen ( $p>0,05$, Spearman-Rangkorrelation). Allerdings resultierte der hochdosierte Einsatz von MMF in einer deutlich abgeschwächten tubulointerstitiellen Fibrose und in signifikant niedrigeren Kreatinin- und Harnstoff-NKonzentrationen im Vergleich zu den unbehandelten Versuchstieren $(p<0,05$, MannWhitney-U-Test). So bewirkte beispielsweise die Hochdosisgabe von MMF eine um $54,2 \%$ niedrigere mittlere Kreatinin-Konzentration und eine um 60,5\% niedrigere mittlere Harnstoff-N-Konzentration im Vergleich zur Placebo-Gruppe. Daher ist von einer verbesserten Nierenfunktion durch die Behandlung mit MMF auszugehen. Weiterhin ließ sich eine hochsignifikante reziproke Korrelation zwischen den MPAKonzentrationen und den Serum-Kreatinin-Konzentrationen feststellen $(p<0,01$, Spearman-Rangkorrelation).

Die Behandlung mit MMF bewirkte demnach keine Lebenszeitverlängerung, dennoch resultierte die Hochdosistherapie in einer verminderten tubulointerstitiellen Fibrose und in einer verbesserten Organfunktion verdeutlicht durch die niedrigeren Retentionsparameter Kreatinin und Harnstoff-N, wobei kein Effekt auf die Proteinurie festgestellt werden konnte. Weitere Untersuchungen zur Erforschung der antifibrotischen Effekte von MMF, gegebenenfalls in Kombination mit anderen antifibrotisch wirksamen Medikamenten wie beispielsweise ACE-Hemmern, 
erscheinen vielversprechend. Weiterführende klinische Studien sind notwendig, um zu eruieren, inwiefern MMF einen potentiellen Ansatz zur Behandlung der progredienten renalen Fibrose, dem lebenslimitierenden Endzustand zahlreicher Erkrankungen mit fortschreitendem Krankheitsgeschehen, darstellt. 


\section{Literaturverzeichnis}

Abbate M, Zoja C, Remuzzi G (2006): How does proteinuria cause progressive renal damage? J Am Soc Nephrol 17, 2974-2984

Abreu JG, Ketpura NI, Reversade B, De Robertis EM (2002): Connective-tissue growth factor (CTGF) modulates cell signalling by BMP and TGF-ß. Nat Cell Biol $\underline{4}$, 599-604

Allison AC, Eugui EM (1993): The design and development of an immunosuppressive drug, mycophenolate mofetil. Springer Semin Immunopathol $\underline{14}$, 353-380

Allison AC, Eugui EM (2000): Mycophenolate mofetil and its mechanism of action. Immunopharmacology $\underline{47}, 85-118$

Allison AC, Hovi T, Watts RWE, Webster ADB (1975): Immunological observations on patients with Lesch-Nyhan syndrome, and on the role of de-novo purine synthesis in lymphocyte transformation. Lancet 1975, II, 1179-1183

Allison AC, Kowalski WJ, Muller CJ, Waters RV, Eugui EM (1993): Mycophenolic acid and brequinar, inhibitors of purine and pyrimidine synthesis, block the glycosylation of adhesion molecules. Transplant Proc $\underline{25}, 67-70$

Altschuler EL (2001): Consideration of mycophenolate mofetil for idiopathic pulmonary fibrosis. Med Hypotheses $\underline{57}, 701-702$

Ando K, Suzuki S, Tamura G, Arima K (1968): Antiviral activity of mycophenolic acid. Studies on antiviral and antitumor antibiotics. IV. J Antibiot 21, 649-652

Azzola A, Havryk A, Chhajed P, Hostettler K, Black J, Johnson P, Roth M, Glanville A, Tamm M (2004): Everolimus and mycophenolate mofetil are potent inhibitors of fibroblast proliferation after lung transplantation. Transplantation $\underline{77}, 275-280$

Badid C, Vincent M, McGregor B, Melin M, Hadj-Aissa A, Veysseyre C, Hartmann DJ, Desmouliere A, Laville M (2000): Mycophenolate mofetil reduces myofibroblast infiltration and collagen III deposition in rat remnant kidney. Kidney Int $\underline{58}, 51-61$

Badid C, Vincent M, Fouque D, Laville M, Desmoulière A (2001): Myofibroblast: a prognostic marker and target cell in progressive renal disease. Ren Fail $\underline{23}, 543-549$

Baer PC, Gauer S, Hauser IA, Scherberich JE, Geiger H (2000): Effects of mycophenolic acid on human renal proximal and distal tubular cells in vitro. Nephrol Dial Transplant $\underline{15}, 184-190$

Baer PC, Wegner B, Geiger H (2004): Effects of mycophenolic acid on IL-6 expression of human renal proximal and distal tubular cells in vitro. Nephrol Dial Transplant 19, 47-52 
Barnard JA, Lyons RM, Moses HL (1990): The cell biology of transforming growth factor ß. Biochim Biophys Acta 1032, 79-87

Berden JHM, Faaber P, Assmann KJM, Rijke TPM (1986): Effects of Cyclosporin A on autoimmune disease in MRL/1 and BXSB mice. Scand J Immunol 24, 405-412

Birkinshaw JH, Raistrick H, Ross DJ (1952): Studies in the biochemistry of microorganisms. The molecular constitution of mycophenolic acid, a metabolic product of Penicillium brevi-compactum Dierckx. Part 3. Further observations on the structural formula for mycophenolic acid. Biochem J $\underline{50}$, 630-634

Blaheta RA, Leckel K, Wittig B, Zenker D, Oppermann E, Harder S, Scholz M, Weber S, Encke A, Markus BH (1999): Mycophenolate mofetil impairs transendothelial migration of allogeneic CD4 and CD8 T-cells. Transplant Proc 31, 1250-1252

Bohle A (1982): Die Bedeutung des Niereninterstitiums für die Nierenfunktion. Klin Wochenschr 60, 1186-1190

Boor P, Sebeková K, Ostendorf T, Floege J (2007): Treatment targets in renal fibrosis. Nephrol Dial Transplant $\underline{22}, 3391-3407$

Border WA, Ruoslahti E (1992): Transforming growth factor- $ß$ in disease: the dark side of tissue repair. J Clin Invest $\underline{90}, 1-7$

Border WA, Noble NA (1994): Transforming growth factor $ß$ in tissue fibrosis. N Engl $\mathrm{J}$ Med $\underline{331}, 1286-1292$

Border WA, Noble NA (1998): Interactions of transforming growth factor- $ß$ and angiotensin II in renal fibrosis. Hypertension $\underline{31}, 181-188$

Bradford MM (1976): A rapid and sensitive method for the quantitation of microgram quantities of protein utilizing the principle of protein-dye binding. Anal Biochem $\underline{72}$, 248-254

Brandhorst G, Streit F, Goetze S, Oellerich M, Armstrong VW (2006): Quantification by liquid chromatography tandem mass spectrometry of mycophenolic acid and its phenol and acyl glucuronide metabolites. Clin Chem $\underline{52}, 1962-1964$

Brenner BM (1985): Nephron adaptation to renal injury or ablation. Am J Physiol 249, 324-337

Budde K, Glander P, Diekmann F, Waiser J, Fritsche L, Dragun D, Neumayer HH (2004): Review of the immunosuppressant enteric-coated mycophenolate sodium. Expert Opin Pharmacother $\underline{5}, 1333-1345$

Bullingham RES, Monroe S, Nicholls A, Hale M (1996): Pharmacokinetics and bioavailability of mycophenolate mofetil in healthy subjects after single-dose oral and intravenous administration. J Clin Pharmacol $\underline{36}$, 315-324 
Cangiotti AM, Sessa A, Meroni M, Montironi R, Ragaiolo M, Mambelli V, Cinti S (1996): Evolution of glomerular basement membrane lesions in a male patient with Alport syndrome: ultrastructural and morphometric study. Nephrol Dial Transplant 11, 1829-1834

Carr SF, Papp E, Wu JC, Natsumeda Y (1993): Characterization of human type I and type II IMP dehydrogenases. J Biol Chem 268, 27286-27290

Carter SB, Franklin TJ, Jones DF, Leonard BJ, Mills SD, Turner RW, Turner WB (1969): Mycophenolic acid: an anti-cancer compound with unusual properties. Nature $\underline{223}, 848-850$

Chomczynski P, Sacchi N (1987): Single-step method of RNA isolation by acid guanidinium thiocyanate-phenol-chloroform extraction. Anal Biochem 162, 156-159

Clutterbuck PW, Oxford AE, Raistrick H, Smith G (1932): Studies in the biochemistry of micro-organisms. XXIV. The metabolic products of the Penicillium brevicompactum series. Biochem J 24, 1441-1458

Cohn RG, Mirkovich A, Dunlap B, Burton P, Chiu SH, Eugui E, Caulfield JP (1999): Mycophenolic acid increases apotosis, lysosomes and lipid droplets in human lymphoid and monocytic cell lines. Transplantation $\underline{68}, 411-418$

Copeland JWGV, Beaumont BW, Merrilees MJ, Pilmore HL (2007): Epithelial-tomesenchymal transition of human proximal tubular epithelial cells: effects of rapamycin, mycophenolate, cyclosporin, azathioprine, and methylprednisolone. Transplantation $\underline{83}$, 809-814

Cosgrove D, Meehan DT, Grunkemeyer JA, Kornak JM, Sayers R, Hunter WJ and Samuelson GC (1996): Collagen COL4A3 knockout: a mouse model for autosomal Alport syndrome. Genes \& Dev 10, 2981-2992

Dubus I, Vendrely B, Christophe I, Labouyrie JP, Delmas Y, Bonnet J, Combe C (2002): Mycophenolic acid antagonizes the activation of cultured human mesangial cells. Kidney Int $\underline{62}, 857-867$

Ebner R, Chen RH, Lawler S, Zioncheck T, Derynck R (1993): Determination of type I receptor specificity by the type II receptors for TGF-ß or activin. Science $\underline{262}, 900-$ 902

Eddy AA (1996): Molecular insights into renal interstitial fibrosis. J Am Soc Nephrol $\underline{7}$, 2495-2508

Eddy AA (2000): Molecular basis of renal fibrosis. Pediatr Nephrol $\underline{15}$, 290-301

Edwards DR, Murphy G, Reynolds JJ, Whitham SE, Docherty AJP, Angel P, Heath JK (1987): Transforming growth factor beta modulates the expression of collagenase and metalloproteinase inhibitor. EMBO J $\underline{6}, 1899-1904$ 
Eugui EM, Almquist SJ, Muller CD, Allison AC (1991a): Lymphocyte-selective cytostatic and immunosuppressive effects of mycophenolic acid in vitro: role of desoxyguanosine nucleotide depletion. Scand J Immunol $\underline{33}, 161-173$

Eugui EM, Mirkovich A, Allison AC (1991b): Lymphocyte-selective antiproliferative and immunosuppressive effects of mycophenolic acid in mice. Scand J Immunol $\underline{33}$, $175-183$

European Mycophenolate Mofetil Cooperative Study Group (1995): Placebocontrolled study of mycophenolate mofetil combined with cyclosporine and corticosteroids for prevention of acute rejection. Lancet $\underline{345}, 1321-1325$

Fan JM, Ng YY, Hill PA, Nikolic-Paterson DJ, Mu W, Atkins RC, Lan HY (1999): Transforming growth factor- $\beta$ regulates tubular epithelial-myofibroblast transdifferentiation in vitro. Kidney Int $\underline{56}, 1455-167$

Filler G, Buffo I (2007): Safety considerations with mycophenolate sodium. Expert Opin Drug Saf $\underline{6}, 445-449$

Florey HW, Gilliver K, Jennings MA, Sanders AG (1946): Mycophenolic acid: an antibiotic from Penicillum brevicompactum Dierckx. Lancet 1946,1, 46-49

Franklin TJ, Cook JM (1969): The inhibition of nucleic acid synthesis by mycophenolic acid. Biochem J $\underline{113}$, 515-524

Frazier K, Williams S, Kothapalli D, Klapper H, Grotendorst GR (1996): Stimulation of fibroblast cell growth, matrix production, and granulation tissue formation by connective tissue growth factor. J Invest Dermatol 107, 404-411

Frei U, Schober-Halstenberg HJ: Nierenersatztherapie in Deutschland. Bericht über Dialysebehandlung und Nierentransplantation in Deutschland 2005/2006. Jahresvergleiche 1995-2005. Quasi Niere gGmbH, Berlin 2006

Fujihara CK, Malheiros DMAC, Zatz R, Noronha IDL (1998): Mycophenolate mofetil attenuates renal injury in the rat remnant kidney. Kidney Int $\underline{54}$, 1510-1519

Fujihara CK, De Lourdes Noronha I, Malheiros DMAC, Antunes GR, De Oliveira IB, Zatz R (2000): Combined mycophenolate mofetil and losartan therapy arrests established injury in the remnant kidney. J Am Soc Nephrol 11, 283-290

Garcia RC, Leoni P, Allison AC (1977): Control of phosphoribosylpyrophosphate synthesis in human lymphocytes. Biochem Biophys Res Commun $\underline{77}$, 1067-1073

Gensburger O, Picard N, Marquet P (2009): Effect of mycophenolate acylglucuronide on human recombinant type 2 inosine monophosphat dehydrogenase. Clin Chem $\underline{55}$, 986-993

Gluzman Y (1981): SV40-transformed simian cell support the replication of early SV40 Mutants. Cell $\underline{23}, 175-182$ 
Gonzalez Molina M, Seron D, Garcia del Moral R, Carrera M, Sola E, Alferez MJ, Gomez Ullate P, Capdevila L, Gentil MA (2004): Mycophenolate mofetil reduces deterioration of renal function in patients with chronic allograft nephropathy. Transplantation $\underline{77}, 215-220$

Gosio B (1896): Ricerche batteriologiche e chimiche sulle alterazioni del mais in Roma. Rev Igiene Sanita Pubb Ann ㄱ, 825-868

Gregory CR, Pratt RE, Huie P, Shorthouse R, Dzau VJ, Bullingham RE, Morris RE (1993): Effects of treatment with cyclosporine, FK 506, rapamycin, mycophenolic acid or deoxyspergualin on vascular muscle proliferation in vitro and in vivo. Transplant Proc $\underline{25}, 770-771$

Greupink R, Bakker HI, Reker-Smit C, van Loenen-Weemaes A, Kok RJ, Meijer DKF, Beljaars L, Poelstra K (2005): Studies on the targeted delivery of the antifibrogenic compound mycophenolic acid to the hepatic stellate cell. J Hepatol $\underline{43}$, 884-892

Gross O, Beirowski B, Koepke ML, Kuck J, Reiner M, Addicks K, Smyth N, SchulzeLohoff E, Weber M (2003): Preemptive ramipril therapy delays renal failure and reduces renal fibrosis in COL4A3-knockout mice with Alport Syndrome. Kidney Int $\underline{63}, 438-446$

Gross O, Schulze-Lohoff E, Koepke ML, Beirowski B, Addicks K, Bloch W, Smyth N, Weber M (2004): Antifibrotic, nephroprotective potential of ACE inhibitor vs AT1 antagonist in a murine model of renal fibrosis. Nephrol Dial Transplant $\underline{19}, 1716-1723$

Gross O, Weber M (2005): From bench to bedside. Von der Molekulargenetik des Alport-Syndroms zu den Prinzipien der Organprotektion bei chronischen Nierenerkrankungen. Med Klin 100, 826-831

Gupta S, Clarkson MR, Duggan J, Brady HR (2000): Connective tissue growth factor: potential role in glomerulosclerosis and tubulointerstitial fibrosis. Kidney Int $\underline{58}, 1389$ 1399

Halloran P, Mathew T, Tomlanovich S, Groth C, Hooftman L, Barker C (1997): Mycophenolate mofetil in renal allograft recipients: a pooled efficacy analysis of three randomized, double-blind, clinical studies in prevention of rejection 1. Transplantation $\underline{63}, 39-47$

Hauser IA, Renders L, Radeke HH, Sterzel RB, Goppelt-Struebe M (1999): Mycophenolate mofetil inhibits rat and human mesangial cell proliferation by guanosine depletion. Nephrol Dial Transplant 14, 58-63

Heller T, Geide A, Bonitz U, Wegner U, Gröne HJ, Armstrong VW, Oellerich M (2008): Effect of the antioxidant idebenone on adverse events under mycophenolate mofetil therapy in a rat model. Transplant $\underline{85}, 739-747$

Heller T, Asif AR, Petrova DT, Doncheva Y, Wieland E, Oellerich M, Shipkova M, Armstrong VW (2009): Differential proteomic analysis of lymphocytes treated with 
mycophenolic acid reveals caspase 3-induced cleavage of Rho GDP dissociation inhibitor 2. Ther Drug Monit 31, 211-217

Hildner K, Märker-Hermann E, Schlaak JF, Becker C, Germann T, Schmitt E, Meyer zum Büschenfelde KH, Neurath MF (1998): Azathioprine, mycophenolate mofetil, and methotrexate specifically modulate cytokine production by T-cells. Ann NY Acad Sci $\underline{859}$, 204-207

Hirano T, Akira S, Taga T, Kishimoto T (1990): Biological and clinical aspects of interleukin 6. Immunol Today $\underline{11}$, 443-449

Horii Y, Muraguchi A, Iwano M, Matsuda T, Hirayama T, Yamada H, Fujii Y, Dohi K, Ishikawa $\mathrm{H}$, Ohmoto $\mathrm{Y}$, et al. (1989): Involvement of IL-6 in mesangial proliferative glomerulonephritis. J Immunol 143, 3949-3955

Hostetter TH, Olson JL, Rennke HG, Venkatachalam MA, Brenner BM (1981): Hyperfiltration in remnant nephrons: a potentially adverse response to renal ablation. Am J Physiol 241, 85-93

Hou CC, Wang W, Huang XR, Fu P, Chen TH, Sheikh-Hamad D, Lan HY (2005): Ultrasound-microbubble-mediated gene transfer of inducible Smad7 blocks transforming growth factor- $\beta$ signaling and fibrosis in rat remnant kidney. Am J Pathol $\underline{166}, 761-771$

Hudson BG,Tryggvason K, Sundaramoorthy M, Neilson EG (2003): Alport's syndrome, Goodpasture's syndrome, and type IV collagen. N Engl J Med $\underline{348}$, 25432556

Ignotz RA, Massagué J (1986): Transforming growth factor ß stimulates the expression of fibronectin and collagen and their incorporation into the extracellular matrix. J Biol Chem 261, 4337-4345

Ignotz RA, Massagué J (1987): Cell adhesion protein receptors as targets for transforming growth factor $ß$ action. Cell $\underline{51}, 189-197$

Isaka Y, Brees DK, Ikegaya K, Kaneda Y, Imai E, Noble NA, Border WA (1996): Gene therapy by skeletal muscle expression of decorin prevents fibrotic disease in rat kidney. Nat Med 2, 418-423

Isaka Y, Akagi Y, Ando Y, Tsujie M, Sudo T, Ohno N, Border WA, Noble NA, Kaneda $Y$, Hori M, Imai E (1999): Gene therapy by transforming growth factor- $ß$ receptor-IgG Fc chimera suppressed extracellular matrix accumulation in experimental glomerulonephritis. Kidney Int $\underline{55}$, 465-475

Isaka Y, Tsujie M, Ando Y, Nakamura H, Kaneda Y, Imai E, Hori M (2000): Transforming growth factor- $ß 1$ antisense oligodeoxynucleotides block interstitial fibrosis in unilateral ureteral obstruction. Kidney Int $\underline{58}, 1885-1892$ 
Javelaud D, Laboureau J, Gabison E, Verrecchia, Mauviel A (2003): Disruption of basal JNK activity differentially affects key fibroblast functions important for wound healing. J Biol Chem $\underline{278}$, 24624-24628

Johnsson C, Gerdin B, Tufveson G (2004): Effects commonly used immunosuppressants on graft-derived fibroblasts. Clin Exp Immunol 136, 405-412

Jonsson CA, Carlsten H (2001): Inosine monophosphate dehydrogenase (IMPDH) inhibition in vitro suppresses lymphocyte proliferation and the production of immunoglobulins, autoantibodies and cytokines in splenocytes from MRLIpr/lpr mice. Clin Exp Immunol 124, 486-491

Kim SJ, Jeang KT, Glick AB, Sporn MB, Roberts AB (1989): Promotor sequences of the human transforming growth factor- $\beta 1$ gene responsive to transforming growth factor-ß1 autoinduction. J Biol Chem 264, 7041-7045

Konno Y, Natsumeda Y, Nagai M, Yamaji Y, Ohno S, Suzuki K, Weber G (1991): Expression of human IMP dehydrogenase types I and II in Escherichia coli and distribution in human normal lymphocytes and leukemic cell lines. J Biol Chem $\underline{266}$, 506-509

Kovacs EJ (1991): Fibrogenic cytokines: the role of immune mediators in the development of scar tissue. Immunol Today $\underline{12}, 17-23$

Laemmli UK (1970): Cleavage of structural proteins during the assembly of the head of bacteriophage T4. Nature $\underline{227}, 680-685$

Lan H, Mu W, Tomita N, Huang XR, Li JH, Zhu HJ, Morishita R, Johnson RJ (2003): Inhibition of renal fibrosis by gene transfer of inducible Smad7 using ultrasoundmicrobubble system in rat UUO model. J Am Soc Nephrol $\underline{14}$, 1435-1448

Lasky JA, Ortiz LA (2001): Antifibrotic therapy for the treatment of pulmonary fibrosis. Am J Med Sci 322, 213-322

Lee WA, Gu L, Miksztal AR, Chu N, Leung K, Nelson PH (1990): Bioavailability improvement of mycophenolic acid through amino ester derivatization. Pharm Res $\underline{7}$, $161-166$

Levey AS, Coresh J, Balk E, Kausz AT, Levin A, Steffes MW, Hogg RJ, Perrone RD, Lau J, Eknoyan G (2003): National Kidney Foundation practice guidelines for chronic kidney disease: evaluation, classification, and stratification. Ann Intern Med 139, 137147

Lowe JK, Brox L, Henderson JF (1977): Consequences of inhibition of guanine nucleotide synthesis of mycophenolic acid and virazole. Cancer Res $\underline{37}, 736-743$

Martínez-Salgado C, Rodríguez-Peña AB, López-Novoa JM (2008): Involvement of small Ras GTPases and their effectors in chronic renal disease. Cell Mol Life Sci $\underline{65}$, 477-492 
Maschio G, Alberti D, Locatelli F, Mann JFE, Motolese M, Ponticelli C, Ritz E, Janin G, Zucchelli P (1999): Angiotensin-converting enzyme inhibitors and kidney protection: the AIPRI trial. The ACE inhibition in progressive renal insufficiency (AIPRI) study group. J Cardiovasc Pharmacol $\underline{33}, 16-20$

Meier-Kriesche HU, Ojo AO, Leichtman AB, Punch JD, Hanson JA, Cibrik DM, Kaplan B (2000): Effect of mycophenolate mofetil on long-term outcomes in african american renal transplant recipients. J Am Soc Nephrol 11, 2366-2370

Meier-Kriesche HU, Li S, Gruessner RWG, Fung JJ, Bustami RT, Barr ML, Leichtman AB (2006): Immunosuppression: Evolution in practice and trends, 19942004. Am J Transplant $\underline{6}, 1111-1131$

Mele TS, Halloran PF (2000): The use of mycophenolate mofetil in transplant recipients. Immunopharmacology $\underline{47}, 215-245$

Merville $P$, Bergé $F$, Deminière $C$, Morel D, Chong G, Durand D, Rostaing L, Mourad G, Potaux L (2004): Lower incidence of chronic allograft nephropathy at 1 year posttransplantation in patients treated with mycophenolate mofetil. Am J Transplant $\underline{4}$, 1769-1775

Mezzano SA, Ruiz-Ortega M, Egido J (2001): Angiotensin II and renal fibrosis. Hypertension $\underline{38}$, 635-638

Miljkovic DJ, Samardzic T, Drakulic D, Stosic-Grujicic S, Trajkovic V (2002): Immunosuppressants leflunomide and mycophenolic acid inhibit fibroblast IL-6 production by distinct mechanism. Cytokine $\underline{19}, 181-186$

Mitsui A, Suzuki S (1969): Immunosuppressive effect of mycophenolic acid. J Antibiot (Tokyo) $\underline{22}, 358-363$

Morales JM (2005): Immunosuppressive treatment and progression of histologic lesions in kidney allografts. Kidney Int $\underline{68}, 124-130$

Morris RE, Hoyt EG, Murphy MP, Eugui EM, Allison AC (1990): Mycophenolic acid morpholinoethylester (RS-61443) is a new immunosuppressant that prevents and halts heart allograft rejection by selective inhibition of $T$ and $B$ cell purine synthesis. Transplant Proc 22, 1659-1662

Nagai M, Natsumeda Y, Weber G (1992): Proliferation-linked regulation of type II IMP dehydrogenase gene in human normal lymphocytes and HL-60 leukemic cells. Cancer Res $\underline{52}$, 258-261

Nangaku M (2002): Final common pathways of progression of renal diseases. Clin Exp Nephrol $\underline{6}, 182-189$

Nangaku M (2004): Mechanisms of tubulointerstitial injury in the kidney: final common pathways to end-stage renal failure. Intern Med $\underline{43}, 9-17$ 
Nankivell BJ, Chapman JR (2006): Chronic allograft nephropathy: current concepts and future directions. Transplantation $\underline{81}, 643-654$

Nankivell BJ, Borrows RJ, Fung CLS, O'Connell PJ, Allen RDM, Chapman JR (2003): The natural history of chronic allograft nephropathy. N Engl J Med $\underline{349}$, 23262633

Nankivell BJ, Wavamunno MD, Borrows RJ, Vitalone M, Fung CLS, Allen RDM, Chapman JR, O'Connell PJ (2007): Mycophenolate mofetil is associated with altered expression of chronic renal transplant histology. Am J Transplant $\underline{7}, 366-376$

Natsumeda Y, Ohno S, Kawasaki H, Konno Y, Weber G, Suzuki K (1990): Two distinct cDNAs for human IMP dehydrogenase. J Biol Chem 265, 5292-5295

Ng YY, Huang TP, Yang WC, Chen ZP, Yang AH, Mu W, Nikolic-Paterson DJ, Atkins RC, Lan HY (1998): Tubular epithelial-myofibroblast transdifferentiation in progressive tubulointerstitial fibrosis in 5/6 nephrectomized rats. Kidney Int $\underline{54}$, 864876

Nihtyanova SI, Brough GM, Black CM, Denton CP (2007): Mycophenolate mofetil in diffuse cutaneous systemic sclerosis - a retrospective analysis. Rheumatology $\underline{46}$, 442-445

Nowak I, Shaw LM (1995): Mycophenolic acid binding to human serum albumin: characterization and relation to pharmacodynamics. Clin Chem $\underline{41}, 1011-1017$

Nowak I, Shaw LM (1997): Effect of mycophenolic acid glucoronide on inosine monophosphate dehydrogenase activity. Ther Drug Monit 19, 358-360

Ojo AO, Meier-Kriesche HU, Hanson JA, Leichtman AB, Cibrik D, Magee JC, Wolfe RA, Agodoa LY, Kaplan B (2000): Mycophenolate mofetil reduces late renal allograft loss independent of acute rejection. Tansplantation $\underline{69}, 2405-2409$

Ohsugi Y, Suzuki S, Takagaki Y (1976): Antitumor and immunosuppressive effects of mycophenolic acid derivatives. Cancer Res $\underline{36}, 2923-2927$

Ohta K, Kim S, Hamaguchi A, Yukimura T, Miura K, Takaori K, Iwao H (1994): Role of angiotensin II in extracellular matrix and transforming growth factor-beta 1 expression in hypertensive rats. Eur J Pharmacol 269, 115-119

Okuda S, Nakamura T, Yamamoto T, Ruoslahti E, Border WA (1991): Dietary protein restriction rapidly reduces transforming growth factor beta 1 expression in experimental glomerulonephritis. Proc Natl Acad Sci USA $\underline{88}, 9765-9769$

Penny MJ, Boyd RA, Hall BM (1998): Mycophenolate mofetil prevents the induction of active Heymann nephritis: association with Th2 cytokine inhibition. J Am Soc Nephrol $\underline{9}$, 2272-2282

Platz KP, Sollinger HW, Hullett DA, Eckhoff DE, Eugui EM, Allison AC (1990): RS61443 - a new, potent immunosuppressive agent. Transplantation 51, 27-31 
Racusen LC, Solez K, Colvin RB, Bonsib SM, Castro MC, Cavallo T, Croker BP, Demetris AJ, Drachenberg CB, Fogo AB, et al. (1999): The Banff working classification of renal allograft pathology. Kidney Int $\underline{55}, 713-723$

Raij L, Azar S, Keane W (1984): Mesangial immune injury, hypertension, and progressive glomerular damage in Dahl rats. Kidney Int 26, 137-143

Remuzzi G, Zoja C, Gagliardini E, Corna D, Abbate M, Benigni A (1999): Combining an antiproteinuric approach with mycophenolate mofetil fully suppresses progressive nephropathy of experimental animals. J Am Soc Nephrol 10, 1542-1549

Roberts AB, Sporn MB, Assoian RK, Smith JM, Roche NS, Wakefield LM, Heine UI, Liotta LA, Falanga V, Kehrl JH, Fauci AS (1986): Transforming growth factor type ß: rapid induction of fibrosis and angiogenesis in vivo and stimulation of collagen formation in vitro. Proc Natl Acad Sci USA $\underline{83}$, 4167-4171

Romero F, Rodriguez-Iturbe B, Parra G, Gonzalez L, Herrera-Acosta J, Tapia E (1999): Mycophenolate mofetil prevents the progressive renal failure induced by $5 / 6$ renal ablation in rats. Kidney Int $\underline{55}$, 945-955

Ross N, Poulalhon N, Farge D, Madeleine I, Mauviel A, Verrecchia F (2007): In vitro evidence for a direct antifibrotic role of the immunosuppressive drug mycophenolate mofetil. J Pharmcol Exp Ther 321, 583-589

Shaw LM, Nowak I (1995): Mycophenolic acid: measurement and relationship to pharmacologic effects. Ther Drug Monit 17, 685-689

Shaw LM, Holt DW, Oellerich M, Meiser B, van Gelder T (2001): Current issues in therapeutic drug monitoring of mycophenolic acid: report of a roundtable discussion. Ther Drug Monit 23, 305-315

Shimamura T, Morrison AB (1975): A progressive glomerulosclerosis occuring in partial five-sixths nephrectomized rats. Am J Pathol $\underline{79}$, 95-106

Shipkova M, Armstrong VW, Wieland E, Niedmann PD, Schütz E, Brenner-Weiß G, Voihsel M, Braun F, Oellerich M (1999): Identification of glucoside and carboxyllinked glucuronide conjugates of mycophenolic acid in plasma of transplant recipients treated with mycophenolate mofetil. Br J Pharmacol 126, 1075-1082

Shull MM, Ormsby I, Kier AB, Pawlowski S, Diebold RJ, Yin M, Allen R, Sidman C, Proetzel G, Calvin D (1992): Targeted disruption of the mouse transforming growth factor-ß1 gene results in multifocal inflammatory disease. Nature $\underline{359}$, 693-699

Sollinger HW (1995): Mycophenolate mofetil for the prevention of acute rejection in primary cadaveric renal allograft recipients. The U.S. Renal Transplant Mycophenolate Mofetil Study Group. Transplantation 므, 225-232

Sollinger H (2004): Enteric-coated mycophenolate sodium: therapeutic equivalence to mycophenolate mofetil in de novo renal transplant patients. Transplant Proc $\underline{36}$, $517-520$ 
Sollinger HW, Deierhoi MH, Belzer FO, Diethelm AG, Kauffman RS (1992): RS61443 - a phase I clinical trial and pilot rescue study. Transplantation $\underline{53}$, 428-432

Song J, Lu YP, Luo GH, Yang L, Ma X, Xia QJ, Shi YJ, Li YP (2008): Effects of mycophenolate mofetil on chronic allograft nephropathy by affecting RHO/ROCK signal pathways. Transplant Proc $\underline{40}$, 2790-2794

Stratton RJ, Wilson H, Black CM (2001): Pilot study of anti-thymocyte globulin plus mycophenolate mofetil in recent-onset diffuse scleroderma. Rheumatology $\underline{40}$, 84-88

Streit F, Shipkova M, Armstrong VW, Oellerich M (2004): Validation of a rapid and sensitive liquid chromatography tandem mass spectrometry method for free and total mycophenolic acid. Clin Chem 무, 152-159

Sutaria PM, Ohebshalom M, McCaffrey TA, Vaughan Jr ED, Felsen D (1998): Transforming growth factor- $\beta$ receptor types I and II are expressed in renal tubules and are increased after chronic unilateral ureteral obstruction. Life Sci $\underline{62}, 1965-1972$

Suzuki S, Kimura T, Ando K, Sawada M, Tamura G (1969): Antitumor activity of mycophenolic acid. J Antibiot 22, 297-302

Sweeney MJ, Gerzon K, Harris PN, Holmes RE, Poore GA, Williams RH (1972a): Experimental antitumor activity and preclinical toxicology of mycophenolic acid. Cancer Res $\underline{32}$, 1795-1802

Sweeney MJ, Hoffman DH, Esterman MA (1972b): Metabolism and biochemistry of mycophenolic acid. Cancer Res $\underline{32}$, 1803-1809

Towbin H, Staehelin T, Gordon J (1979): Electrophoretic transfer of proteins from polyacrylamide gels to nitrocellulose sheets: procedure and some applications. Proc Natl Acad Sci U S A $\underline{76}$, 4350-4354

Tricontinental Mycophenolate Mofetil Renal Transplantation Study Group (1996): A blinded, randomized clinical trial of mycophenolate mofetil for the prevention of acute rejection in cadaveric renal transplantation. Transplantation $\underline{61}, 1029-1037$

Waller JR, Brook NR, Bicknell GR, Murphy GJ, Nicholson ML (2005): Mycophenolate mofetil inhibits intimal hyperplasia and attenuates the expression of genes favouring smooth muscle cell proliferation and migration. Transplant Proc $\underline{37}, 164-166$

Watson ML (1958): Staining of tissue sections for electron microscopy with heavy metals. J Cell Biol $\underline{4}, 475-486$

Weidenbörner M: Lexikon der Lebensmittelmykologie. 1. Auflage, Springer Verlag, Berlin 1999

Williams RH, Lively DH, Delong DC, Cline JC, Sweeney MJ, Poore GA, Larsen SH (1968): Mycophenolic acid: antiviral and antitumor properties. J Antibiot 21, 463-464 
Wynn TA (2007): Common and unique mechanisms regulate fibrosis in various fibroproliferative diseases. J Clin Invest 117, 524-529

Wynn TA (2008): Cellular and molecular mechanism of fibrosis. J Pathol $\underline{214}$, 199210

Yang J, Dai C, Liu Y (2002): Hepatocyte growth factor gene therapy and angiotensin II blockade synergistically attenuate renal interstitial fibrosis in mice. J Am Soc Nephrol 13, 2464-2477

Yu L, Noble NA, Border WA (2002): Therapeutic strategies to halt renal fibrosis. Curr Opin Pharmacol 2, 177-181

Yu L, Border WA, Anderson I, McCourt M, Huang Y, Noble NA (2004): Combining TGF-ß inhibition and angiotensin II blockade results in enhanced antifibrotic effect. Kidney Int $\underline{66}, 1774-1784$

Zatz R (1996): Haemodynamically mediated glomerular injury: the end of a 15-yearold contoversy? Curr Opin Nephrol Hypertens $\underline{5}$, 468-475

Zatz R, Noronha IL, Fujihara CK (2002): Experimental and clinical rationale for use of MMF in nontransplant progressive nephropathies. Am J Physiol Renal Physiol 283, 1167-1175

Zeisberg M, Strutz F, Müller GA (2001): Renal fibrosis: an update. Curr Opin Nephrol Hypertens 10, 315-320 


\section{Danksagung}

An dieser Stelle möchte ich mich bei allen bedanken, die für das Gelingen dieser Arbeit beigetragen haben.

Herrn Prof. Dr. Dr. Oellerich danke ich für die Bereitstellung der interessanten Fragestellung, für die Möglichkeit des experimentellen Arbeitens sowie für die fachliche Betreuung.

Herrn Prof. Dr. Armstrong und insbesondere Herrn Dr. Gunnar Brandhorst gilt aufgrund der hervorragenden Betreuung und der fachkompetenten Unterstützung mein besonderer Dank. Ihre ausgezeichneten Anregungen sowie ständige Hilfsbereitschaft und Motivation vor allem von Herrn Dr. Brandhorst haben mich stets vorangebracht.

Frau Dr. Darinka Petrova möchte ich ebenfalls für die geduldige Einarbeitung in die einzelne Methoden sowie für Ihre unersetzliche fachliche Hilfe und guten Ideen danken.

Bei allen Mitarbeitern und Mitarbeiterinnen der Klinischen Chemie möchte ich mich für die exzellente technische Assistenz, die geduldige Beantwortung meiner Fragen sowie für die nette Arbeitsatmosphäre herzlich bedanken. Mein besonderer Dank gilt hierbei Frau Ulrike Bonitz für die Durchführung der Methoden der Real-Time-PCR sowie für die freundliche Bereitstellung ihrer Daten.

Herrn PD Dr. Groß und Mitarbeitern danke ich für die Bereitstellung des Tiermodells sowie deren fachliche Kompetenz und Hilfsbereitschaft. Bei Herrn Prof. Miosge und Mitarbeitern möchte ich mich für die Ermöglichung der histologischen Untersuchungen und deren fachliche Hilfe bedanken. Dr. Schunck und Mitarbeitern danke ich für die Betreuung der Versuchstiere. 


\section{Lebenslauf}

Am 16.07.1983 wurde ich in Magdeburg geboren.

Von 1990 bis 1994 besuchte ich die Grundschule in Altenweddingen. Anschließend besuchte ich das Börde-Gymnasium Wanzleben, wo ich 2003 meine Schullaufbahn mit der Allgemeinen Hochschulreife beendete.

Am 01.04.2004 begann ich das Studium der Humanmedizin an der Georg-AugustUniversität Göttingen. Am 17.03.2006 absolvierte ich den Ersten Abschnitt der Ärztlichen Prüfung. Am 23.02.2009 begann ich mit der Durchführung des Praktischen Jahres, welches ich z. T. in Göttingen, z. T. an Akademischen Lehrkrankenhäusern der UMG absolvierte. Den Zweiten Abschnitt der Ärztlichen Prüfung werde ich im Juni 2010 ablegen.

Zum Zeitpunkt der Abgabe der Dissertation studiere ich im 13. Fachsemester Humanmedizin. 